Aline Bassi Denis Bordini do Amaral

\title{
Avaliação do grau de conversão monomérica, parâmetros de cinética de polimerização e determinação de monômeros residuais em resinas experimentais
}

Tese apresentada ao Instituto de Química de São Carlos da Universidade de São Paulo para obtenção do título de doutor em ciências.

Área de concentração: Química Analítica e Inorgânica.

Orientadora: Prof $^{a}$. Dr ${ }^{a}$. Ana Maria de Guzzi Plepis

\section{Exemplar revisado}

O exemplar original encontra-se disponível no Serviço de Pós-Graduação do IQSC-USP 
Dedicatória 


\section{DEDICATÓRIA}

- ADeus, que em sua infinita bondade me abençoou com essa vida maravilhosa.

- Aos meus pais Geraldo e Ivone, que além de me darem a vida, só por isto já me sentiria infinitamente grata, me presentearam com mais, com muito amor, carinho e dedicação. Com humildade me ensinaram a ser responsável, dedicada e acima de tudo humilde. Trabalharam para que meus sonhos pudessem ser realizados. Compartilho com eles os méritos desta conquista.

- Ao meu amado marido Mauricio, por me fazer feliz e apoiar os meus sonhos, demonstrando sempre muito amor, companheirismo, dedicação e compreensão, sempre pronto a me ajudar. Caminhamos juntos nessa jornada e isto foi essencial para mim nessa conquista.

- A toda minha família, em especial aos meus irmãos Eduardo e Anali pelo apoio e incentivo. E a minha sobrinha Isabella que proporciona alegria e felicidade em minha vida. 
Agradecimentos Especiais 


\section{AGRADECIMENTOS ESPECIAIS}

- A minha orientadora Profa. Ana Maria de Guzzi Plepis, um exemplo de humildade e honestidade, agradeço pelo incentivo e confiança que permitiu que eu fizesse minhas escolhas na realização dessa tese, bem como pela convivência bastante agradável e amizade durante todos estes anos que ficarão sempre guardados em minha memória.

- A minha querida amiga Profa Cristina Diagone, um exemplo de humildade e competência, a quem não tenho palavras para agradecer pela importância para a realização dessa tese, se desdobrando em muitos momentos para me ajudar.

- Aos meus sogros Joaquim e Vera, por eles tenho eterna gratidão, pois sempre me incentivaram, principalmente nos momentos mais dificeis, acompanhando toda essa trajetória da minha vida, sendo muito importantes para mim. 


\section{Agradecimentos}




\section{AGRADECIMENTOS}

- Ao Instituto de Química de São Carlos da Universidade de São Paulo e todos os seus funcionários pela oportunidade da realização desse trabalho.

- Ao Laboratório de Bioquímica e Biomaterias do Instituto de Química de São Carlos. Agradeço a todos os colegas que sempre foram receptivos durante o doutorado e, em especial agradeço a Virginia, que sempre muito atenciosa e prestativa, me orientou em muitos momentos.

- Ao Laboratório de Cromatografia, em especial ao Prof. Fernando Lanças, que possibilitou a realização das análises cromatográficas desse trabalho neste laboratório. Aos funcionários Alcimar, Elaine e Odete que sempre foram muito receptivos e aos colegas Paulo, Carlos, Ariane e Raquel que me ajudaram várias vezes.

- Ao Laboratório de Eletroquímica, em especial ao Prof. Hamilton Varela, que possibilitou a utilização do aparelho de FT-IR e ao funcionário Mauro que sempre foi muito atencioso e prestativo e me ajudou na realização das análises por espectroscopia de absorção no infravermelho.

- A todos os professores do curso de pós-graduação do IQSC, pelos ensinamentos transmitidos ao longo do curso de doutorado.

- À empresa Kavo do Brasil (Joinville - SC) que emprestou os equipamentos de fotoativação utilizados nessa tese.

- Ao meu eterno professor de inglês Gary Monroe que nunca mediu esforços para nos ensinar e ajudar (in memoriam).

- Ao Rommel Viana que me ajudou muito, principalmente com os artigos.

-A Anuradha Prakki e Renato Cilli parceiros em um artigo. 
- A Silvia da pós-graduação do IQSC, pelas orientações.

-As funcionárias da biblioteca do IQSC, em especial a Eliana, pelas orientações na formatação da tese.

-À Pro Reitoria, pelo auxilio concedido ao congresso 87th General Session and Exhibition da International Association for Dental Research realizado em Miami, 2009.

-A Alcione, que atenciosamente me ajudou na correção gramatical dessa tese.

-A Karoline que me ajudou na formatação dessa tese e a Dayana que sempre me ajudou indiretamente.

-Ao meu irmão Eduardo e minha cunhada Tatiana Vanzo, que em vários momentos me ajudaram nas correções de inglês de artigos e abstracts enviados para congressos.

- À empresa 3M/ESPE, que forneceu resinas para testes piloto.

- Aos meus cunhados, Caio, Ricardo e Américo, e cunhadas, Tatiana e Muriel, pelo apoio e incentivo e aos meus sobrinhos Matheus, Alice e Isabella que me fazem muito feliz.

- E não esquecendo das professoras Maria Cecília Veronezi e Maria Silvia de Lima Pazim que um dia plantaram uma sementinha da curiosidade para a pesquisa em mim e as quais hoje sou muito grata. 
"Jas grandes 6atalhas da vida, o primeiro passo para a vitória é o desejo de vencer" Mahatma Gandhi 


\section{RESUMO}

DENIS, A.B. Avaliação do grau de conversão monomérica, parâmetros de cinética de polimerização e determinação de monômeros residuais em resinas experimentais. 2012. 115f. Tese (Doutorado) - Instituto de Química de São Carlos, Universidade de São Paulo, São Carlos, 2012

Este estudo teve como objetivo investigar múltiplos aspectos relacionados a polimerização da resina composta como: o grau de conversão monomérica (GC), parâmetros da cinética de polimerização e a determinação de monômeros residuais TEGDMA e BisGMA, além de avaliar o desempenho de aparelhos fotoativadores. As resinas compostas experimentais foram manipuladas variando-se os fotoiniciadores R1-) canforoquinona/amina, R2-) PPD/amina, R3-) PPD + canforoquinona/amina) e foram utilizados dois aparelhos para a fotoativação (I-) lâmpada halógena (Demetron LC/ SDS Kerr-USA) e II-) LED (Poly 600/Kavo-Brasil) ambos com $600 \mathrm{~mW} \mathrm{~cm}^{-2}$, por $40 \mathrm{~s}$. O GC após $300 \mathrm{~s}$ e os parâmetros de cinética como taxa máxima de conversão $\left(R p^{\text {maxx }}\right)$, tempo em que ocorreu a taxa máxima de polimerização $\left(t_{\text {máx }}\right)$ e a conversão quando ocorreu a $\mathrm{Rp}^{\text {max }}$, foram determinados por meio de espectroscopia de absorção no infravermelho em tempo real (RT-FTIR), Os espectros foram coletados dos espécimes $(\mathrm{n}=5)$ no modo cinética, durante $305 \mathrm{~s}$, entre 1680 e $1550 \mathrm{~cm}^{-1}$. As 5 primeiras varreduras coletadas serviram para fornecer o espectro de absorção da resina não polimerizada (utilizado no cálculo do GC). $\mathrm{Na} 6^{\circ}$ varredura, o fotoativador foi ligado (por 40 segundos) enquanto o espectro continuava a ser coletado até $300 \mathrm{~s}$ após a ativação da luz. A presença de monômeros residuais (TEGDMA e BisGMA) foi avaliada por meio da cromatografia líquida de alta eficiência (HPLC), sendo que os espécimes $(n=6)$ foram imersos em acetonitrila ( 5 mL-24 h) com agitação mecânica, o método desenvolvido utilizou: HPLC, coluna $\mathrm{C} 18$, fase móvel A: água com trietilamina $(0,05 \%)$ acidificada com ácido acético $(\mathrm{pH}$ 4) e B: acetonitrila, modo de eluição com gradiente $\left(40-85 \%-17 \mathrm{~min} / 55^{\circ} \mathrm{C}\right)$, fluxo de $1 \mathrm{~mL}$ $\min ^{-1}$, detector UV em $210 \mathrm{~nm}$, injeção de $20 \mu \mathrm{L}$. Em relação aos resultados de GC após $300 \mathrm{~s}$ os maiores valores foram para a resina R1 tanto fotoativada com LED $(65,90 \% \pm 1,81)$ quanto com a lâmpada halógena $(64,40 \% \pm 0,83)$, e os menores valores encontrados foram quando a resina R2 foi fotoativada pelo LED $(35,64 \% \pm 1,73)$ e a única resina que apresentou diferenças significantes em relação as fontes de luz foi a R2. Os valores da $\mathrm{Rp}^{\text {máx }}$ diminuíram nas resinas que apresentavam o fotoiniciador PPD. O tempo de ocorrência da taxa máxima de conversão $\left(\mathrm{t}_{\text {máx }}\right)$ aconteceu mais rapidamente para a resina com CQ. Todas as resinas apresentaram

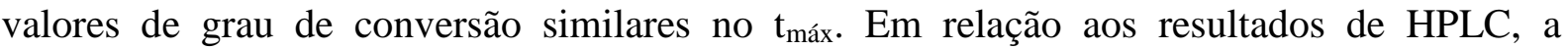
quantidade de monômeros extraídos $(\mathrm{M} / \mathrm{M} \%)$ variou de 1,98\% $\pm 0,16$ à 3,34\% $\pm 0,07$ para os monômeros TEGDMA e de 3,57\% $\pm 0,30$ à 7,57\% $\pm 0,40$ para os monômeros BisGMA. A resina R2 apresentou a maior quantidade de monômeros residuais quando fotoativada com ambas as fontes, principalmente quando fotoativada com o LED. As resinas R1 e R3 obtiveram comportamento parecidos para ambos fotoativadores. Conclui-se que a resina R3 pode ser uma boa opção, pois quando comparada com a resina R1 apresentou vantagens como: redução na $\mathrm{Rp}^{\text {máx }}$, bem como o momento em que esta ocorreu $\left(\mathrm{t}_{\text {máx }}\right)$, além de ser adequadamente fotoativada com aparelhos de LED.

Palavras chave: resina, fotoiniciador, grau de conversão, cinética de polimerização, monômeros residuais 


\begin{abstract}
DENIS, A.B. Evaluation of degree of monomer conversion, the polymerization kinetic parameters and determination of residual monomers in experimental resins. 2012. 115f. Tese (Doutorado) - Instituto de Química de São Carlos, Universidade de São Paulo, São Carlos, 2012
\end{abstract}

This study aimed to investigate multiple aspects of composite resin polymerization as the degree of monomer conversion (DC), the kinetic parameters of polymerization and the determination of residual monomers TEGDMA and BisGMA, and evaluate the performance of light curing units. The experimental composites were manipulated by varying the photoinitiators R1-) camphorquinone/amine, R2-) PPD/amine, R3-) PPD + camphorquinone/ amine) and two devices were used for the polymerization I-) halogen lamp (Demetron LC / SDS Kerr, USA) and II-) LED (Poly 600/Kavo-Brasil) both with $600 \mathrm{~mW} \mathrm{~cm}^{-2}$ for $40 \mathrm{~s}$. DC after $300 \mathrm{~s}$ and the kinetic parameters such as maximum rate of polymerization conversion $\left(\mathrm{Rp}^{\max }\right)$, time of occurrence of the maximum rate of polymerisation $\left(\mathrm{t}_{\max }\right)$ and the conversion occurred when $\mathrm{Rp}^{\max }$ were determined by infrared absorption spectroscopy in real time (RTFTIR), the infrared spectrum was collected from the specimen $(n=5)$ in order kinetics for 305 $\mathrm{s}$, between 1680 and $1550 \mathrm{~cm}^{-1}$. The first 5 scans were used to provide the collected absorption spectrum of the uncured resin (calculated DC). In the sixth scan, the curing unit was connected (by 40 seconds) while the spectrum continued to be collected up to $300 \mathrm{~s}$ after activation of the light. The presence of residual monomers (TEGDMA and BisGMA) was assessed by high performance liquid chromatography (HPLC), and the specimens $(n=6)$ were immersed in acetonitrile $(5 \mathrm{~mL}-24 \mathrm{~h})$ with mechanical stirring, the method developed used: HPLC, C18 column, mobile phase A: water with triethylamine $(0,05 \%)$ acidified with acetic acid $(\mathrm{pH} 4)$ and phase $\mathrm{B}$ : acetonitrile, gradient elution mode $\left(40-85 \%-17 \mathrm{~min} / 55^{\circ} \mathrm{C}\right)$, flow 1 $\mathrm{mL} / \mathrm{min}$, UV detector at $210 \mathrm{~nm}$, injection of $20 \mu \mathrm{L}$. Regarding the results of DC after 300s were the highest values for both R1 resin polymerized with LED $(65.90 \% \pm 1.81)$ and with a halogen lamp $(64.40 \% \pm 0.83)$, and lower values when the resin was found that $\mathrm{R} 2$ was polymerized by LED $(35.64 \% \pm 1.73)$ and the only resin that showed significant differences in the sources of light was the R2. The values of the resins decreased $\mathrm{Rp}^{\max }$ who had PPD photoinitiator. The time of occurrence of the maximum rate of conversion $\left(t_{\max }\right)$ occurred more rapidly for the resin with CQ. And all resins showed values similar degree of conversion in $t_{\max }$. For HPLC results, the amount of monomer extracted $(\mathrm{M} / \mathrm{M} \%)$ ranged from $1.98 \%$ \pm 0.16 to $3.34 \% \pm 0.07$ for the monomers of TEGDMA and $3.57 \% \pm 0.30$ to $7.57 \% \pm 0.40$ for the monomers BisGMA. Resin R2 showed the highest amount of residual monomers as polymerized with both sources, especially when polymerized with LED. Resins R1 and R3 had similar behavior for both curing units. In conclusion, the resin R3 can be a good choice, as compared with the resin obtained $\mathrm{R} 1$ advantages as reduction in $\mathrm{Rp}^{\mathrm{max}}$ as well as the time it occurred $\left(\mathrm{t}_{\max }\right)$, and be suitably photoactivated with LED devices.

Key words: resin, photoinitiator, degree of conversion, polymerization kinetics, residual monomers 


\section{LISTA DE FIGURAS}

Figura 1- Fórmula estrutural do Bisfenol glicidil dimetacrilato (BisGMA) ..........................25

Figura 2- Fórmula estrutural do Trietileno glicol dimetacrilato (TEGDMA) ........................ 26

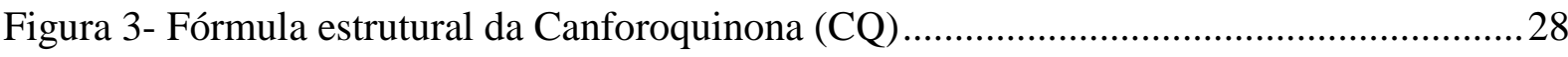

Figura 4- Fórmula estrutural da N,N-dimetil-p-toluidina (DMPT) ......................................... 28

Figura 5- Fórmula estrutual do fotoiniciador fenil-propanodiona (PPD) ................................29

Figura 6- Lâmpada halógena Demetron LC/ SDS Kerr ......................................................... 42

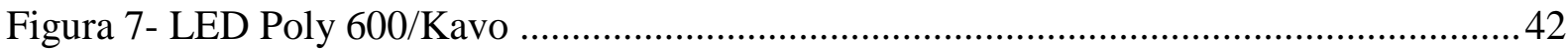

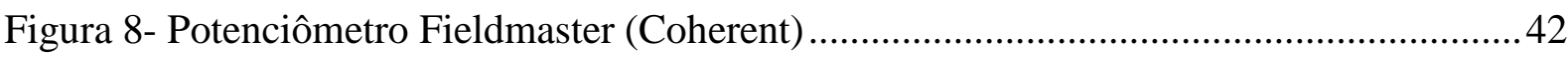

Figura 9- Esquema geral das resinas, fontes de luz e métodos utilizados .............................. 43

Figura 10- Espectrofotômetro NEXUS 670 FT-IR/Nicolet ................................................. 44

Figura 11- Unidade de refletância total atenuada (ATR) ..................................................... 44

Figura 12- Matriz posicionada na superfície do cristal de ATR ............................................. 45

Figura 13- Esquema da fotoativação da amostra em íntimo contato com o cristal ZnSe......... 45

Figura 14- Fotoativação dos espécimes no aparelho de FT-IR .............................................46

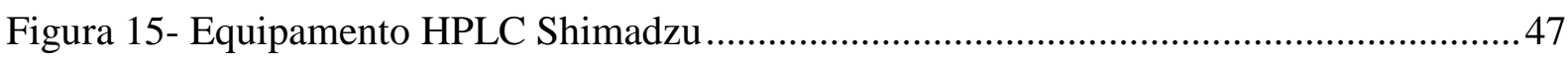

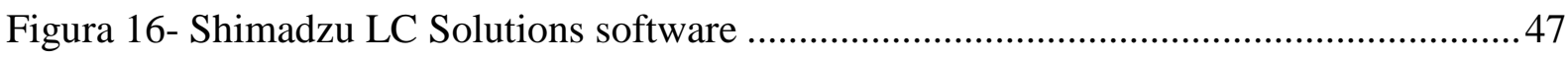

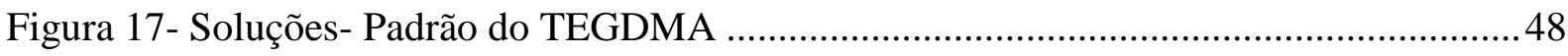

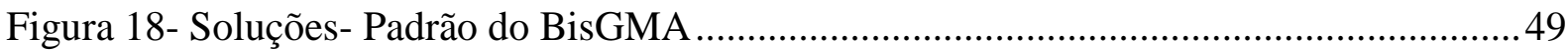

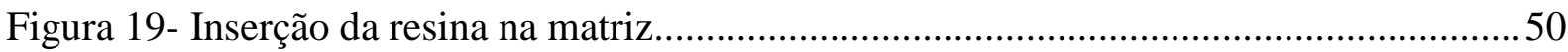

Figura 20- Espécimes imersos em acetonitrila por 24 horas com agitação mecânica..............51

Figura 21- Esquema demonstrativo da extração dos monômeros residuais e injeção das

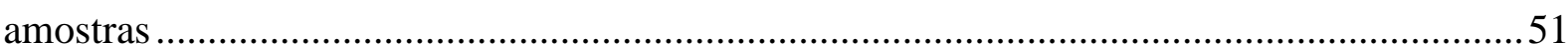

Figura 22- Medições em um cromatograma (fonte: SOARES, 2006) ....................................53

Figura 23- Fator de cauda (TF) (fonte: VAN ITERSON) ..................................................54

Figura 24- Espectro infravermelho da conversão das duplas ligações de carbono por FT-IR no pico correspondente as cadeias alifáticas em tempo real ........................................................59

Figura 25- Gráfico da média e desvio padrão do grau de conversão (\%) após 300 segundos 61 Figura 26- Gráfico do grau de conversão das resinas em tempo real......................................61

Figura 27- Gráfico da média e desvio padrão da taxa máxima de conversão $\left(\mathrm{Rp}^{\text {máx }}\right)$.............63

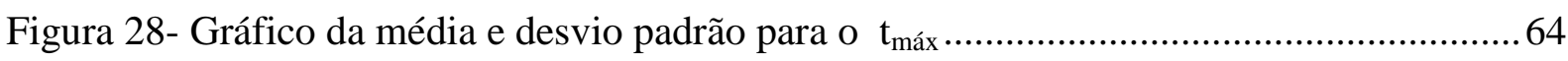

Figura 29- Gráfico da média e desvio padrão do grau de conversão no $t_{\text {máx }}$............................. 66 
Figura 30- Porcentagem de monômeros residuais em função do tempo de extração em

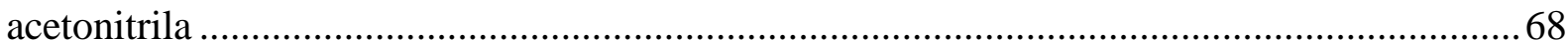

Figura 31- Cromatograma dos monômeros liberados dos espécimes .....................................69

Figura 32- Cromatogramas sobrepostos do padrão e da seletividade .....................................71

Figura 33- Curvas de calibração dos monômeros TEGDMA (A) e BisGMA (B) ................... 72

Figura 34- Gráfico da média e desvio padrão dos monômeros residuais TEGDMA ................ 80

Figura 35- Gráfico da média e desvio padrão dos monômeros residuais BisGMA ..................81 


\section{LISTA DE TABELAS}

Tabela 1- Gradiente de eluição da fase móvel 49

Tabela 2 - Parâmetros de conformidade do sistema e recomendações (US-FDA, 2000)

Tabela 3 - Valores do grau de conversão monomérica das resinas após 300 segundos

$(\mathrm{n}=5)$

Tabela 4 - Média, desvio padrão e resultado da Análise de Variância e Teste de Tukey para o grau de conversão (\%) após 300 segundos

Tabela 5 - Taxa máxima de conversão $\left(\mathrm{Rp}^{\text {máx }}\right)$ para as diferentes resinas e fontes de luz $(\mathrm{n}=5)$

Tabela 6 - Média, desvio padrão e resultado da Análise de Variância e Teste de Tukey para a taxa máxima de conversão $(\% / s)$.

Tabela 7 - $t_{\text {máx }}$ para as diferentes resinas e fontes de luz $(n=5)$

Tabela 8 - Média, desvio padrão e resultado da Análise de Variância e Teste de Tukey para o $\mathrm{t}_{\text {máx }}$

Tabela 9 - Grau de conversão no $t_{\text {máx }}$ para as diferentes resinas fotoativadas com as duas fontes de luz $(n=5)$

Tabela 10 - Média, desvio padrão e resultado da Análise de Variância e Teste de Tukey para o grau de conversão no $t_{\text {máx }}$

Tabela 11 - Determinação de monômeros residuais em diferentes solventes

Tabela 12 - Determinação de monômeros residuais utilizando ou não agitação mecânica .....67

Tabela 13 - Determinação de monômeros residuais em função do tempo de extração 68

Tabela 14 - Parâmetros avaliados de conformidade do sistema e recomendações .70

Tabela 15 - Exatidão na determinação dos monômeros TEGDMA e BisGMA 73

Tabela 16 - Variabilidade intra- e inter-dias dos monômeros avaliados 74

Tabela 17 - Robustez do método de determinação dos monômeros em função do fluxo e temperatura da coluna

Tabela 18 - Monômeros residuais extraídos da resina R1 fotoativada com LED e lâmpada halógena $(n=6)$

Tabela 19 - Monômeros residuais extraídos da resina R2 fotoativada com LED e lâmpada halógena $(\mathrm{n}=6)$

Tabela 20 - Monômeros residuais extraídos da resina R3 fotoativada com LED e lâmpada

halógena $(n=6)$ 
Tabela 21 - Média, desvio padrão e resultado da Análise de Variância e Teste de Tukey para os monômeros residuais TEGDMA .

Tabela 22 - Média, desvio padrão e resultado da Análise de Variância e Teste de Tukey para

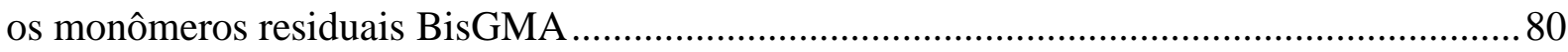




\section{LISTA DE ABREVIATURAS E SIGLAS}

Abs Absorbância

ANVISA Agência Nacional de Vigilância Sanitária

ATR Refletância total atenuada

BAPO Óxido bis-alquil fosfínico

BisEMA BisGMA etoxilado

BisGMA Bisfenol glicidil dimetacrilato

$\mathrm{CH}_{3}$ BisGMA BisGMA propoxilado

$\mathrm{CH}_{3} \quad$ Metila

CQ Canforoquinona

CV\% Coeficiente de variação por cento

$\mathrm{C}=\mathrm{C} \quad$ Duplas ligações carbônicas

${ }^{\circ} \mathrm{C} \quad$ Graus Celsius

DSC Calorimetria exploratória diferencial

DMPT N,N dimetil-p-toluidina

DMAEMA N,N dimetil amino etil metacrilato

FDA Food and Drug Administration

FT-IR Espectroscopia de absorção no infravermelho por transformada de Fourier

GC Grau de conversão monomérica

h Horas

HPLC Cromatografia líquida de alta eficiência

ICH International Conference on Harmonisation

INMETRO Instituto Nacional de Metrologia, Normalização e Qualidade Industrial

$\mathrm{J} \mathrm{cm}^{-2} \quad$ Joules por centímetro quadrado

k Fator de retenção

Kp $\quad$ Coeficiente de propagação

Kt Coeficiente de terminação

LD Limite de detecção

LED Diodo emissor de luz

LQ Limite de quantificação

MAPO Óxido mono-alquil fosfínico

$\mathrm{mW} \mathrm{cm} \mathrm{cm}^{-2}$ Miliwatts por centímetro quadrado

mm Milímetro 


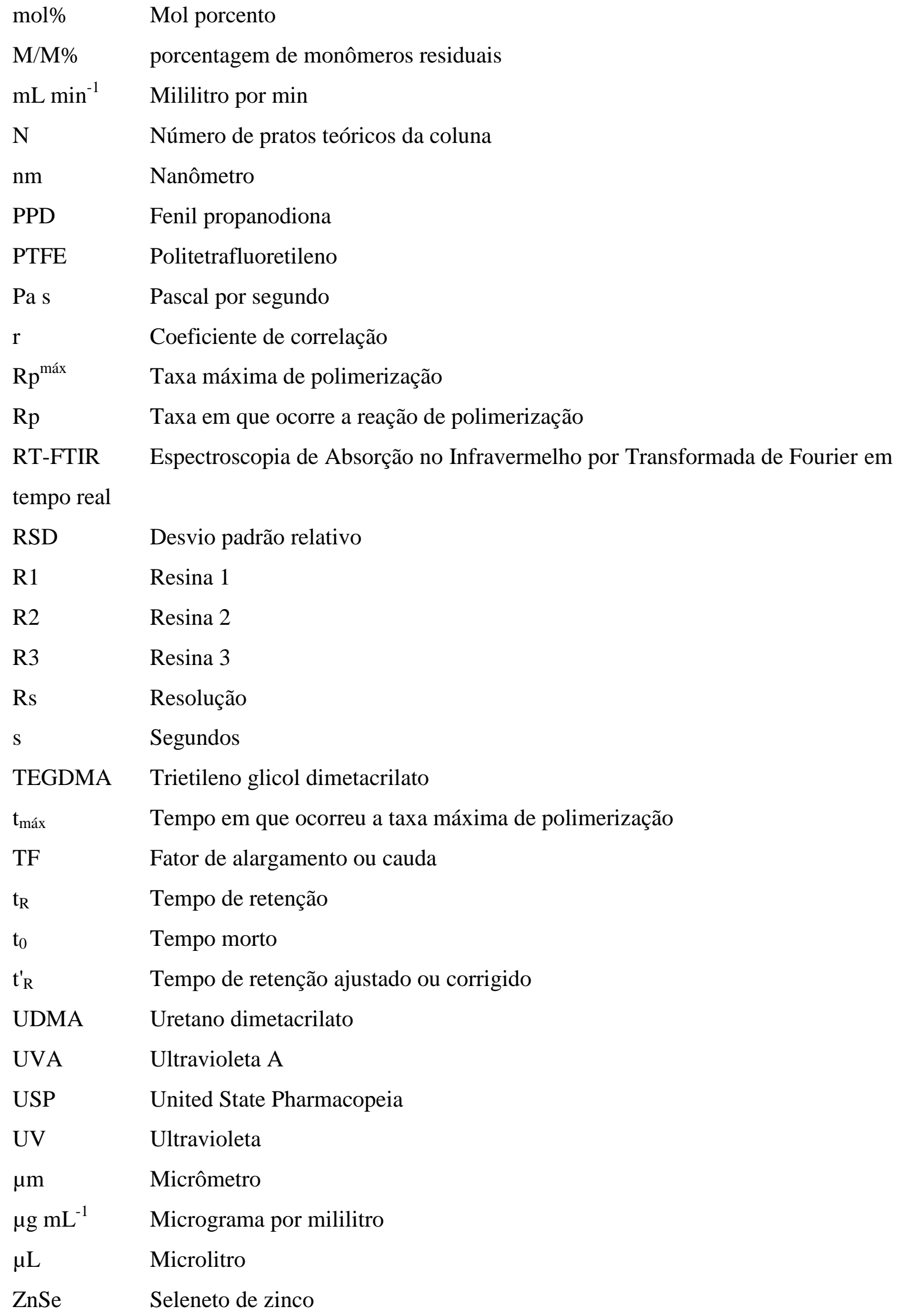




\section{SUMÁRIO}

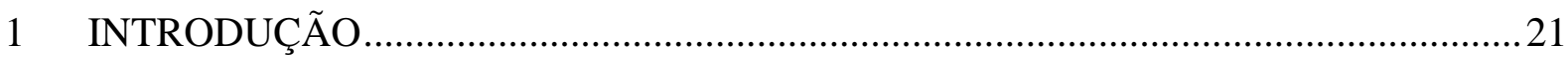

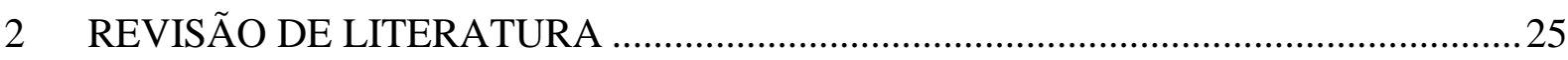

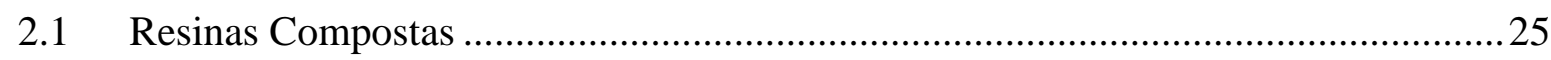

2.2 Paramêtros de cinética de reação de polimerização das resinas .................................30

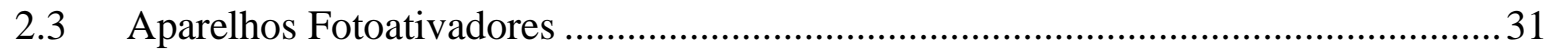

2.4 Espectroscopia de Absorção no Infravermelho por Transformada de Fourier em tempo real (RT-FTIR) aplicada ao estudo de polimerização fotoiniciada

2.5 Métodos Cromatográficos de Análise aplicados a avaliação de monômeros residuais

2.5.1 Desenvolvimento, otimização e validação do método cromatográfico de análise

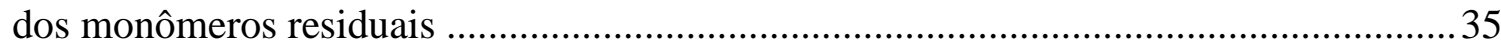

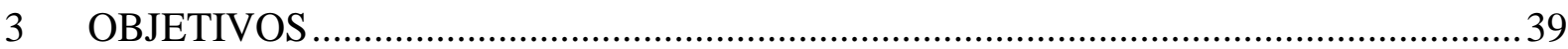

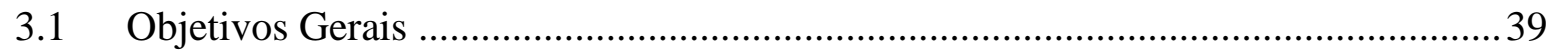

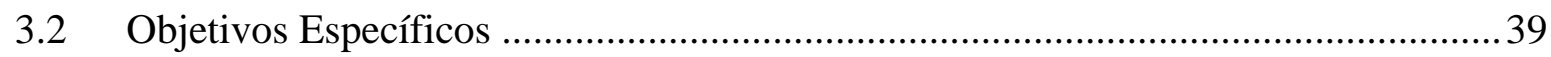

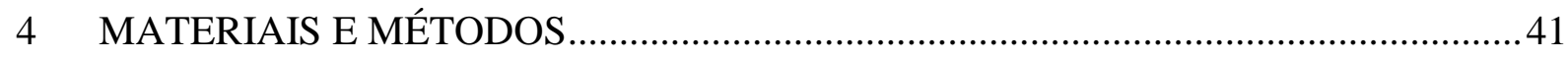

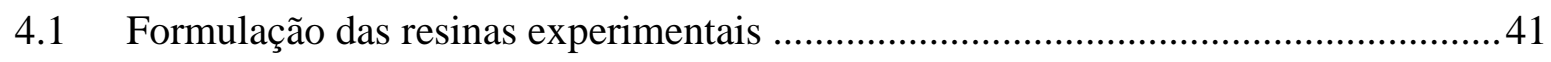

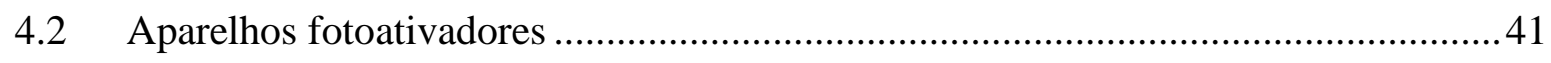

4.3 Grau de conversão e parâmetros de cinética de polimerização ................................... 44

4.4 Avaliação dos monômeros residuais por HPLC ….................................................... 47

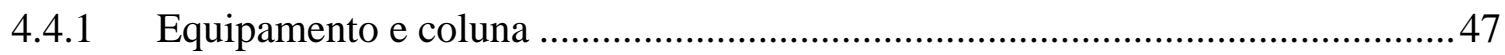

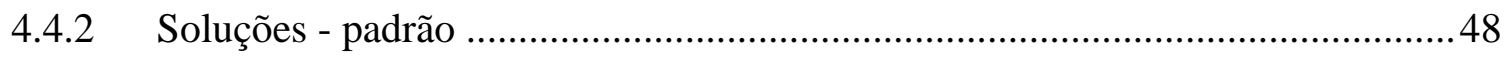

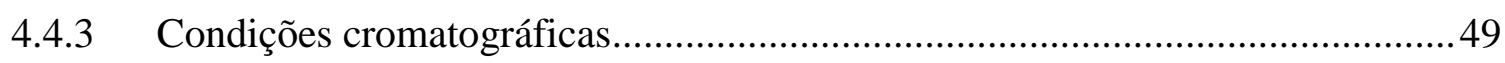

4.4.4 Preparo dos espécimes das resinas experimentais para análise por HPLC ........50

4.4.5 Otimização do método para a avaliação dos monômeros residuais ....................50

4.4.6 Procedimento de extração dos monômeros residuais .........................................51

4.4.7 Validação do método cromatográfico de análise dos monômeros residuais ......52

4.4.7.1 "System Suitability” ou Adequabilidade....................................................52

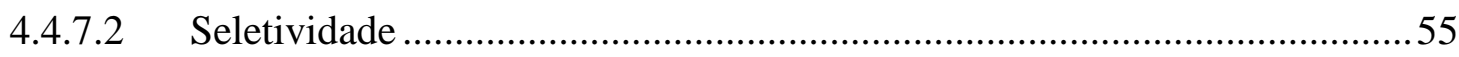

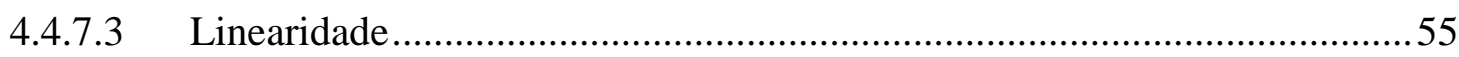

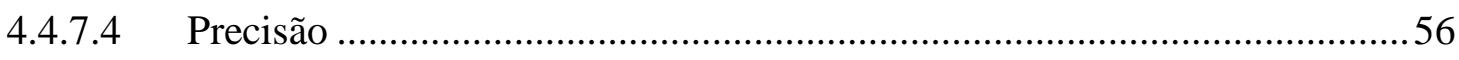

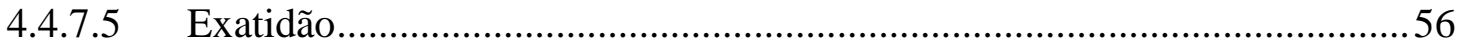

4.4.7.6 Limite de Detecção(LD) e Limite de Quantificação(LQ) ............................56 


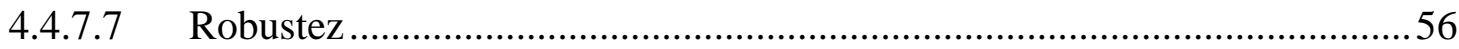

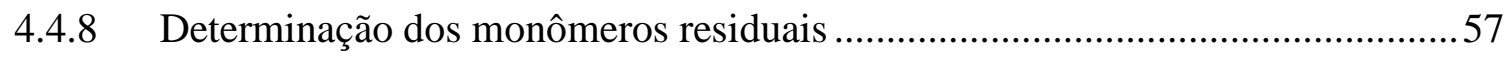

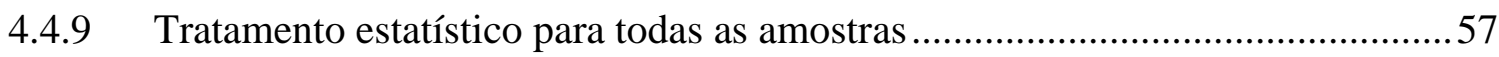

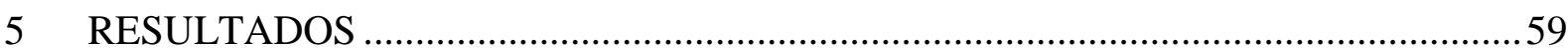

5.1 Determinação do grau de conversão e parâmetros de cinética ...................................59

5.1.1 Grau de conversão monomérica total após 300segundos ...................................59

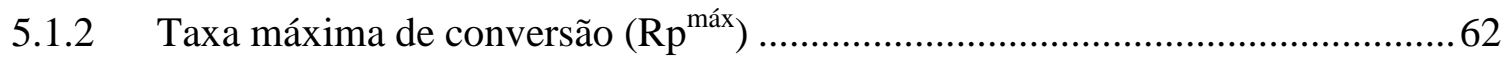

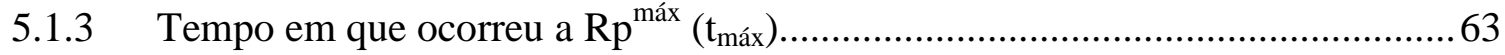

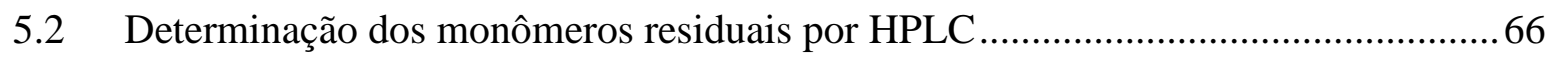

5.2.1 Otimização do método cromatográfico de análise dos monômeros residuais.... 66

5.2.2 Validação do método cromatográfico de analise dos monômeros residuais ......69

5.2.3 Determinação dos monômeros residuais nas amostras reais ............................... 75

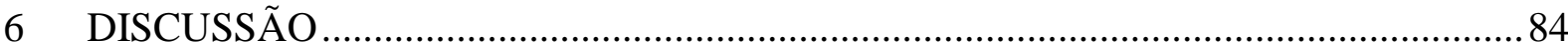

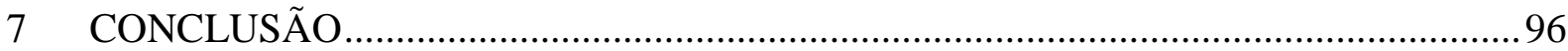

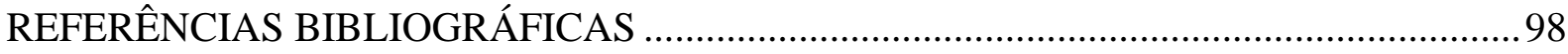

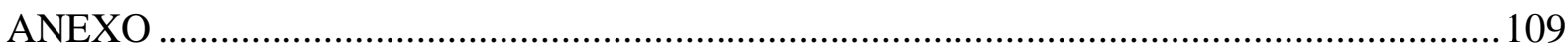




\section{INTRODUÇÃO}

Os materiais resinosos são muito utilizados na clínica odontológica, podendo estes serem empregados para restaurações de cavidades, selantes de fóssulas e fissuras, cimentação de peças protéticas, como material provisório, para colagem de braquetes ortodônticos, para obturações endodônticas, entre outros.

Muitas mudanças têm sido realizadas nos materiais resinosos desde sua introdução na odontologia há mais de 50 anos. Essas mudanças têm como objetivo melhorar suas propriedades físico-mecânicas, biológicas e estéticas. (FERRACANE, 2011).

Um maior grau de conversão confere ao material restaurador melhores propriedades mecânicas, como: resistência ao desgaste, à compressão, ao cisalhamento, resistência flexural e dureza (FERRACANE, 1985; PEUTZFELDT, 1997; ASMUSSEN; PEUTZFELDT, 2001b; PEUTZFELDT; ASMUSSEN, 2005). Entretanto, um alto grau de conversão leva a formação de tensões de contração que são geradas internamente no material e são transmitidas em parte à interface adesiva dente-restauração, comprometendo a integridade marginal e apresentando como consequência a formação de fendas, que podem levar a microinfiltração da restauração e sensibilidade pós-operatória (HOFMANN et al., 2003; ATAI; WATTS, 2006).

Em contrapartida, uma polimerização insuficiente da resina composta interfere não só nas propriedades mecânicas do material, mas também nas propriedades biológicas, favorecendo a liberação de seus componentes não ligados a rede polimérica, podendo causar reações alérgicas, efeitos citotóxicos e genotóxicos. Além disso estes monômeros residuais podem alcançar à polpa dentária via túbulos dentinários (WATAHA et al., 1999; SCHWENGBERG et al., 2005; CAMPANHA et al., 2006; GOLDBERG, 2008). Dessa maneira, uma melhor polimerização do material melhora também a sua biocompatibilidade, uma vez que ela está associada, principalmente à natureza e quantidade dos componentes liberados (PALACIO; ZAVAGLIA, 2003).

O grau de conversão monomérica das resinas pode ser influenciado dependendo da composição dos monômeros, fotoiniciadores, densidade de energia e comprimento de onda concedido pela técnica de fotoativação para iniciar o processo de polimerização, entre outros fatores (CORRÊA, 2003; EMAMI; SODERHOLM, 2005; D'ALPINO et al., 2007; OGUNYINKA et al., 2007).

O fotoiniciador mais utilizado atualmente nos materiais resinosos odontológicos é a canforoquinona (CQ), mas ela apresenta algumas desvantagens tais como a cor amarelo intenso, o que prejudica a incorporação em resinas de coloração bem clara, muito utilizadas 
ultimamente em dentes clareados e também apresenta uma baixa eficiência de polimerização (SUN; CHAE, 2000).

Para contornar esses problemas estão sendo testados outros fotoiniciadores como é o caso do fenil-propanodiona (PPD), sendo este fotoiniciador menos dependente da presença da amina terciária para gerar radicais livres, além de apresentar cor amarelo claro e seu estado líquido à temperatura ambiente, o que facilita sua incorporação à resina composta em maiores quantidades. (PARK et al., 1999; SUN; CHAE, 2000; NEWMANN et al., 2006).

Pesquisas estão sendo realizadas no sentido de avaliar a associação da CQ mais o PPD em uma mesma resina (PARK et al., 1999; SCHNEIDER et al., 2008), pois acredita-se que é possível reduzir as tensões de contração da resina, pela diminuição da taxa máxima de polimerização $\left(R p^{m a ́ x}\right)$, sem alteração no grau de conversão, sendo esses parâmetros observados nas reações de cinética de reação da resina (SCHNEIDER et al., 2008; SCHNEIDER et al., 2009ab; BRANDT et al., 2011). Um dos principais desafios dos pesquisadores atualmente é conseguir diminuir as tensões de contração da resina sem diminuir suas propriedades mecânicas.

Estes fotoiniciadores que apresentam cor mais clara absorvem luz com comprimento de onda inferior à canforoquinona, mais próximos ao ultravioleta (NEUMANN et al., 2005). Esse comprimento de onda é perfeitamente coberto pelos aparelhos de lâmpada halógena, mas não é totalmente atingido pela grande maioria dos aparelhos de LED, devido ao seu estreito espectro de emissão em torno de $470 \pm 20 \mathrm{~nm}$. Isso faz com que as resinas contendo esses diferentes fotoiniciadores não sejam adequadamente polimerizadas por estes aparelhos, podendo apresentar baixo grau de conversão e baixas propriedades mecânicas (UHL et al., 2003; NEUMANN et al., 2005). Mas, a associação dos dois fotoiniciadores (CQ e PPD) apresenta um pico máximo de absorção em torno de 452nm (SCHNEIDER et al., 2008), possibilitando perfeitamente sua ativação por aparelhos dentro da faixa azul do espectro eletromagnético.

Os aparelhos de LED estão, cada vez mais, sendo utilizados na clínica odontológica, havendo até uma tendência de substituição total do aparelho tradicional de fotoativação de lâmpada halógena pelo de LED, devido as grandes vantagens que esses equipamentos têm demonstrado. Por isso é necessário também o estudo da efetividade desses equipamentos em relação as resinas com o fotoiniciador PPD.

Diferentes métodos podem ser utilizados para avaliação do grau de conversão monomérica: métodos de análise térmica como: calorimetria exploratória diferencial (DSC) e análise térmica diferencial (DTA) (IMAZATO et al., 2003; SCHNEIDER et al., 2009a), 
métodos vibracionais como: espectroscopia de absorção no infravermelho por transformada de Fourier (FT-IR) e espectroscopia Raman. (SOH; YAP, 2004; EMAMI; SODERHOLM, 2005; SCHNEIDER et al., 2008; BRANDT et al., 2011)

Estudos para a avaliação de parâmetros da cinética de polimerização da resina composta utilizando outros fotoiniciadores como o PPD ainda são necessários, e pouco ainda se sabe a respeito da presença de monômeros residuais, possíveis de serem liberados nesse tipo de resina composta, parâmetro que pode ser avaliado pelo método cromatográfico de análise. 


\section{REVISÃO DE LITERATURA}

\subsection{Resinas Compostas}

As resinas compostas odontológicas foram desenvolvidas em 1962 por Bowen em resposta à necessidade de um material restaurador estético. Este desenvolveu um monômero denominado de Bisfenol glicidil dimetacrilato (Bis-GMA). A adição de partículas de quartzo silanizadas a este material diminuiu radicalmente a contração de polimerização, expansão térmica e sorção de água, ao mesmo tempo em que aumentou o módulo de elasticidade e a dureza superficial (BOWEN, 1963).

As resinas compostas são constituídas basicamente por um monômero multifuncional de cadeia longa que se polimeriza consigo mesmo e com um diluente tetrafuncional resultando em uma rede tridimensional de ligações cruzadas. Esta rede se cerca e se liga a partículas inorgânicas revestidas por silano. Além dos monômeros a matriz resinosa apresenta outros componentes como iniciadores, estabilizadores e pigmentos (PEUTZFELDT, 1997; ANDRZEJEWSKA, 2001).

O monômero BisGMA é o monômero mais usado em odontologia e caracteriza-se por ser uma molécula longa e rígida com duplas ligações de carbono reativas em ambas as extremidades (Figura 1), tendo um alto peso molecular e apresentando-se como um liquido altamente viscoso a temperatura ambiente (SIDERIDOU et al., 2002).

Figura 1- Fórmula estrutural do Bisfenol glicidil dimetacrilato (BisGMA)

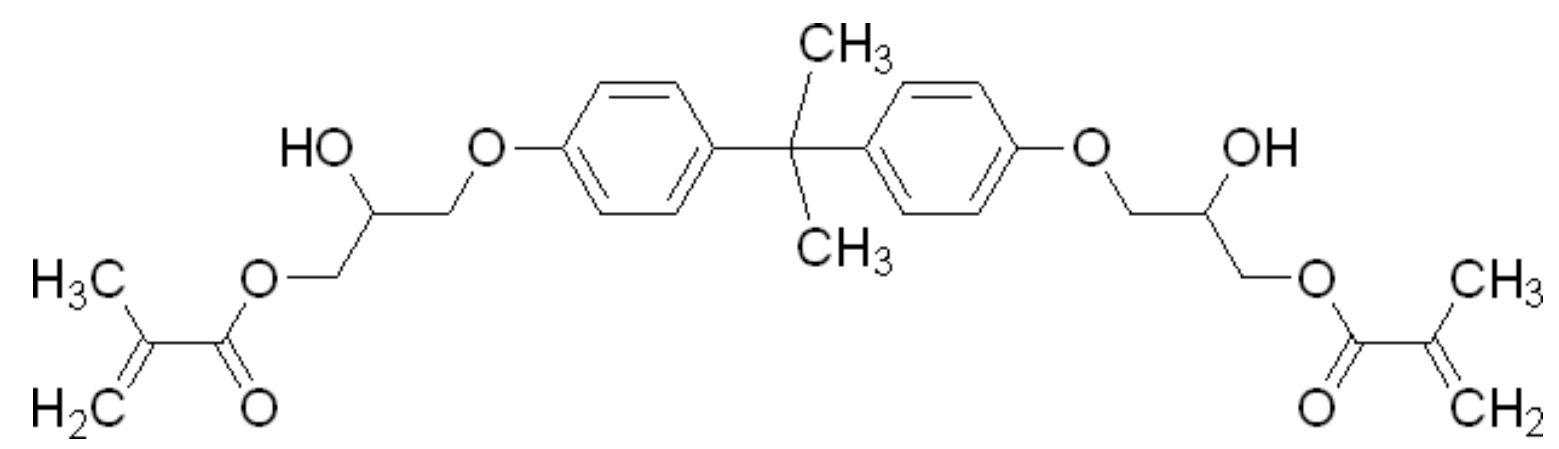

Um dos monômeros mais usados como diluente do BisGMA é o trietileno glicol dimetacrilato (TEGDMA), sendo uma molécula linear relativamente flexível, que assim como o BisGMA possui ligações insaturadas de carbono nas extremidades (Figura 2). Ele funciona não somente como diluente, mas também como um agente de ligação cruzada, melhorando 
grandemente a polimerização do monômero $\mathrm{e}$ as propriedades físicas da resina (PEUTZFELDT, 1997).

Figura 2- Fórmula estrutural do Trietileno glicol dimetacrilato (TEGDMA)

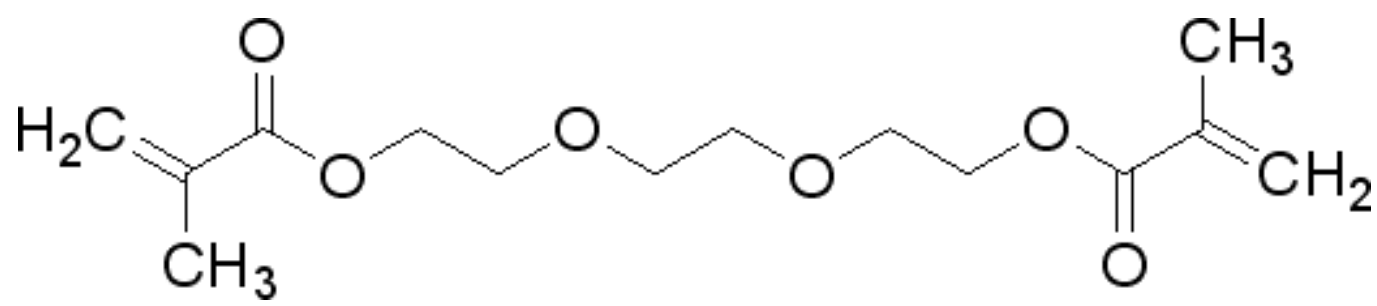

Outras formulações de resinas com diferentes combinações entre monômeros e diluentes também são encontradas como é o caso do monômero uretano dimetacrilato (UDMA) (PEUTZFELDT, 1997), do BisEMA- bisfenol A dimetacrilato etoxilado conhecido como BisGMA etoxilado, sendo este monômero um análogo do BisGMA, obtido por uma modificação na molécula de BisGMA através da substituição dos grupamentos pendentes da hidroxila por um átomo de hidrogênio (SIDERIDOU et al., 2002). Outro análogo do BisGMA é o BisGMA propoxilado ( $\mathrm{CH}_{3}$ BisGMA), cujos grupamentos hidroxila da cadeia são substituidos pelo $\mathrm{CH}_{3}$, sendo sua síntese obtida a partir da propoxilação de difenóis e posterior metacrilação. (KALACHANDRA et al., 1997; PRAKKI et al., 2007)

Estudos mostram que a incorporação de aditivos como dicetonas (diacetil) e propanal (aldeídos) a dimetacrilatos pode levar a um significante aumento no seu grau de conversão, melhora em propriedades mecânicas e na resistência ao desgaste das resinas compostas, devido a melhora nas reações de transferência de cadeias (PRAKKI et al., 2007; PRAKKI et al., 2008; PRAKKI et al., 2009). Denis et al. (2012a) estudaram a incorporação de aditivos em pequenas quantidades e observaram que somente o grupo que possuía a maior quantidade de aditivos (24 mol\%), obteve diferenças significantes dos demais grupos em relação ao grau de conversão, dureza, transição vítrea e propriedades reológicas.

A polimerização das resinas compostas ativadas por luz visível se processa por uma reação de adição exotérmica do tipo vinílica desencadeada via radicais livres e promove a formação de uma rede polimérica tridimensional através de ligações cruzadas intermoleculares e estas etapas incluem as fases de indução/iniciação, propagação e terminação (ANDRZEJEWSKA, 2001).

A cadeia polimérica formada por monômeros multifuncionais é conduzida pelas ligações $\mathrm{C}=\mathrm{C}$ no desenvolvimento de macro-radicais. A reação de polimerização nunca ocorre 
por completo, ficando uma grande quantidade de monômeros residuais que não reagiram com as duplas ligações (FERRACANE; CONDOR, 1990; FERRACANE, 1994). Essa quantidade de ligações duplas pendentes pode depender da composição do monômero, do sistema de fotoiniciação e da densidade de energia do aparelho fotoativador. (ANDRZEJEWSKA, 2001; D’ALPINO et al., 2007; OGUNYINKA et al., 2007).

O fotoiniciador é uma molécula que absorve luz e gera radicais livres que iniciam o processo de polimerização. Existem duas categorias de fotoiniciadores (STANSBURY 2000; ALLEN 1996):

Tipo I - que absorvem a luz e geram radicais livres por fragmentação de sua molécula.

Tipo II- que após a absorção de luz interagem com uma segunda substância doadora de hidrogênio (co-iniciadora) para que os radicais sejam gerados.

Os fotoiniciadores do tipo I têm absorção máxima na região UVA e o término da curva de absorção na faixa visível do espectro. Os fotoiniciadores do tipo II absorvem luz na região visível e também próximo à região ultravioleta (CORRÊA, 2003)

As resinas atuais são fotoativadas por luz visível, dentro da faixa azul do espectro eletromagnético e utilizam geralmente um $\alpha$ dicetona como fotoiniciador: a canforoquinona (CQ) que é um fotoiniciador do Tipo II (Figura 3). Esta substância tem coloração amarela e por isso é incorporada em pequenas quantidades na matriz, com o objetivo de não comprometer a aparência estética final da restauração. Ao absorver luz visível entre 400 à $550 \mathrm{~nm}$ (com pico máximo de absorção em $468 \mathrm{~nm}$ ), a CQ atinge um estado de excitação triplete, atrai as moléculas da amina terciária contida na matriz orgânica (por ex. N,N-dimetilp-toluidina/DMPT) e a transferência de um elétron da amina para a CQ forma um complexo denominado exciplex com fortes características de transferência de cargas (STANSBURY, 2000). No exciplex a amina transfere um hidrogênio localizado no carbono $\alpha$ para a dicetona, resultando na produção de um radical amino e um radical cetila. $\mathrm{O}$ radical amino deriva da amina e é responsável pelo ínicio da reação de polimerização, enquanto o radical cetila da canforoquinona é inativo (ANDRZEJEWSKA, 2001; RUEGGEBERG, 1999; MOSNACEK;

LUKAK, 2002) 
Figura 3- Fórmula estrutural da Canforoquinona (CQ)

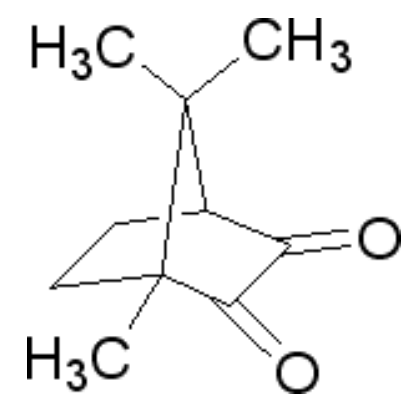

Teshima et al. (2003) observaram que a associação da CQ com a amina terciária aromática N,N-dimetil-p-toluidina (DMPT) (Figura 4) gerou mais radicais livres que do que a associação com a amina terciária alifática Metacrilato de 2- (N,N dimetilamino) etil metacrilato (DMAEMA). Stansbury (2000) também afirmou que as aminas terciárias aromáticas são mais eficientes na formação de radicais livres. Esse fato se deve provavelmente porque as aminas aromáticas (DMPT) podem doar mais hidrogênio que as aminas alifáticas (DMAEMA).

Figura 4- Fórmula estrutural da N,N-dimetil-p-toluidina (DMPT)

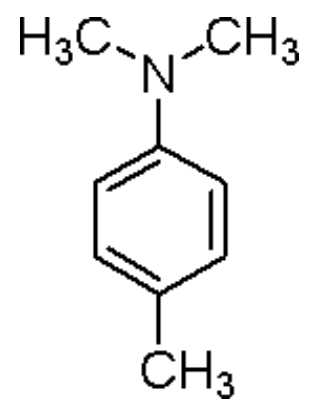

Apesar da maioria das resinas compostas utilizarem o sistema convencional $\mathrm{CQ} / A m i n a$, existem outros fotoiniciadores que também têm sido estudados para o empregado em produtos odontológicos como: óxido mono-alquil fosfínico (MAPO) (DECKER et al., 2001; NEUMANN et al., 2006), óxido bis-alquil fosfínico (BAPO) (DECKER et al., 2001; NEUMANN et al., 2006), fenil propanodiona (PPD) (PARK et al., 1999; SUN; CHAE, 2000).

O fotoiniciador fenil propanodiona (PPD) é também uma $\alpha$ dicetona (Figura 5), um fotoiniciador do tipo I, sendo um liquido viscoso de cor amarelo claro que tem sido sugerido como um possível substituto da CQ, ou a sua associação a ela. O pico de absorção máxima de luz da CQ ocorre no espectro azul com comprimento de onda de 468 nm, já o PPD possui espectro de absorção com pico máximo em 393 nm, porém a curva de absorção se estende até 
a região visível, próximo de $450 \mathrm{~nm}$, possibilitando sua ativação na presença de luz azul (NEUMANN et al., 2005; NEUMANN et al., 2006; OGUNYINKA et al., 2009).

Segundo alguns trabalhos, o fotoiniciador PPD apresentou diferenças em relação a $\mathrm{CQ}$, quanto ao comportamento em um meio reacional contendo amina. Enquanto a fotodecomposição da $\mathrm{CQ}$ cresceu com o maior conteúdo de amina no meio, a do PPD decresceu. Isto indica que em presença de amina no mecanismo de transferência de elétron e de próton, foi predominante para a CQ e não para o PPD (PARK et al., 1999; SUN; CHAN 2000, NEWMANN et al., 2006). Entretanto estudos mais recentes (EMAMI; SODERHOLM 2005, SCHROEDER et al., 2008 e SCHNEIDER et al., 2009a) demonstraram uma maior efetividade quando a amina foi utilizada em associação com o PPD.

Figura 5- Fórmula estrutual do fotoiniciador fenil-propanodiona (PPD)

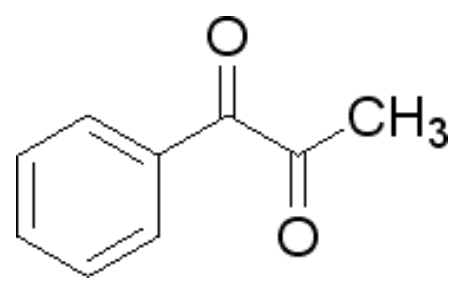

A utilização do fotoiniciador PPD tem sido sugerida também por poder diminuir o grau de amarelamento da resina, pois o PPD apresenta uma coloração mais clara que a CQ facilitando sua incorporação à resina em maiores quantidades (SUN; CHAE, 2000; NEWMANN et al., 2006). Entretando, segundo Schneider et al. (2008), esta diminuição no grau de amarelamento da resina ocorre somente quando o PPD é utilizado em concentrações bem baixas.

Segundo Park et al. (1999) e Sun e Chan (2000), existe a possibilidade de um efeito sinérgico na combinação da CQ + PPD, resultante de um segundo modo de geração de radicais livres. Além do que, essa combinação poderia promover um maior espectro de absorção também aumentando a eficiência do sistema fotoiniciador. Entretanto Neumann et al. (2006) não encontraram esse efeito sinérgico.

Acredita-se que é possível por meio dessa associação de fotoiniciadores reduzir as tensões de contração da resina, pela diminuição da taxa máxima de polimerização $\left(\mathrm{Rp}^{\text {máx }}\right.$ ), sem alteração no grau de conversão final e das propriedades mecânicas como dureza e resistência a compressão (SCHNEIDER et al., 2008, SCHNEIDER et al., 2009ab, BRANDT et al, 2011). 
Os principais objetivos da utilização desses novos fotoiniciadores são a obtenção de uma matriz resinosa mais clara, o aumento da reatividade do sistema de iniciação (RUEGGEBERG, 1999; SUN; CHAE, 2000) e a diminuição nas tensões de contração da resina (SCHNEIDER et al., 2008; SCHNEIDER et al., 2009ab; BRANDT et al., 2011).

\subsection{Paramêtros de cinética de reação de polimerização das resinas}

A cinética da reação de polimerização de monômeros multifuncionais a base de dimetacrilatos, como os usados em odontologia, é um processo complexo e exibe características peculiares como auto-aceleração, autodesaceleração, conversão limitada, ciclização e aprisonamento de radicais. Este comportamento ocorre devido à formação da rede polimérica e consequente diminuição da mobilidade do meio reacional à medida que se processa (SIDERIDOU et al., 2002).

A taxa em que a reação de polimerização ( $R p)$ ocorre é em função dos parâmetros: kp (taxa de propagação ou coeficiente de propagação) e kt (taxa de terminação ou coeficiente de terminação) (ANDRZEJEWSKA, 2001). A taxa de propagação diz respeito à reação química entre macrorradical e um monômero que será adicionado à rede polimérica deste radical. Já a taxa de terminação é a reação química que ocorre entre dois macrorradicais. Para que a propagação ocorra é preciso que um monômero se choque com um radical, sendo a terminação controlada por difusão, isto faz com que a taxa de propagação aumente em relação a terminação, observando assim um aumento abrupto na taxa de reação Rp, sendo esse aumento chamado de auto aceleração, ou efeito Trommsdorff, ou Norrisch-Smith (ANDRZEJEWSKA, 2001). A taxa de reação vai aumentando com o tempo até que atinge um ponto máximo e então cai abruptamente, sendo esse ponto máximo chamado de taxa máxima de polimerização $\left(\mathrm{Rp}^{\mathrm{máx}}\right)$, Assim, o meio que antes era controlado por difusão passa ser controlado por difusão reacional.

A reação de polimerização da resina composta nunca é dada por completa, ficando monômeros não reagidos, ou seja, não convertidos. O grau de conversão de uma resina composta normalmente está em torno de 45 a $75 \%$, dependendo da composição dos monômeros, das partículas de carga, tipo de fotoiniciador e das técnicas de fotoativação (FERRACANE; CONDOR, 1990; FERRACANE, 1994; PEUTZFELDT, 1997; PEUTZFELDT; ASMUSSEN, 2005 ). 
O desempenho clínico de materiais resinosos dependem do grau de conversão, como também da estrutura polimérica formada. A densidade de ligações cruzadas tem um papel importante nas propriedades dos polímeros. As cadeias poliméricas com menor densidade de ligações cruzadas são mais susceptíveis à ação de solvente, devido ao aumento do volume livre e devido ao fato das interações entre as cadeias predominar às ligações lineares (PEUTZFELDT; ASMUSSEN, 2005; ASMUSSEN; PEUTZFELDT, 2001b).

Estes monômeros residuais, assim como fotoiniciadores não reagidos e seus produtos fotoreativos podem ser facilmente extraídos da massa de resina para a saliva num processo de lixiviação, podendo em consequência produzir reações alérgicas, citotóxicas e genotóxicas (WATAHA et al., 1999; SCHWENGBERG et al., 2005; CAMPANHA et al., 2006; GOLDBERG, 2008) ou estimular o crescimento bacteriano ao redor de restaurações (HANSEL et al., 1998; REICHL et al., 2002). Monômeros residuais podem também agir como plastificantes, reduzindo a resistência mecânica da restauração e aumentando a sorção e podem ser responsáveis também por alterar a cor da resina devido à oxidação do material (FERRACANE, 1985).

\subsection{Aparelhos Fotoativadores}

Para ativar os agentes fotoiniciadores das resinas compostas, os aparelhos fotoativadores tradicionais utilizam uma lâmpada halógena que emite luz pelo aquecimento de um filamento de tungstênio. Essas unidades utilizam um filtro que permite a passagem apenas dos comprimentos de onda entre 400 à $500 \mathrm{~nm}$, que é a faixa útil do espectro eletromagnético para as resinas compostas com a canforoquinona como fotoiniciador.

Porém, essas unidades apresentam algumas desvantagens como: o bulbo das lâmpadas utilizadas tem vida útil reduzida. Além disso, o bulbo e o filtro se degradam rapidamente devido a alta temperatura de funcionamento e a grande quantidade de calor produzido e o resultado é a diminuição da efetividade desses componentes com o tempo (FRANCO; LOPES, 2003).

A falta de manutenção constante desses aparelhos faz com que não atinjam mais a intensidade de luz mínima divulgada pelos fabricantes, resultando em materiais que não são polimerizados de maneira adequada (MILL et al., 2002).

Para evitar problemas inerentes as lâmpadas halógenas, foi proposta a tecnologia dos diodos emissores de luz (Light Emittion Diodes - LED). Os aparelhos de LED emitem luz pela passagem de uma corrente por semicondutores, sem a utilização de filamentos aquecidos. 
Um semicondutor para produzir luz necessita da aplicação de uma tensão para vencer a barreira de energia interna. $O$ LED se constitui na combinação de dois diferentes semicondutores, um tipo $\mathrm{n}$, que tem excesso de elétrons e, outro tipo p, que tem falta de elétrons, mas rico em lacunas ou "buracos receptores" de elétrons. Quando a tensão é aplicada entre esses dois semicondutores, haverá a passagem de elétrons da camada $\mathrm{n}$ para a $\mathrm{p}$, resultando em um fluxo de elétrons e "buracos" (FRANCO; LOPES, 2003).

A grande maioria dos aparelhos de LED emitem luz num estreito espectro, geralmente $470 \pm 20 \mathrm{~nm}$, correspondendo a faixa azul do espectro visível. Esta banda estreita coincide com o pico máximo de absorção da canforoquinona, não sendo necessário, portanto a utilização de filtros. Além disso, esses equipamentos emitem luz sem gerar calor, tendo uma vida útil de milhares de horas sem ocorrer degradações significativas na sua intensidade. Essas vantagens fizeram com que diversas pesquisas contribuíssem para a significativa evolução da tecnologia dos aparelhos de LED (RUEGGEBERG et al., 2005).

Muitos estudos compararam a fotoativação de resinas compostas com o fotoiniciador CQ utilizando diferentes fontes de luz e diversos equipamentos. Alguns trabalhos não encontraram grandes diferenças entre as fontes de luz principalmente em relação a testes mecânicos (MICALI; BASTING, 2004; DENIS, 2007; RASTELLI et al., 2008; CALIXTO et al., 2008; DENIS et al., 2012c). Em compensação outros encontraram um melhor resultado para a lâmpada halógena em relação ao LED (JANT et al., 2000; KURACHI et al., 2001). Entretanto, outros trabalhos mostraram uma melhor efetividade com os aparelhos de LED (BALA et al.; 2005; PRICE et al., 2005; SILVA et al., 2008), além do laser de argônio que se mostrou também muito efetivo (COBB et al., 1996; VARGAS et al., 1998)

Essa grande variação nos resultados em relação a comparação entre fontes de luz e/ou equipamentos de fotoativação ocorre principalmente devido às diferenças nos comprimentos de onda emitidos por esses equipamentos, intensidades de luz e tempo de exposição.

Com o aprimoramento dos aparelhos de LED, mais estudos são necessários para avaliar o seu desempenho frente a fotoativação de resinas com o fotoiniciador PPD. Brandt et al. (2011), avaliaram o grau de conversão de resinas com PPD e CQ e constataram que o aparelho de LED obteve melhor efetividade que o aparelho de lâmpada halógena nas resinas com o fotoiniciador PPD, e ele acredita que essa efetividade ocorreu devido a altas doses de energia $\left(\mathrm{J} \mathrm{cm}^{-2}\right)$ que esses equipamento de LED de ultima geração apresentam. 


\subsection{Espectroscopia de Absorção no Infravermelho por Transformada de Fourier em tempo real (RT-FTIR) aplicada ao estudo de polimerização fotoiniciada}

A espectroscopia de absorção na região do infravermelho por transformada de Fourier em tempo real (RT-FTIR) é uma técnica não destrutiva que está sendo amplamente utilizada nos últimos anos para o acompanhamento da cinética de reação de resinas compostas fotoativadas (DARONCH et al., 2006; BRANDT et al., 2011).

O monitoramento das bandas de absorção no infravermelho do monômero e/ou do polímero permite o acompanhamento rápido e contínuo do processo de fotoativação, permitindo que a velocidade de desaparecimento da dupla ligação do monômero, no caso de monômeros vinilicos, seja monitorada em tempo real podendo assim avaliar-se quantitativamente a evolução do processo de polimerização.

A técnica de espectroscopia de absorção no infravermelho baseia-se na frequência de irradiação infravermelha e na frequência vibracional da matéria. A irradiação infravermelha quando absorvida pela amostra converte-se em energia vibracional molecular. A frequência vibracional depende das massas relativas dos átomos ligados, das constantes de força das ligações e da geometria das moléculas (SILVERSTEIN; WEBSTER, 2000).

Esta técnica vem sendo aplicada em estudos da avaliação do grau de conversão monomérica e no estudo da cinética de polimerização de resinas compostas (BRAGA; FERRACANE, 2002; TRUJILLO et al., 2004; DARONCH et al., 2006; D'ALPINO et al., 2007; BRANDT et al., 2011; DENIS et al., 2012b), sendo considerada adequada para esses propósitos.

\subsection{Métodos Cromatográficos de Análise aplicados a avaliação de monômeros residuais}

A cromatografia é uma técnica físico-química de separação de componentes de uma mistura, realizada através da distribuição destes componentes entre duas fases, que estão em íntimo contato. É um método analítico usado para separar, detectar e quantificar compostos (LANÇAS, 2003).

O princípio da separação cromatográfica de uma mistura baseia-se nas diferenças de velocidade de transporte das substâncias individuais quando dissolvidas em um líquido ou gás (fase móvel) que flui através de um determinado meio (fase estacionária). Uma substância com maior afinidade pela fase estacionária irá fluir mais lentamente que as outras. As características das fases móvel e estacionária, do analito na fase móvel, do meio que serve 
como fase estacionária e a dinâmica do fluxo determinam a velocidade e precisão com que determinadas substâncias serão separadas (COLLINS et al., 1997; LANÇAS, 2003).

A escolha correta do tipo de cromatografia a ser empregada depende das características do analito que se pretende analisar. Os dois tipos mais utilizados de cromatografia são: cromatografia gasosa e a cromatografia líquida.

A cromatografia gasosa é empregada para amostras ou derivado volátil, termicamente estável na temperatura de operação do sistema cromatográfico (COLLINS et al., 1997; LANÇAS, 2003). No caso da cromatografia líquida, há a necessidade de que a amostra seja solúvel na fase móvel a ser utilizada. Esta técnica possui diferentes mecanismos de separação e, consequentemente, várias modalidades cromatográficas. Para a escolha da modalidade correta, deve-se considerar algumas propriedades como massa molecular, solubilidade, estrutura, entre outras. Desta maneira, a técnica de cromatografia líquida de alta eficiência (HPLC) em fase reversa é a mais adequada para a avaliação dos monômeros residuais BisGMA e TEGDMA em virtude de suas estruturas químicas, pois são compostos nãovoláteis. E para serem analisados por cromatografia gasosa precisam ser derivatizados, ou seja, introduzir em suas estruturas grupos que apresentem volatilidade.

Esta técnica vem sendo utilizada com o propósito de se avaliar monômeros residuais e compostos lixiviados da resina composta, os quais são determinados por meio de liberação em água e saliva artificial ou extração com diversos solventes orgânicos (SPAHL et al., 1998; MICHELSEN et al., 2007; MOHARAMZADEH et al., 2007). Dependendo das quantidades remanescentes de alguns componentes da resina composta, estes podem causar reações alérgicas, efeitos citotóxicos e genotóxicos ou efeitos alérgicos, além disso estes monômeros residuais podem alcançar a polpa dentária via túbulos dentinários (WATAHA et al., 1999; SCHWENGBERG et al., 2005; CAMPANHA et al., 2006; GOLDBERG, 2008).

Do percentual não reagido das duplas ligações, isto é do valor do grau de conversão, somente $10 \%$ ou menos de monômeros residuais são capazes de serem extraídos da resina e o restante encontra-se como grupamento pendente na cadeia (FERRACANE, 1994), esses monômeros que são parcialmente reagidos, podem produzir um efeito plastificante no polímero mas não são passíveis de solubilização (VAKIPARTA et al., 2006). Somente os monômeros, que não participam da formação da rede polimérica, podem ser extraídos da massa polimérica por meios aquosos ou solventes orgânicos (FERRACANE, 1994; MULLER et al., 1997). O tipo de solvente usado na extração pode ter efeito significante na quantidade de monômeros residuais extraídos (FERRACANE, 1994; MOHARAMZADEH et al., 2007). 
Por isso é interessante também o estudo da quantidade de monômeros BisGMA e TEGDMA possíveis de serem extraídos utilizando resinas com diferentes fotoiniciadores.

\subsubsection{Desenvolvimento, otimização e validação do método cromatográfico de análise dos monômeros residuais}

Quando se utilizada a cromatografia como ferramenta analítica é importante o desenvolvimento de um método capaz de separar, detectar e quantificar os compostos de interesse.

Para uma boa separação cromatografia é necessário a otimização do método para obter-se um menor alargamento possível da banda cromatográfica, dentro de um tempo de corrida razoável. O pico cromatográfico ideal deve ter uma forma gaussiana.

A avaliação da eficiência do sistema cromatográfico é alcançada com experimentos de adequabilidade, ou seja, "system suitability", que pode ser definido como um conjunto de testes para garantir que o equipamento utilizado está apto a gerar resultados de exatidão e precisão aceitáveis.

Parâmetros como fator de retenção $(k)$, repetibilidade, resolução (Rs), fator de alargamento ou cauda e números de pratos teóricos são medidos e baseados nos limites recomendados de acordo com a United States Food and Drug Administration (US-FDA, 2000).

A melhor forma de se evitar problemas com um método analítico é realizar uma validação adequada durante o desenvolvimento desse método. A validação deve garantir, através de estudos experimentais, que o método desenvolvido atenda às exigências das aplicações analíticas, assegurando a confiabilidade dos resultados (ANVISA, 2003).

O conceito de validação é algo que está em constante evolução e a existência de diversos órgãos reguladores faz com que existam diversas definições. Os principais órgãos reguladores e guias são: os internacionais - ICH (International Conference on Harmonisation), US-FDA (United States Food and Drug Administration), USP (United State Pharmacopeia) e os nacionais - ANVISA (Agência Nacional de Vigilância Sanitária) e INMETRO (Instituto Nacional de Metrologia, Normalização e Qualidade Industrial).

Durante a validação de um método, diversos parâmetros são avaliados como: seletividade, linearidade, precisão, exatidão, limite de detecção, limite de quantificação e robustez. Os intervalos de aceitação desses parâmetros podem variar de acordo com o tipo de matriz no qual o método está sendo desenvolvido (ANVISA, 2003). 
De acordo com alguns guias, normas e resoluções, a validação analítica é dividida em dois tipos de métodos analíticos: ensaios bioanalíticos e analíticos. Os métodos analíticos são empregados normalmente para realizar determinações de compostos em matrizes tais como produtos farmacêuticos, medicamentos, fitoterápicos, cosméticos, etc. Em contrapartida, os métodos bioanalíticos são empregados em estudos para determinar concentrações de compostos em matrizes tais como: sangue, soro, plasma, urina. Em ensaios analíticos a quantidade do componente a ser determinada é normalmente superior aos ensaios bioanalíticos (ICH, 1995).

A seletividade é realizada para avaliar o grau de interferência de espécies como outro ingrediente ativo, excipientes, impurezas e produtos de degradação, bem como outros compostos de propriedades similares que possam estar, porventura, presentes no mesmo tempo de retenção, garantindo assim que o pico de resposta seja exclusivamente do composto de interesse.

A linearidade é a capacidade de um método analítico gerar resultados diretamente proporcionais à concentração da substância em exame, dentro de uma faixa analítica especificada. (CHASIN et al., 1998).

A precisão é o parâmetro que avalia a proximidade entre várias medidas efetuadas em uma mesma amostra e pode ser expressa pelo cálculo do desvio padrão relativo (RSD) ou coeficiente de variação (CV\%) de uma série de medidas, obtidas em condições de repetibilidade e/ ou reprodutibilidade (ANVISA, 2003).

A precisão pode ser classificada em três níveis:

- Precisão intra-corrida (repetibilidade): é a concordância entre os resultados, dentro de um curto período de tempo, com o mesmo analista e a mesma instrumentação.

-Precisão inter-corridas (precisão intermediária): é a concordância entre os resultados do mesmo laboratório, mas obtido em dias diferentes, com analistas diferentes e/ou com equipamentos diferentes.

-Precisão inter-laboratorial (reprodutibilidade): é a avaliação da concordância entre os resultados obtidos em laboratórios diferentes. É utilizado quando precisa-se de uma padronização de um método analítico, por exemplo inclusão em farmacopéias (ANVISA, 2003).

A exatidão representa o grau de concordância entre os resultados encontrados e um valor de referência aceito como verdadeiro (SHABIR, 2003).

O limite de detecção é definido com a menor concentração do analito presente na amostra que possa ser detectado, mas não quantificado (ICH, 1995). 
O limite de quantificação é definido como a menor concentração do analito em uma amostra que pode ser determinado com precisão e exatidão aceitáveis nas condições operacionais do método (ICH, 1995).

A robustez do método mostra a sensibilidade que este apresenta frente a pequenas variações nas condições cromatográficas de análise, indicando o grau de confiança em seu uso rotineiro (USP, 2007). 


\section{Objetivos}




\section{OBJETIVOS}

\subsection{Objetivos Gerais}

A-) Estudar o grau de conversão e parâmetros de cinética de polimerização das resinas experimentais em função dos diferentes fotoiniciadores.

B-) Avaliar e quantificar os monômeros residuais (TEGDMA e BisGMA) nas resinas experimentais com diferentes fotoiniciadores, após desenvolvimento e validação do método cromatográfico.

C-) Avaliar o desempenho dos aparelhos fotoativadores nas resinas experimentais.

\subsection{Objetivos Específicos}

1-) Testar a hipótese que a resina experimental com dois fotoiniciadores (CQ + PPD) terá um desempenho melhor ou igual ao da resina com somente CQ em relação ao grau de conversão.

2-) Testar a hipótese que a resina experimental com dois fotoiniciadores (CQ + PPD) terá uma redução na taxa máxima de polimerização $\left(\operatorname{Rp}{ }^{\text {máx }}\right)$ em relação a resina com somente CQ.

3-) Testar a hipótese que a possível alteração nos parâmetros de cinética de polimerização da resina experimental com dois fotoiniciadores (CQ + PPD) pode levar a um aumento na quantidade de monômeros residuais TEGDMA e BisGMA extraídos em relação a resina com somente CQ.

4-) Testar a hipótese que o aparelho de LED terá um desempenho próximo ao do aparelho de lâmpada halógena na resinas experimental com os dois fotoiniciadores (CQ + PPD). 


\section{MATERIAIS E MÉTODOS}

\subsection{Formulação das resinas experimentais}

Os monômeros dimetacrilatos 2,2-bis-[4-(2-hidroxi-3-metacriloxipropil-1-oxi)fenilpropano] (BisGMA/Aldrich, lote-06627BH) e Trietilenoglicol dimetacrilato (TEGDMA/Aldrich, lote-07709KE437) foram utilizados na manipulação das resinas experimentais.

As substâncias utilizadas nos sistemas de fotoiniciação da matriz orgânica foram: a amina N,N-dimetil-p-toluidina (DMPT/Fluka, lote-32107361) como co-iniciador, e como fotoiniciadores a canforoquinona (dl-2,3-diceto-1,7,7-trimetilnorcanfano- CQ/Fluka, lote1293239) e a fenil propanodiona (PPD/ Aldrich, lote-S34870-116).

Três resinas experimentais foram preparadas por meio da combinação dos monômeros BisGMA e TEGDMA na concentração em peso de 70\%/30\% respectivamente e pela incorporação dos seguintes sistemas de fotoiniciação:

R1-) CQ (0,2\% em peso) e DMPT (0,2\% em peso)

R2-) PPD (0,2\% em peso) e DMPT (0,2\% em peso)

R3-) PPD ( $0,1 \%$ em peso $)+$ CQ $(0,1 \%$ em peso $)$ e DMPT ( $0,2 \%$ em peso $)$

As relações entre fotoiniciador e co-iniciador foram mantidas constantes (1:1) em peso em todas as resinas.

\subsection{Aparelhos fotoativadores}

Foram utilizados os seguintes aparelhos fotoativadores:

-lâmpada halógena Demetron LC/ SDS Kerr (sn- 67009594, USA) (Figura 6)

-LED Poly 600/Kavo (sn- 2008100188, Brasil) (Figura 7)

Os dois aparelhos de fotoativação foram utilizados com densidade de potência de $600 \mathrm{~mW} \mathrm{~cm} \mathrm{~cm}^{-2}$, por 40 segundos em cada espécime, de forma convencional. Os dois equipamentos possuem a ponteira com formato cilíndrico com $10 \mathrm{~mm}$ de diâmetro e a dose de energia de ambos equipamentos foi de $24 \mathrm{~J} \mathrm{~cm}^{-2}$. 
Figura 6- Lâmpada halógena Demetron LC/ SDS Kerr

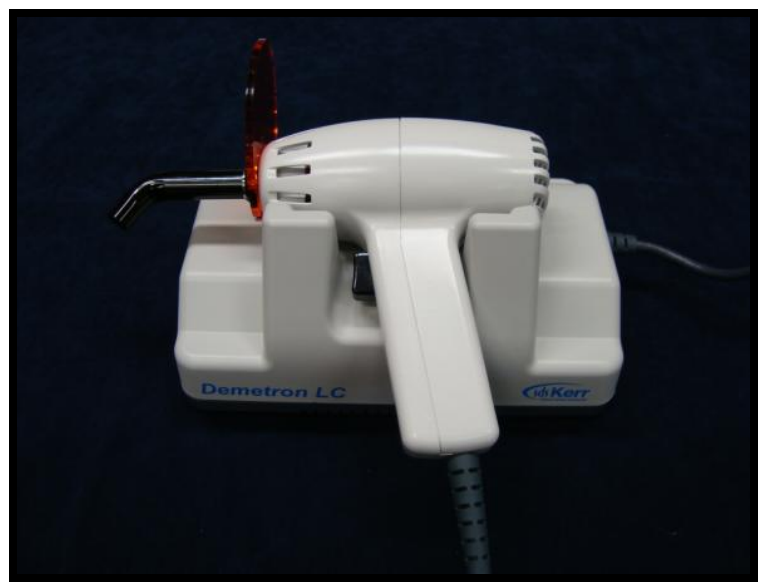

Figura 7- LED Poly 600/Kavo

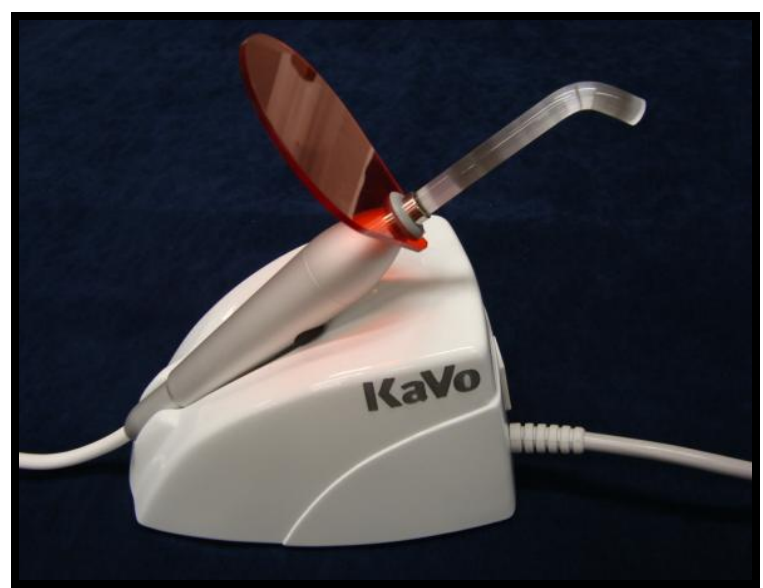

A intensidade de luz ou densidade de potência dos aparelhos foram mensuradas e padronizadas por meio de um potenciômetro (Fieldmaster/ Coherent) (Figura 8).

Figura 8- Potenciômetro Fieldmaster (Coherent)

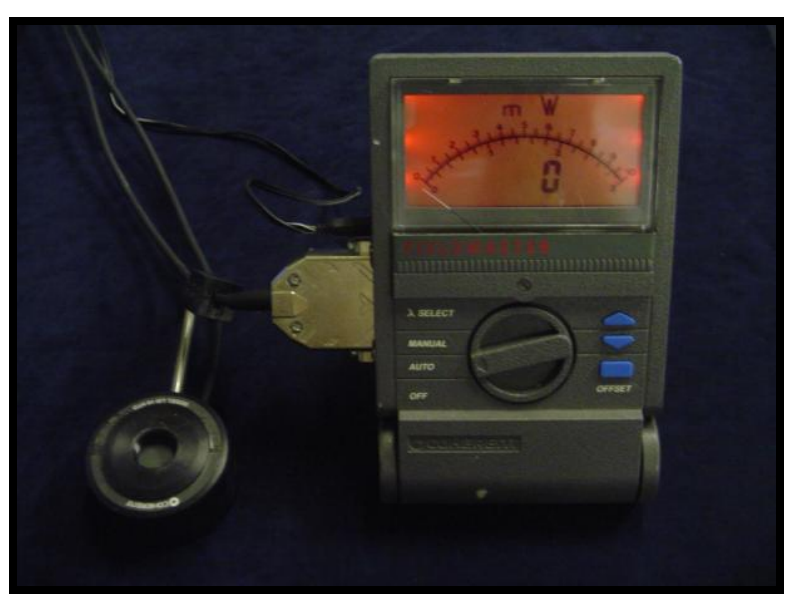


Todos os espécimes tanto para a análise por meio do FT-IR em tempo real e cromatografia HPLC foram preparados com as três resinas (R1, R2 e R3) e fotoativados com as duas fontes de luz (lâmpada halógena e LED) (Figura 9).

Figura 9- Esquema geral das resinas, fontes de luz e métodos utilizados

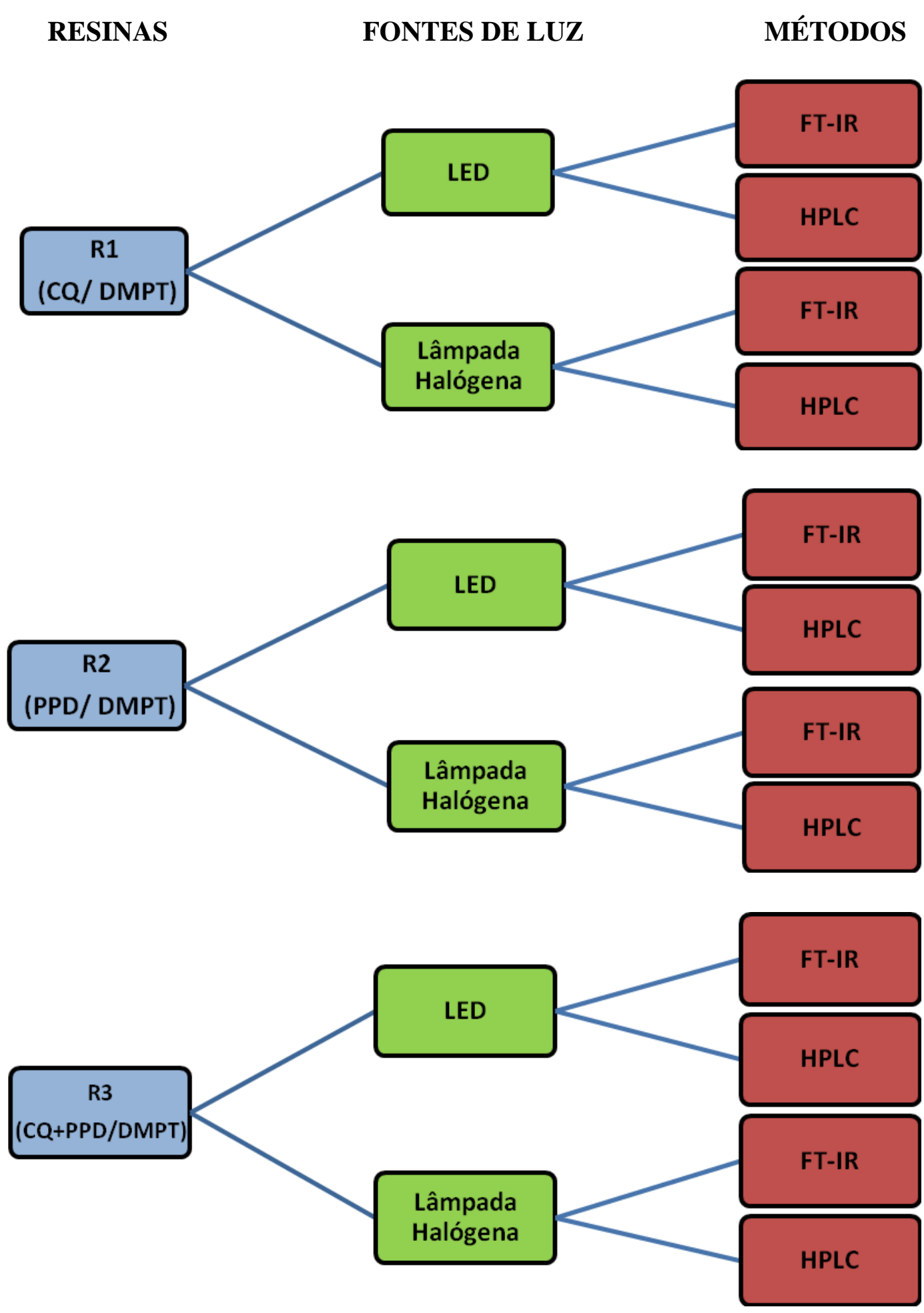




\subsection{Grau de conversão e parâmetros de cinética de polimerização}

A determinação do grau de conversão e cinética de polimerização das resinas experimentais foi feita por meio de espectrofotômetro infravermelho com transformada de Fourier (NEXUS 670 FT-IR/Nicolet - ns- AEQ0000517) (Figura 10). Este aparelho possui uma unidade de refletância total atenuada (ATR) (Figura 11), que corresponde a uma plataforma acoplada ao espectrofotômetro que possui um jogo de espelhos que conduzem a luz para dentro do cristal de Seleneto de Zinco ( $\mathrm{ZnSe})$ que fica na superfície desta plataforma e funciona como substrato ativo de irradiação infravermelha. (Figura 12).

Figura 10- Espectrofotômetro NEXUS 670 FT-IR/Nicolet

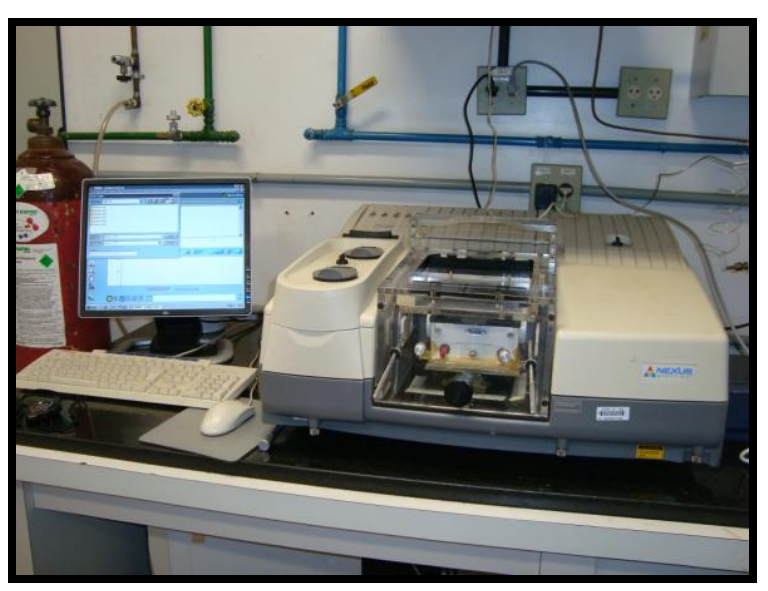

Figura 11- Unidade de refletância total atenuada (ATR)

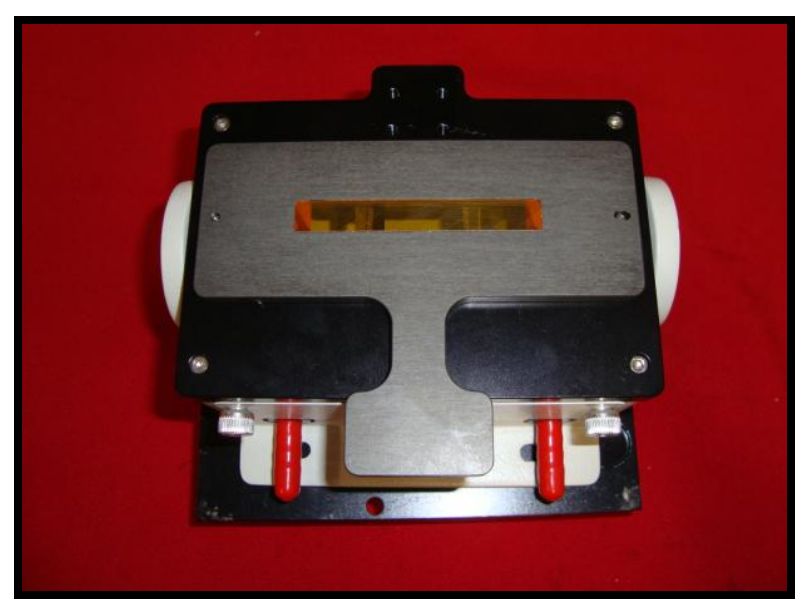

O FTIR emite a energia infravermelha, que é direcionada para o elemento de ATR, onde uma onda evanescente se estende para fora da superfície do cristal de Seleneto de Zinco ( $\mathrm{ZnSe}$ ), penetrando no espécime a ser examinado que é colocado sobre a unidade de ATR. A 
irradiação resultante é, então, forçada a retornar para dentro do cristal e direcionada ao detector do aparelho (Figura 13). Desta forma, a energia infravermelha absorvida pela amostra nesta interface cristal $\mathrm{ZnSe} / \mathrm{resina}$ indica as espécies atômicas características presentes. Assim, é possível medir a conversão do componente resinoso em íntimo contato com a superfície do cristal.

Uma matriz de teflon foi posicionada na superfície do cristal e as resinas experimentais foram inseridas no orifício dessa matriz $(5 \mathrm{~mm}$ de diâmetro por $1 \mathrm{~mm}$ de profundidade) (Figura 12), uma tira de poliéster foi posicionada sobre a resina no topo da matriz onde ficou em íntimo contato com as fontes fotoativadoras (Figura 13 e 14).

Figura 12- Matriz posicionada na superfície do cristal de ATR

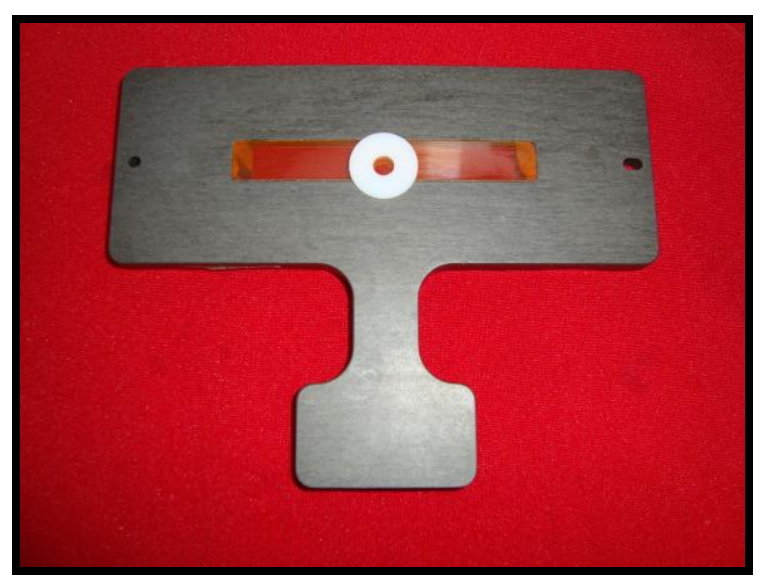

Figura 13- Esquema da fotoativação da amostra em íntimo contato com o cristal ZnSe.

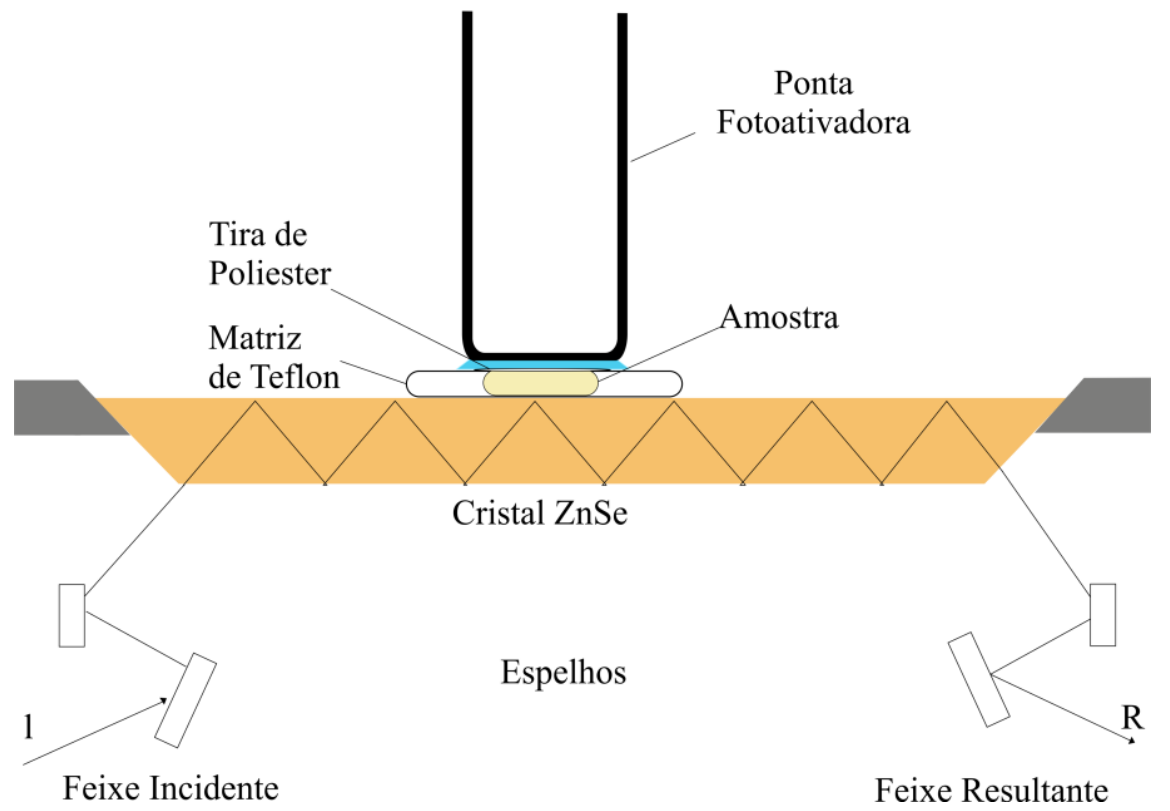


Os espectros infravermelho dessas amostras foram coletados no modo cinética, na velocidade de 3 varreduras por segundo, durante 305 segundos, com resolução de $2 \mathrm{~cm}^{-1}$ entre 1680 e $1550 \mathrm{~cm}^{-1}$. As 5 primeiras varreduras coletadas serviram para fornecer o espectro de absorção da resina não polimerizada (utilizado no cálculo do grau de conversão). Na $6^{\underline{0}}$ varredura, o fotoativador foi ligado (por 40 segundos) (Figura 14) enquanto o espectro continuava a ser coletado até 300 segundos após a ativação da luz. Cinco repetições foram feitas para cada condição experimental e todas as análises foram realizadas com temperatura do ambiente controlada $\left(23 \pm 1^{\circ} \mathrm{C}\right)$ e umidade controlada $(60 \pm 5 \%)$.

Figura 14- Fotoativação dos espécimes no aparelho de FT-IR

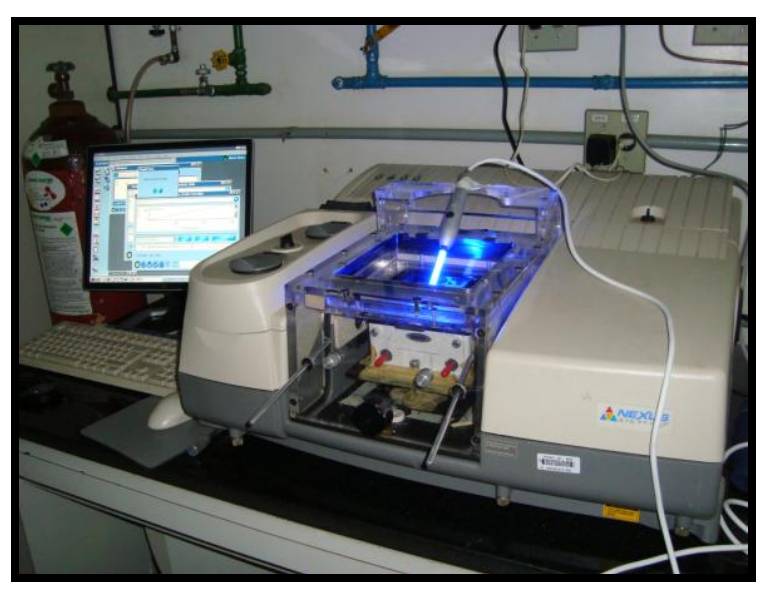

Após a obtenção dos picos de absorbância, o percentual de duplas ligações carbônicas não convertidas $(\% \mathrm{C}=\mathrm{C})$ foi determinado pela taxa de intensidade de absorção entre ligações $\mathrm{C}=\mathrm{C}$ em $1.637 \mathrm{~cm}^{-1}$ (pico correspondente as cadeias alifáticas) e ligações $\mathrm{C}=\mathrm{C}$ em $1.610 \mathrm{~cm}^{-1}$ (pico correspondente as cadeias aromáticas), antes e após a polimerização (ASMUSSEN; PEUTZFELDT, 2001a). O grau de conversão (GC) correspondente foi calculado pela subtração desta taxa de $100 \%$.

$$
\begin{aligned}
& (\% C=C)=\frac{A b s\left(1.637 \mathrm{~cm}^{-1}\right) / A b s\left(1.610 \mathrm{~cm}^{-1}\right) \text { polimero }}{A b s\left(1.637 \mathrm{~cm}^{-1}\right) / A b s\left(1.610 \mathrm{~cm}^{-1}\right) \text { monômero }} \\
& G C=100 \%-(\% C=C)
\end{aligned}
$$

Os parâmetros de cinética da polimerização observados foram: taxa máxima de conversão $\left(\mathrm{Rp}^{\mathrm{máx}}\right)$, tempo em que ocorreu a taxa máxima de polimerização $\left(\mathrm{t}_{\text {máx }}\right)$, a conversão quando ocorreu a $\mathrm{Rp}^{\text {máx }}$ e a conversão total registrada no ponto de máxima conversão, isto é após 300 s. A taxa de conversão (Rp) foi obtida pelo cálculo da primeira derivada dos perfis de conversão em tempo real, para dessa maneira ser calculado a maior taxa de polimerização 
no intervalo de 1 segundo $\left(\mathrm{Rp}^{\text {máx }}\right)$. Os demais parâmetros foram calculados a partir dos valores de conversão em tempo real e da taxa de conversão.

A partir dos valores obtidos, foram calculadas as médias e os desvios padrão absoluto para cada condição amostral.

\subsection{Avaliação dos monômeros residuais por HPLC}

\subsubsection{Equipamento e coluna}

O método desenvolvido para a análise utilizou um equipamento de HPLC Shimadzu prominence bomba LC-20AD (Kyoto, Japan) com autoinjetor modelo SIL-20A, detector UVVis SPD-20A, forno CTO-20A e controladora CBM-20A (Figura 15). Os cromatogramas dos monômeros residuais foram tratados pelo Shimadzu LC Solutions software (Figura 16).

Figura 15- Equipamento HPLC Shimadzu

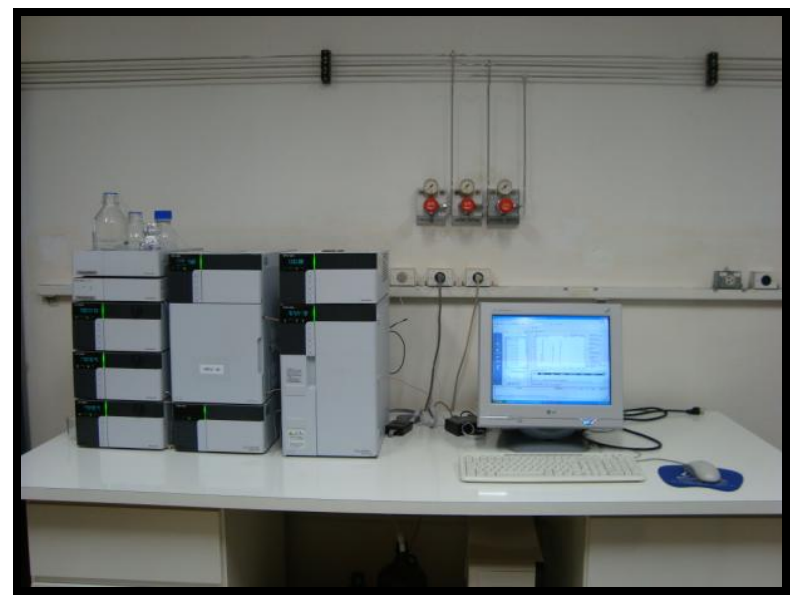

Figura 16- Shimadzu LC Solutions software

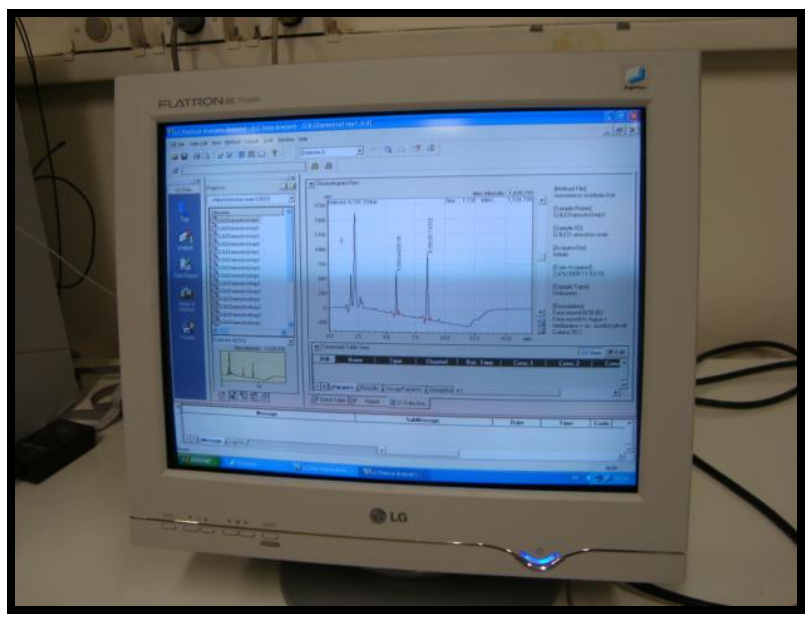


A coluna utilizada foi a octadecil (C18 NST São Carlos, Brasil/ pn- 18-154605 e sn330407) com $5 \mu \mathrm{m}$ de tamanho das partículas e 15 x 0,46 cm de tamanho (fase reversa). Essa coluna foi selecionada devido sua polaridade adequada para análise dos monômeros residuais.

\subsubsection{Soluções - padrão}

Soluções-estoque foram preparadas dissolvendo os monômeros (TEGDMA e BisGMA) em acetonitrila /J.T. Baker- St. Louis, MO, USA (lote-1113C63) grau de HPLC até a concentração final de $1.000 \mu \mathrm{g} \mathrm{mL}^{-1}$.

Dessas soluções-estoque foram preparadas soluções-padrão de TEGDMA e BisGMA diluídas em acetonitrila (grau de HPLC) que foram utilizadas como padrões analíticos de calibração em HPLC (Figuras 17 e 18). Essas soluções-padrão foram filtradas em membranas hidrofóbicas (Millipore).

Figura 17- Soluções- Padrão do TEGDMA

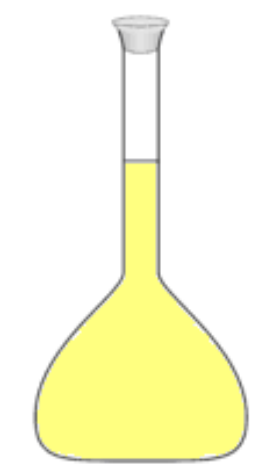

Solução-Estoque TEGDMA $\left(1.000 \mu \mathrm{g} \mathrm{mL}^{-1}\right)$
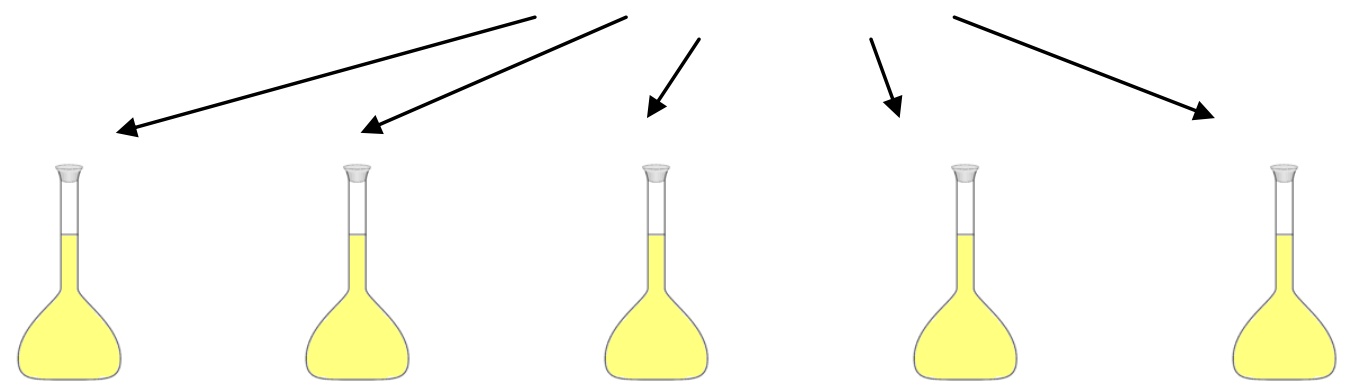

$44 \mu \mathrm{g} \mathrm{mL}^{-1} \quad 90 \mu \mathrm{g} \mathrm{mL}^{-1}$

$136 \mu \mathrm{g} \mathrm{mL}^{-1}$

$279 \mu \mathrm{g} \mathrm{mL}^{-1}$

$360 \mu \mathrm{g} \mathrm{mL}^{-1}$

(Soluções- Padrão para Curva de Calibração) 
Figura 18- Soluções- Padrão do BisGMA

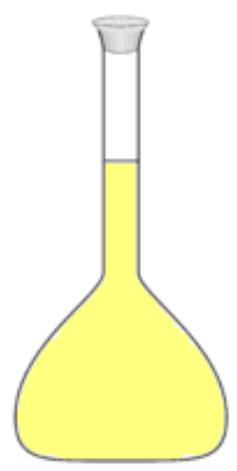

Solução-Estoque BisGMA

$\left(1.000 \mu \mathrm{g} \mathrm{mL}^{-1}\right)$

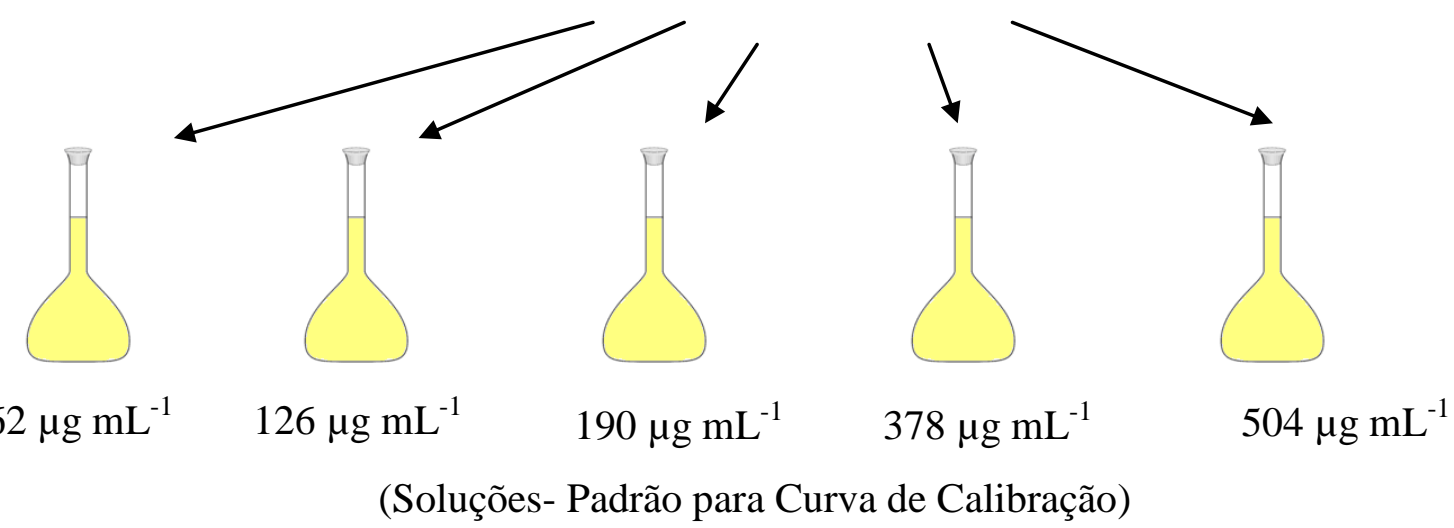

\subsubsection{Condições cromatográficas}

A separação cromatográfica foi feita utilizando a seguinte fase móvel: FASE A- água + trietilamina à 0,05\% (Riedel/lote- 6R10523) acidificada com ácido acético pH=4 (J.T. Baker/lote- V11C53) e FASE B- acetonitrila (J.T. Baker/lote-1113C63) com grau de HPLC. A água foi ultra purificada utilizando um sistema (Purelab Ultra e Option S/ Elga, Brasil).

Durante a etapa de desenvolvimento do método, várias condições cromatográficas foram avaliadas com o intuito de obter o melhor desempenho cromatográfico (performance nas análises) e a melhor condição otimizada foi utilizada, sendo: o modo de eluição foi o de gradiente (Tabela 1), o fluxo foi de 1,0 mL $\mathrm{min}^{-1}$, o detector UV em $210 \mathrm{~nm}$ de comprimento de onda, a temperatura da coluna em $55^{\circ} \mathrm{C}$ e injeção de $20 \mu \mathrm{L}$.

Tabela 1- Gradiente de eluição da fase móvel

\begin{tabular}{ccc}
\hline Tempo(min) & \% & Fase \\
\hline 0 & 40 & B \\
\hline 10 & 85 & B \\
\hline 17 & 40 & B \\
\hline
\end{tabular}




\subsubsection{Preparo dos espécimes das resinas experimentais para análise por HPLC}

As resinas experimentais foram realizadas conforme explicado anteriormente em 4.1 Formulação das resinas experimentais.

Para o preparo dos espécimes foi utilizado uma matriz de teflon com $5 \mathrm{~mm}$ de diâmetro e $1 \mathrm{~mm}$ de profundidade, essa matriz foi posicionada sobre uma placa de vidro de 10 mm de espessura e uma tira de poliéster foi fixada na base da matriz e a resina foi inserida no interior do orifício da matriz com uma espátula e, após a inserção da resina, foi posicionada também uma tira de poliéster para nivelamento da porção inicial que ficou voltada para o aparelho fotoativador (Figura 19).

Figura 19- Inserção da resina na matriz

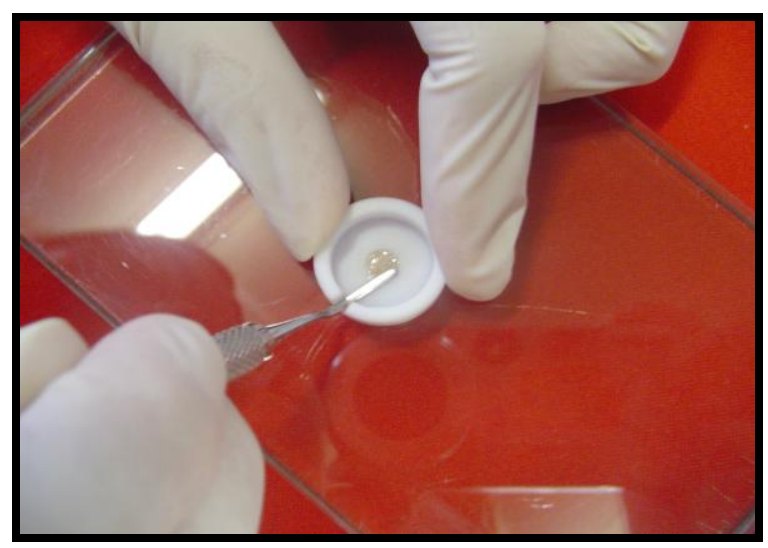

A fotoativação da resina foi realizada conforme explicado em 4.2 - Aparelhos fotoativadores.

\subsubsection{Otimização do método para a avaliação dos monômeros residuais}

Durante o período de desenvolvimento do método para análise dos monômeros residuais foi realizada a otimização desse método que consistiu na avaliação de diferentes solventes como: metanol (J.T.Baker/lote-j25c28), etanol 75\% (J.T.Baker/lote-y25c02) e acetonitrila (J.T. Baker/lote-1113C63), em diferentes tempos de extração (2 h, 6 h, 12 h, 24 h, e 72 h) e o uso de agitação mecânica ou não. Foram utilizadas 3 amostras de cada condição experimental com 3 injeções de cada. E as melhores condições de extração dos monômeros residuais ocorreram quando os espécimes foram imersos em acetonitrila por $24 \mathrm{~h}$ com agitação mecânica (Tabelas encontram-se nos Resultados). 


\subsubsection{Procedimento de extração dos monômeros residuais}

Espécimes realizados com resina experimental (R1, R2 e R3) foram imersos em $5 \mathrm{~mL}$ de acetonitrila em temperatura ambiente. Uma barra magnética de PTFE (10 mm) foi utilizada para a agitação das amostras por 24 horas (Figura 20). Foram injetados $20 \mu \mathrm{L}$ do extrato dessas amostras no equipamento de HPLC (Figura 21).

Figura 20- Espécimes imersos em acetonitrila por 24 horas com agitação mecânica

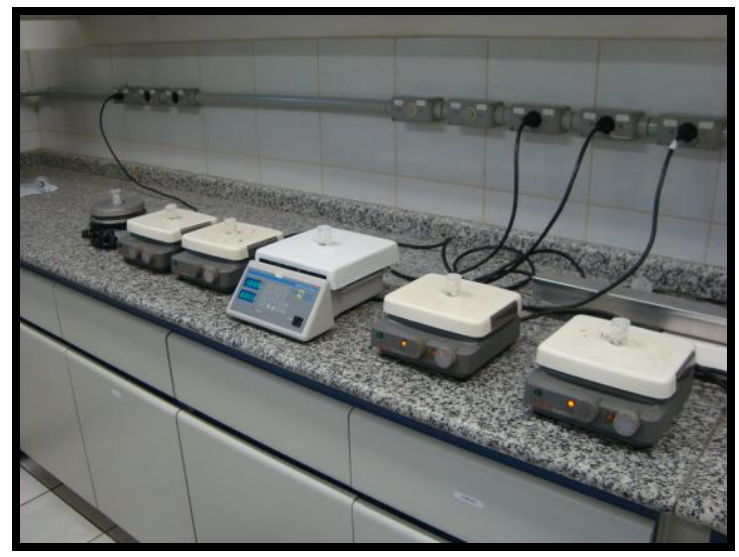

Figura 21- Esquema demonstrativo da extração dos monômeros residuais e injeção das amostras
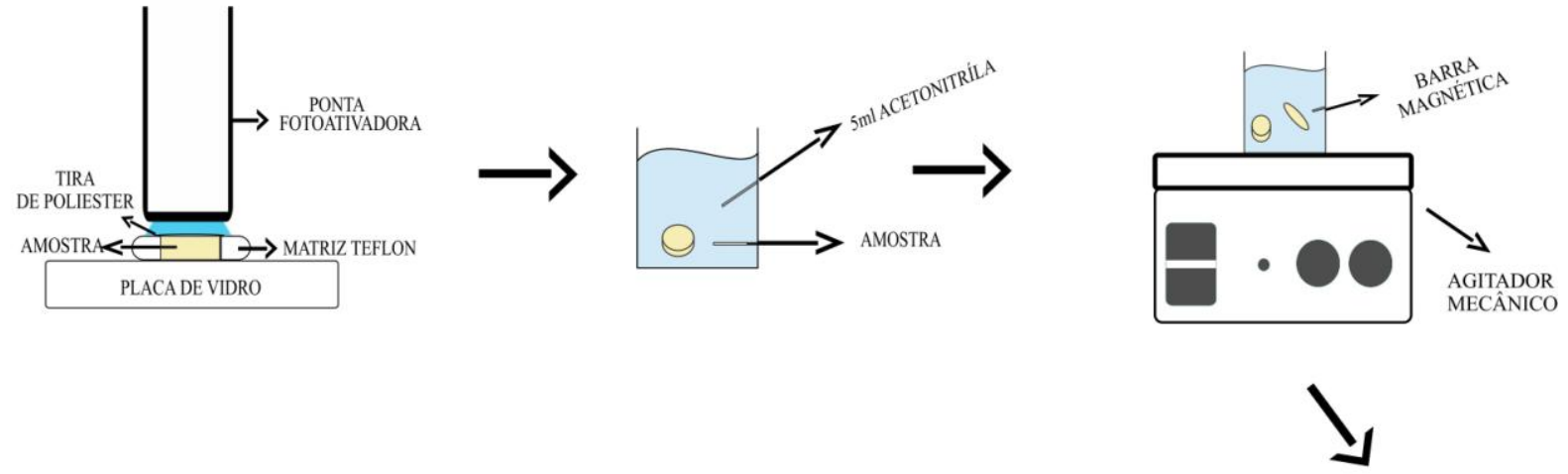

CROMATOGRAMA

EXTRATO

APÓS 24 HORAS

AMOSTRA

COM AGITAC̄̃̃O
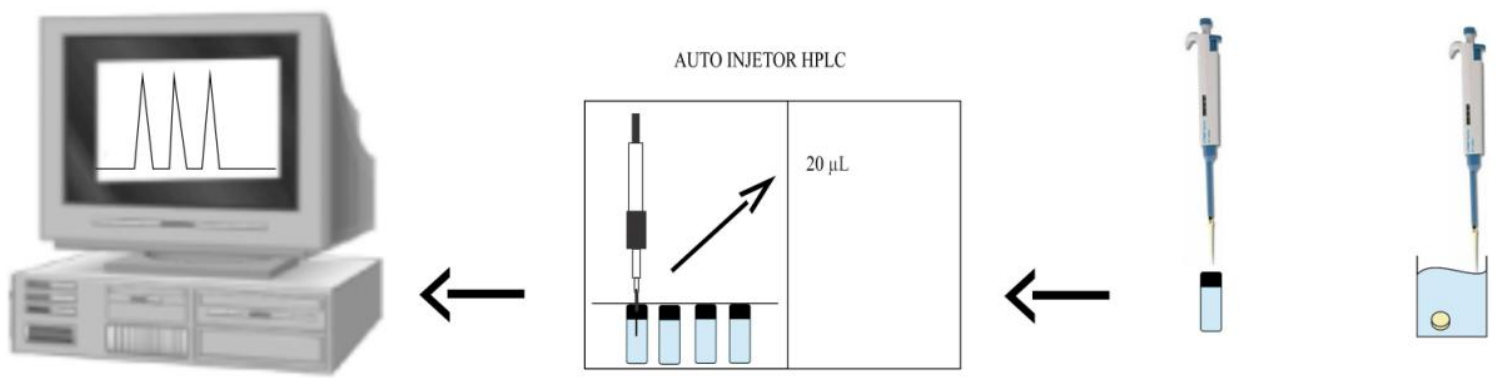


\subsubsection{Validação do método cromatográfico de análise dos monômeros residuais}

Após escolher e testar o sistema cromatográfico e otimizar o método para a avaliação dos monômeros residuais, foi feita a validação do método para garantir a credibilidade desse método, atendendo às exigências das aplicações analíticas, assegurando a confiabilidade dos resultados. Seguimos a Resolução RE $n^{0}$ 899, 2003 da Agência Nacional de Vigilância Sanitária para métodos analíticos.

\subsubsection{1 "System Suitability" ou Adequabilidade}

Antes de realizar os experimentos de validação ou mesmo as análises das amostras, foi primeiramente avaliado o sistema utilizado para análise para a verificação da capacidade em fornecer dados de qualidade aceitável. Esta avaliação é alcançada com experimentos de conformidade do sistema "system suitability", que pode ser definida como um conjunto de testes para garantir que o equipamento utilizado está apto a gerar resultados de exatidão e precisão aceitáveis.

Para o teste de "system suitability" foram utilizadas as soluções padrões (item 4.4.2 Soluções-padrão) com injeções em sextuplicata. Este teste foi utilizado para verificar a performance do sistema cromatográfico para que esse seja adequado para a análise das amostras.

Os parâmetros a serem medidos e seus limites recomendados, de acordo com a USFDA, estão na Tabela 2. Para garantir a conformidade do sistema no mínimo dois destes critérios são requeridos (RIBANI et al., 2004). 
Tabela 2 - Parâmetros de conformidade do sistema e recomendações (US-FDA, 2000)

\begin{tabular}{|l|l|}
\hline Parâmetro & Recomendação \\
\hline Fator de retenção (k) & $\begin{array}{l}\text { O pico deve estar bem separado de } \\
\text { outros picos e do pico } \\
\text { correspondente ao tempo de retenção } \\
\text { de um composto retido }\left(\mathrm{t}_{\mathrm{M}}\right) \mathrm{k}>2.0\end{array}$ \\
\hline Repetibilidade (RSD) & RSD $\leq 1 \%$ para $\mathrm{N} \geq 5$ \\
\hline Resolução $\left(\mathrm{R}_{\mathrm{s}}\right)$ & $\begin{array}{l}\mathrm{R}_{\mathrm{s}}>2 \text { entre o pico de interesse e o } \\
\text { interferente potencial mais próximo } \\
\text { (outro produto de interesse, } \\
\text { impureza, produto de degradação, } \\
\text { padrão interno, excipientes, etc) }\end{array}$ \\
\hline Fator de alargamento ou cauda(TF) & TF $\leq 2$ \\
\hline Número de pratos da coluna $(\mathrm{N})$ & Em geral deve ser $>2000$ \\
\hline
\end{tabular}

Para o cálculo desses parâmetros foi necessário antes entender alguns princípios básicos de cromatografia.

Ao obter um cromatograma, que é um gráfico que registra a concentração ou massa do composto à medida que ele elui da coluna por unidade de tempo (Figura 22), recebemos várias informações como:

Figura 22- Medições em um cromatograma (fonte: SOARES, 2006)

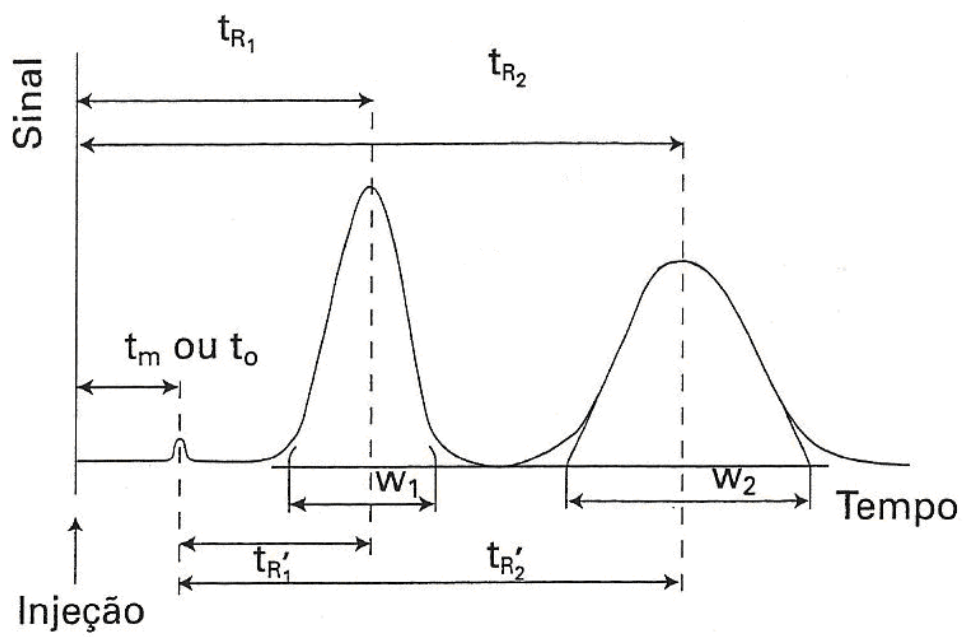

Tempo de retenção $\left(t_{R}\right)$ : que é o tempo transcorrido desde a injeção da amostra até a eluição do ponto máximo do pico, podendo ser expresso em minutos. 
Tempo morto $\left(t_{0}\right.$ ou $\left.t_{m}\right)$ : que é o tempo necessário para eluir um pico não retido, como o de uracila para cromatografia líquida.

Tempo de retenção ajustado ou corrigido $\left(t^{\prime}{ }_{R}\right)$ : é o tempo de retenção menos o tempo morto, ou seja $t_{R}^{\prime}=t_{R}-t_{0}$, ele mede o tempo que a amostra permanece na fase líquida.

Fator de retenção: $k=t_{R}-t_{0} / t_{0}$ - É a razão entre o tempo de retenção corrigido e o tempo morto e ele indica a relação entre o tempo que o composto esteve retido na fase estacionária e o tempo que esteve sendo carregado pela fase móvel.

Resolução $\left(R_{s}\right)$ : a resolução depende de dois fatores: a largura dos picos $(w b)$ e a medida da separação dos máximos dos picos adjacentes $(\Delta t)$, determinado pela equação 1 .

$$
R_{s}=\frac{t_{R 2}-t_{R 1}}{1 / 2\left(w_{b 1}+w_{b 2}\right)}=\frac{\Delta t}{1 / 2\left(w_{b 1}+w_{b 2}\right)}=\frac{2 \Delta t}{w_{b 1}+w_{b 2}} \quad \text { (equação 1) }
$$

Fator de cauda (TF): a simetria é medida pela relação entre as duas metades da largura do pico, medidas a $5 \%$ da altura a partir da linha de base (Figura 23), determinado pela equação 2.

Figura 23- Fator de cauda (TF) (fonte: VAN ITERSON)

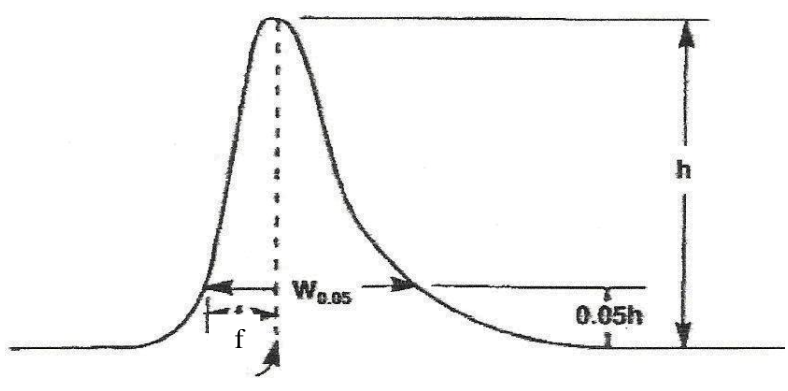

$$
T F=w_{0,05} / 2 f \quad \text { (equação 2) }
$$

sendo:

$w_{0,05}$ - largura do pico a $5 \%$ da altura a partir da linha de base

$f$ - metade anterior da largura do pico a $5 \%$ da altura a partir da linha de base

Pratos (N): um prato teórico é a altura necessária de uma coluna (em geral em centímetros) para que ocorra o equilíbrio do soluto entre a fase estacionária e móvel. $\mathrm{O}$ 
número de pratos teóricos de uma coluna cromatográfica pode ser determinado pela equação 3.

$$
N=16\left(\frac{t_{R}}{w_{b}}\right)^{2} \text { ou } N=5,545\left(\frac{t_{R}}{w_{h}}\right)^{2} \quad \text { (equação 3) }
$$

sendo:

$t_{R}$ - tempo de retenção

$w_{b}$ - largura da base do pico

$w_{h}$ - largura na meia-altura

\subsubsection{Seletividade}

A seletividade foi realizada para avaliar o grau de interferência de espécies como: outro ingrediente ativo, excipientes, impurezas e produtos de degradação, bem como outros compostos de propriedades similares que possam estar, porventura, presentes.

A seletividade avaliou se existiu algum interferente no tempo de retenção dos compostos avaliados neste estudo (TEGDMA e BisGMA), por meio da preparação de uma solução em acetonitrila contento todos os outros componentes da resina (CQ, PPD e DMPT).

\subsubsection{Linearidade}

A linearidade foi determinada usando as cinco soluções padrões em triplicata como descrito no item 4.4.2 - Soluções padrões, de acordo com o ICH, 1995. As curvas analíticas de calibração foram construídas pela correlação entre o sinal medido (área do pico) e a concentração dos monômeros avaliados (TEGDMA e BisGMA).

A linearidade é usualmente expressa em termos da variância em torno da inclinação da reta de regressão linear, calculada a partir de resultados obtidos na análise de amostras com diferentes concentrações do principio ativo de acordo com a relação matemática estabelecida através do método dos mínimos quadrados. A inclinação da reta de regressão e sua variância fornecem uma medida matemática da linearidade enquanto que a intersecção é uma medida da tendência do método.

Por meio da equação $\mathbf{y}=\mathbf{a x}+\mathbf{b}$ foi possível determinar os coeficientes de regressão $\mathbf{a}$ e b e também foi possível calcular a partir de pontos experimentais, o coeficiente de correlação r. Este parâmetro permitiu uma estimativa da qualidade da curva obtida, pois 
quanto mais próximo de 1,0, menor a dispersão do conjunto de pontos experimentais e menor a incerteza dos coeficientes de regressão estimados.

\subsubsection{Precisão}

A precisão do método foi avaliada em análises em sextuplicata.

A repetibilidade foi avaliada pela precisão intra- e inter-dias, onde seis espécimes com triplicata de injeções foram avaliados em um dia (precisão intra-dia) e após dois dias (precisão inter-dias).

A precisão foi avaliada através da estimativa do desvio padrão relativo (RSD), também conhecido como coeficiente de variação (CV\%).

\subsubsection{Exatidão}

Para avaliação da exatidão ensaios, em triplicata em três níveis diferentes de concentração da amostra foram utilizados, para o TEGDMA 90, 136 e $279 \mu \mathrm{g} \mathrm{mL}^{-1}$ e para o BisGMA 126, 190 e $378 \mu \mathrm{g} \mathrm{mL}^{-1}$, onde foram calculados os desvios de padrão relativo (RSD) ou $(\mathrm{CV} \%)$ entre o valor encontrado (valor real) e os valores nas três concentrações examinadas (valor teórico ou nominal), de acordo com recomendações do ICH e ANVISA.

\subsubsection{Limite de Detecção(LD) e Limite de Quantificação(LQ)}

O limite de detecção (LD) foi determinado pela menor concentração dos monômeros avaliados nas condições operacionais do método desenvolvido, onde o pico do analito foi 5 vezes maior que o ruído da linha de base.

O limite de quantificação (LQ) foi determinado pela menor concentração dos monômeros avaliados que puderam ser medidos e quantificados nas condições operacionais do método desenvolvido. A relação sinal-ruído foi de 10:1.

\subsubsection{Robustez}

A robustez foi avaliada pela pequena alteração em parâmetros do método desenvolvido. Foram alterados o fluxo da fase móvel para 0,9 e $1,1 \mathrm{~mL} \mathrm{~min}^{-1}$ comparando-se 
com o do método de $1,0 \mathrm{~mL} \mathrm{~min}^{-1}$ e a temperatura da coluna para 53 e $57^{\circ} \mathrm{C}$ comparando-se com $55^{\circ} \mathrm{C}$ do método desenvolvido.

\subsubsection{Determinação dos monômeros residuais}

Para a determinação da quantidade de monômeros residuais (TEGDMA e BisGMA) nas resinas experimentais, seis espécimes com triplicata de injeções foram avaliados para cada condição amostral. Os monômeros residuais foram calculados a partir das áreas sob a curva dos picos produzidos no tempo de retenção desses monômeros.

Nas soluções das amostras, a concentração de monômeros residuais $\left(\mathrm{C}_{\text {monômero }}\right.$

$\mu \mathrm{g} \mathrm{mL}^{-1}$ ) foi determinada utilizando equações de regressão linear a partir da curva de calibração, comparando-se com concentrações conhecidas dos monômeros (item 4.4.7.3Linearidade).

A partir das concentrações dos monômeros residuais, os valores foram convertidos para massa, levando em conta as massas individuais de cada espécime e o volume do solvente para a extração desses monômeros residuais. E para a padronização para melhor comparação dos resultados, os valores foram transformados em porcentagem.

\subsubsection{Tratamento estatístico para todas as amostras}

Os dados tanto da análise cromatográfica HPLC quanto da análise por FT-IR foram descritos em tabelas e gráficos pelos parâmetros de média e desvio padrão.

Para verificar se os dados possuíam distribuição normal utilizou-se o teste de Kolmogorov-Smirnov (RAZALI; WAH, 2011). Todos os grupos não apresentaram desvio significativo da normalidade $(\mathrm{p}>0,05)$ e, portanto utilizaram-se testes paramétricos nas análises estatísticas.

Para comparação entre as resinas (R1, R2 e R3) e fontes fotoativadoras (lâmpada halógena e LED) foi utilizado Análise de Variância a dois critérios e o teste post-hoc de Tukey.

Em todos os testes foi adotado nível de significância de 5\% (p<0,05).

Todos os procedimentos estatísticos foram executados no programa Statistica versão 5.1 (StatSoft Inc., Tulsa, USA). 
Resultados 


\section{RESULTADOS}

\subsection{Determinação do grau de conversão e parâmetros de cinética}

Os espectros de absorção na região do infravermelho (FT-IR) do grau de conversão monomérica das resinas considerando o tempo de fotoativação podem ser observados na Figura 24. A conversão das duplas ligações de carbono no pico correspondente as cadeias alifáticas inicia-se com a fotoativação da resina ocorrendo principalmente nos primeiros segundos, sendo esse processo observado em tempo real até 300 segundos.

Figura 24- Espectro infravermelho da conversão das duplas ligações de carbono por FT-IR no pico correspondente as cadeias alifáticas em tempo real

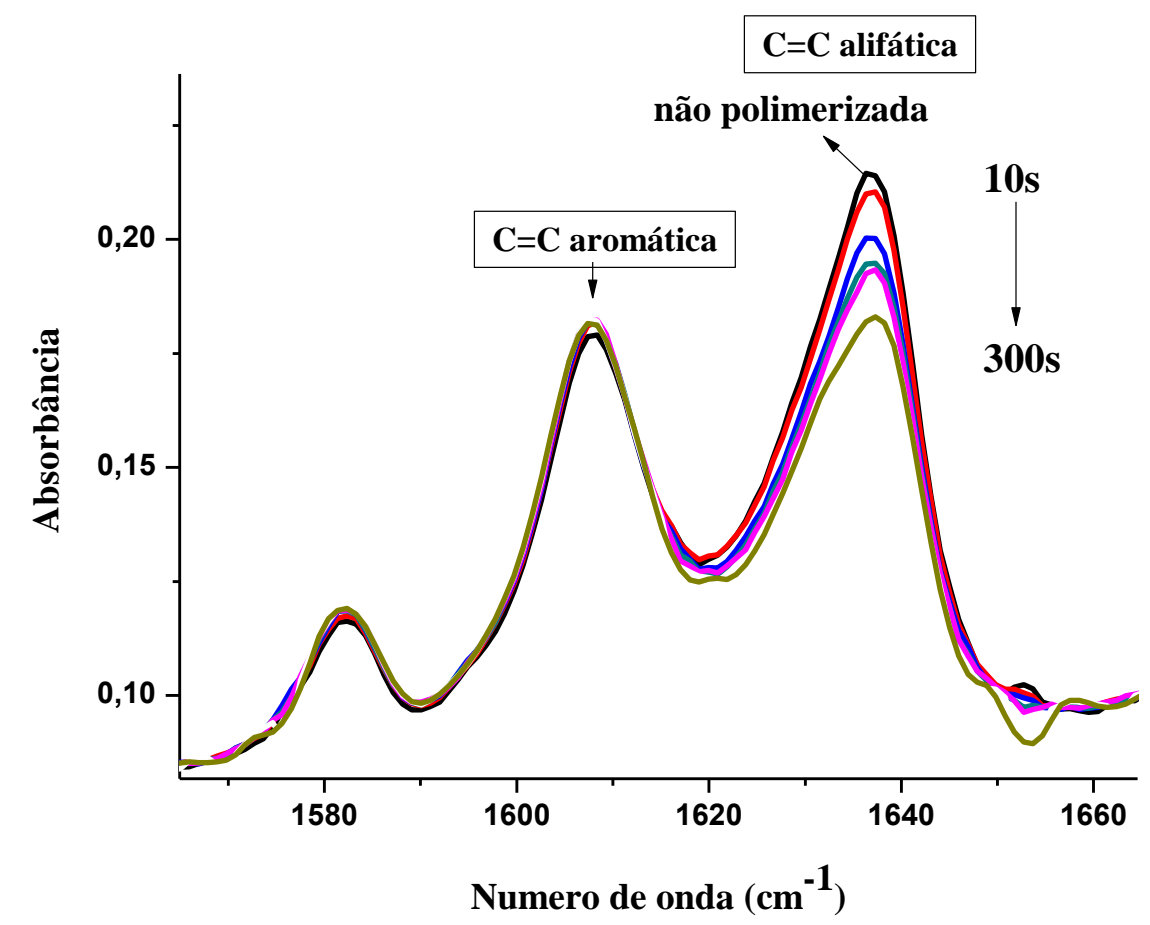

\subsubsection{Grau de conversão monomérica total após 300segundos}

Os valores dos graus de conversão monomérica das três resinas (R1, R2 e R3), fotoativadas pelas 2 diferentes fontes de luz (LED e lâmpada halógena), quantificados após 300 segundos encontram- se na Tabela 3. 
Tabela 3 - Valores do grau de conversão monomérica das resinas após 300 segundos $(n=5)$

\section{Grau de Conversão (\%)}

\begin{tabular}{l|ccccc|ccccc}
\hline & \multicolumn{5}{|c|}{ LED } & \multicolumn{5}{c}{ lâmpada halógena } \\
\cline { 2 - 11 } $\mathbf{R 1}$ & 65,33 & 68,91 & 64,06 & 65,38 & 65,81 & 65,62 & 63,96 & 64,00 & 63,57 & 64,85 \\
$\mathbf{R 2}$ & 36,75 & 34,11 & 34,15 & 38,08 & 35,11 & 45,23 & 43,01 & 40,11 & 40,18 & 42,07 \\
$\mathbf{R 3}$ & 55,41 & 56,00 & 53,55 & 57,15 & 58,14 & 56,04 & 56,25 & 55,55 & 58,35 & 59,01 \\
\hline
\end{tabular}

A partir da observação de diferenças númericas entre os grupos, foi realizada a análise estatística para se verificar a possibilidade de significância entre os valores encontrados. Optou-se por um teste estatístico paramétrico, uma análise de variância (ANOVA) a dois critérios, já que havia a presença de duas variáveis, resina e fonte de luz e foi utilizado também o teste post-hoc de Tukey com nível de significância de 5\% (p<0,05) para comparações multiplas e interações (Tabela 4) .

Tabela 4 - Média, desvio padrão e resultado da Análise de Variância e Teste de Tukey para o grau de conversão (\%) após 300 segundos

\begin{tabular}{llllll}
\hline \multirow{2}{*}{ Resina } & \multicolumn{2}{l}{ LED } & & \multicolumn{2}{l}{ lâmpada halógena } \\
\cline { 2 - 3 } \cline { 5 - 6 } Rédia & $\mathrm{dp}$ & & média & $\mathrm{dp}$ \\
\hline R2 & $65,90^{\mathrm{d}}$ & $\pm 1,81$ & & $64,40^{\mathrm{d}}$ & $\pm 0,83$ \\
R2 & $35,64^{\mathrm{a}}$ & $\pm 1,73$ & & $42,12^{\mathrm{b}}$ & $\pm 2,14$ \\
R3 & $56,05^{\mathrm{c}}$ & $\pm 1,75$ & & $57,04^{\mathrm{c}}$ & $\pm 1,54$
\end{tabular}

Grupos com a mesma letra sobrescrita não possuem diferença estatisticamente significante entre si.

Com base na estatística foi possível determinar que todas as resinas apresentaram diferenças significantes entre si, e que somente a resina R2 apresentou diferença significante entre as fontes de luz, sendo que nas demais não houve essa diferença entre as fontes.

$\mathrm{O}$ menor valor médio de grau de conversão foi encontrado quando a resina R2 foi fotoativada pelo $\operatorname{LED}(35,64 \% \pm 1,73)$ e os maiores valores de conversão foram encontrados para a resina R1 tanto fotoativada com LED $(65,90 \% \pm 1,81)$ quanto com a lampâda halógena $(64,40 \% \pm 0,83)$, estando ilustrado na Figura 25. 
Figura 25- Gráfico da média e desvio padrão do grau de conversão (\%) após 300 segundos

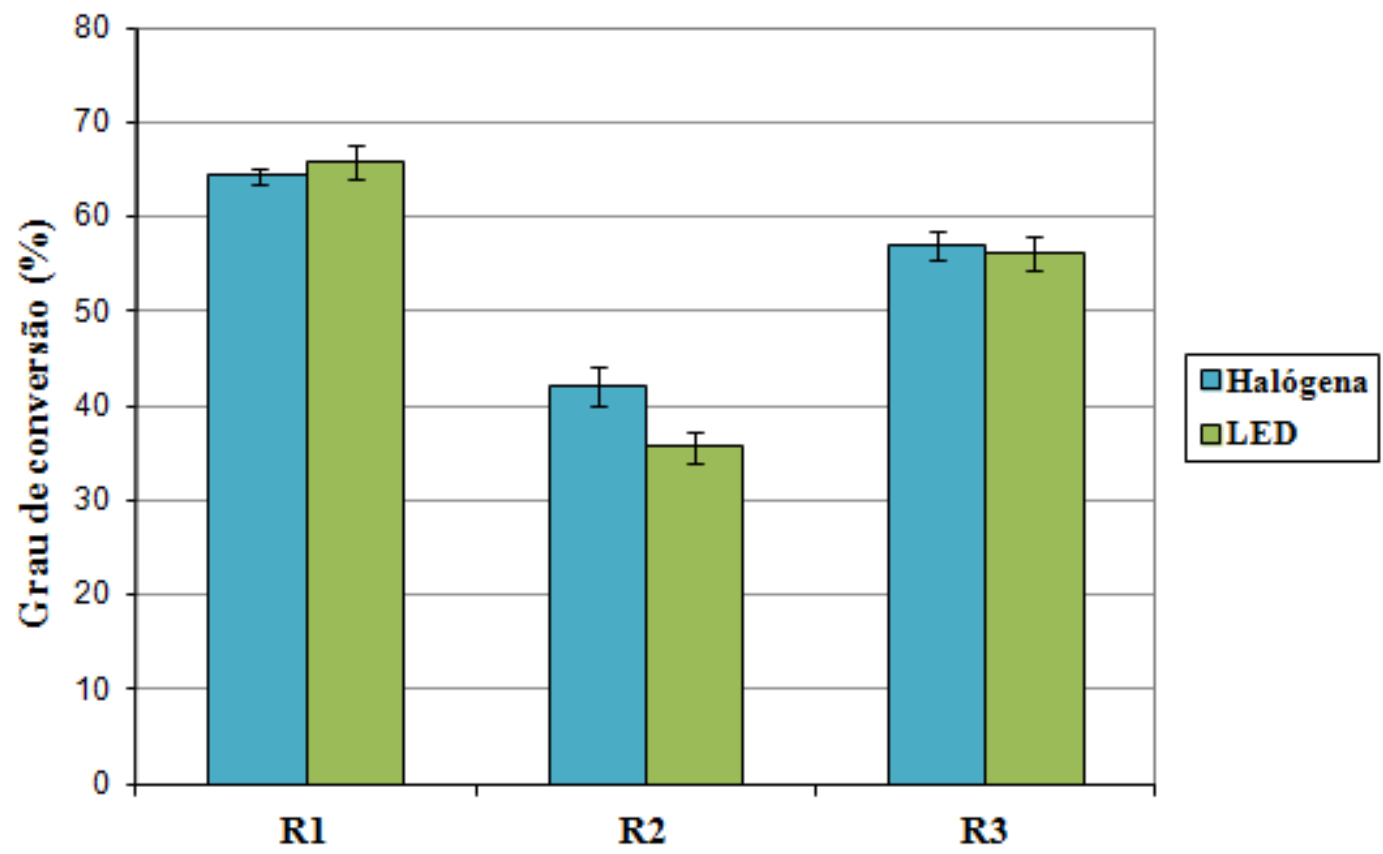

A figura 26 mostra a conversão da resina em tempo real avaliada por FT-IR para as três resinas (R1, R2 e R3) fotoativadas com as duas fontes de luz (LED e lâmpada halógena). Observou-se que a maior parte da reação ocorre nos primeiros segundos contando a partir do momento em que o aparelho de fotoativação é acionado. A reação ocorre principalmente nos primeiros 60 segundos e após esse período não ocorre grandes alterações tendendo a um valor constante.

Figura 26- Gráfico do grau de conversão das resinas em tempo real

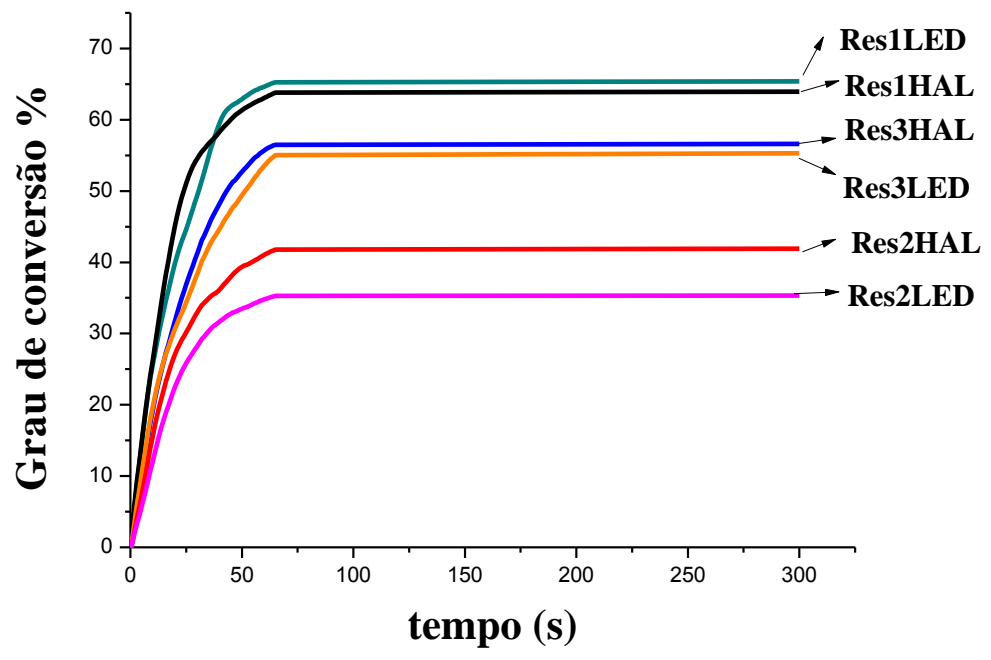




\subsubsection{Taxa máxima de conversão $\left(\operatorname{Rp}^{\text {máx }}\right)$}

Os valores da taxa máxima de conversão $\left(\mathrm{Rp}^{\text {máx }}\right)$ para as três resinas (R1, R2 e R3) fotoativadas com as duas fontes de luz (LED e lâmpada halógena) encontram-se na Tabela 5.

Tabela 5 - Taxa máxima de conversão $\left(\mathrm{Rp}^{\text {máx }}\right)$ para as diferentes resinas e fontes de luz $(\mathrm{n}=5)$

$$
\operatorname{Rp}^{\text {máx }}(\% / s)
$$

\begin{tabular}{c|rrrrr|rrrrr}
\hline & \multicolumn{5}{|c|}{ LED } & \multicolumn{5}{c}{ lâmpada halógena } \\
\cline { 2 - 11 } $\mathbf{R 1}$ & 3,63 & 3,86 & 2,21 & 3,26 & 2,54 & 3,06 & 2,94 & 3,63 & 2,84 & 3,19 \\
$\mathbf{R 2}$ & 1,18 & 1,04 & 0,97 & 1,71 & 1,41 & 1,71 & 1,69 & 1,56 & 1,61 & 1,75 \\
$\mathbf{R 3}$ & 2,65 & 2,31 & 2,03 & 2,34 & 2,01 & 1,92 & 2,21 & 2,00 & 2,06 & 2,03 \\
\hline
\end{tabular}

Devido a variações nos valores, a análise estatística foi feita para os resultados de $\mathrm{Rp}^{\text {máx }}$ (Tabela 6) e foi detectado que todas as resinas apresentaram diferenças significantes entre si, mas não houve diferença entre as fontes de luz para uma mesma resina.

Tabela 6 - Média, desvio padrão e resultado da Análise de Variância e Teste de Tukey para a taxa máxima de conversão $(\% / \mathrm{s})$

\begin{tabular}{cccccc}
\hline \multirow{2}{*}{ Resina } & \multicolumn{2}{c}{ LED } & & \multicolumn{2}{c}{ lâmpada halógena } \\
\cline { 2 - 3 } \cline { 5 - 6 } R1 & média & $\mathrm{dp}$ & & média & $\mathrm{dp}$ \\
\hline R2 & $3,10^{\mathrm{c}}$ & $\pm 0,71$ & & $3,13^{\mathrm{c}}$ & $\pm 0,31$ \\
R3 & $2,26^{\mathrm{a}}$ & $\pm 0,30$ & & $1,66^{\mathrm{a}}$ & $\pm 0,08$ \\
& $2,27^{\mathrm{b}}$ & $\pm 0,26$ & & $2,04^{\mathrm{b}}$ & $\pm 0,11$ \\
\hline
\end{tabular}

Grupos com a mesma letra sobrescrita não possuem diferença estatisticamente significante entre si.

$\mathrm{O}$ valor médio de $\mathrm{Rp}^{\text {máx }}$ mais alto encontrado foi para a resina $\mathrm{R} 1(3,13 \% / \mathrm{s} \pm 0,31)$ fotoativada por lâmpada halógena e o valor médio mais baixo foi para resina $\mathrm{R} 2(1,26 \% / \mathrm{s}$ $\pm 0,30$ ) fotoativada por LED (Figura 27). Os valores da $\mathrm{Rp}^{\text {máx }}$ foram menores para resinas (R2 e R3) que apresentam o fotoiniciador PPD em sua composição quando comparados com a resina com somente a CQ (R1). 
Figura 27- Gráfico da média e desvio padrão da taxa máxima de conversão $\left(\mathrm{Rp}^{\text {máx }}\right)$

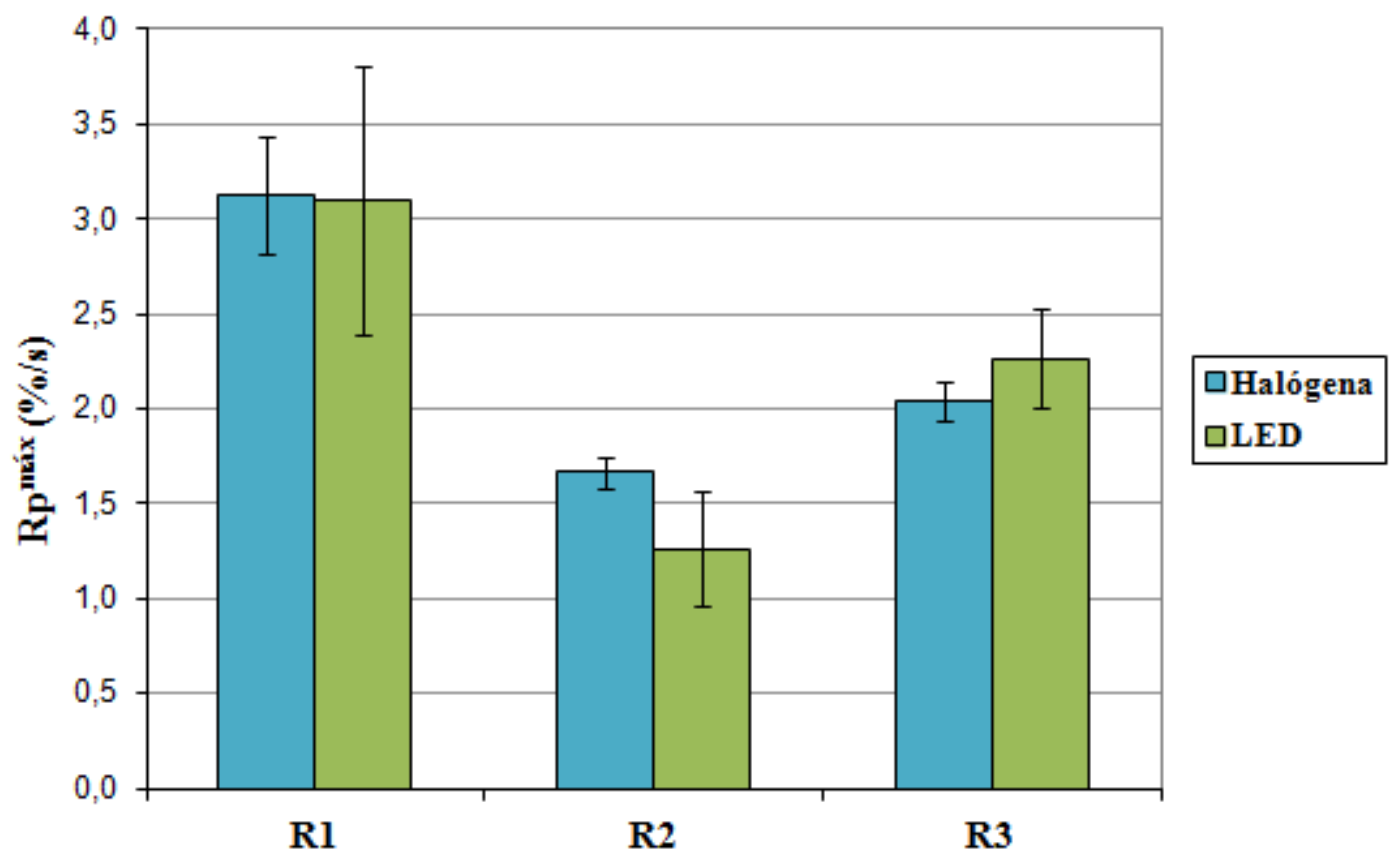

\subsubsection{Tempo em que ocorreu a $\operatorname{Rp}^{\text {máx }}\left(t_{\text {máx }}\right)$}

Os valores do $\mathrm{t}_{\text {máx }}$, isto é tempo em que ocorreu a $\mathrm{Rp}^{\text {máx }}$ para todas as condições, encontra-se na Tabela 7. A ocorrência da taxa máxima de conversão variou desde um tempo de 4 segundos até 10 segundos.

Tabela 7 - $\mathrm{t}_{\text {máx }}$ para as diferentes resinas e fontes de luz $(n=5)$

$$
\mathbf{t}_{\text {máx }}(\mathbf{s})
$$

\begin{tabular}{llllll|lllll}
\hline & & \multicolumn{3}{c|}{ LED } & \multicolumn{5}{c}{ lâmpada halógena } \\
$\mathbf{R} 1$ & 4 & 4 & 5 & 4 & 4 & 4 & 4 & 4 & 6 & 5 \\
$\mathbf{R 2}$ & 9 & 10 & 9 & 9 & 10 & 7 & 8 & 8 & 8 & 8 \\
$\mathbf{R 3}$ & 6 & 6 & 7 & 7 & 8 & 7 & 6 & 6 & 6 & 7 \\
\hline
\end{tabular}

Os valores de $t_{\text {máx }}$ foram analisados estatisticamente (Tabela 8) e foi possível observar que ocorreram diferenças significantes entre as fontes de luz, somente para a resina R2. 
A resina R1 não obteve diferenças significantes comparando-se com a resina R3 ambas fotoativadas com as duas diferentes fontes de luz.

A resina R2 fotoativada com LED obteve diferença significante em relação a todos os outros grupos, obtendo maior valor médio de $\mathrm{t}_{\text {máx }}(9,40 \mathrm{~s} \pm 0,55)$, ilustrado na Figura 28.

As resinas que possuíam PPD na sua composição tiveram um $\mathrm{t}_{\text {máx }}$ maior que as resinas que somente tinham CQ na composição.

Tabela 8 - Média, desvio padrão e resultado da Análise de Variância e Teste de Tukey para o $t_{\text {máx }}$

\begin{tabular}{|c|c|c|c|c|}
\hline \multirow{2}{*}{ Resina } & \multicolumn{2}{|l|}{ LED } & \multicolumn{2}{|c|}{ lâmpada halógena } \\
\hline & média & $\mathrm{dp}$ & média & $\mathrm{dp}$ \\
\hline $\mathrm{R} 1$ & $4,20^{\mathrm{a}}$ & $\pm 0,45$ & $4,60^{\mathrm{a}}$ & $\pm 0,89$ \\
\hline $\mathrm{R} 2$ & $9,40^{c}$ & $\pm 0,55$ & $7,80^{\mathrm{b}}$ & $\pm 0,45$ \\
\hline R3 & $6,80^{\mathrm{ab}}$ & $\pm 0,84$ & $6,40^{\mathrm{a}}$ & $\pm 0,55$ \\
\hline
\end{tabular}

Grupos com a mesma letra sobrescrita não possuem diferença estatisticamente significante entre si.

Figura 28- Gráfico da média e desvio padrão para o $t_{\text {máx }}$

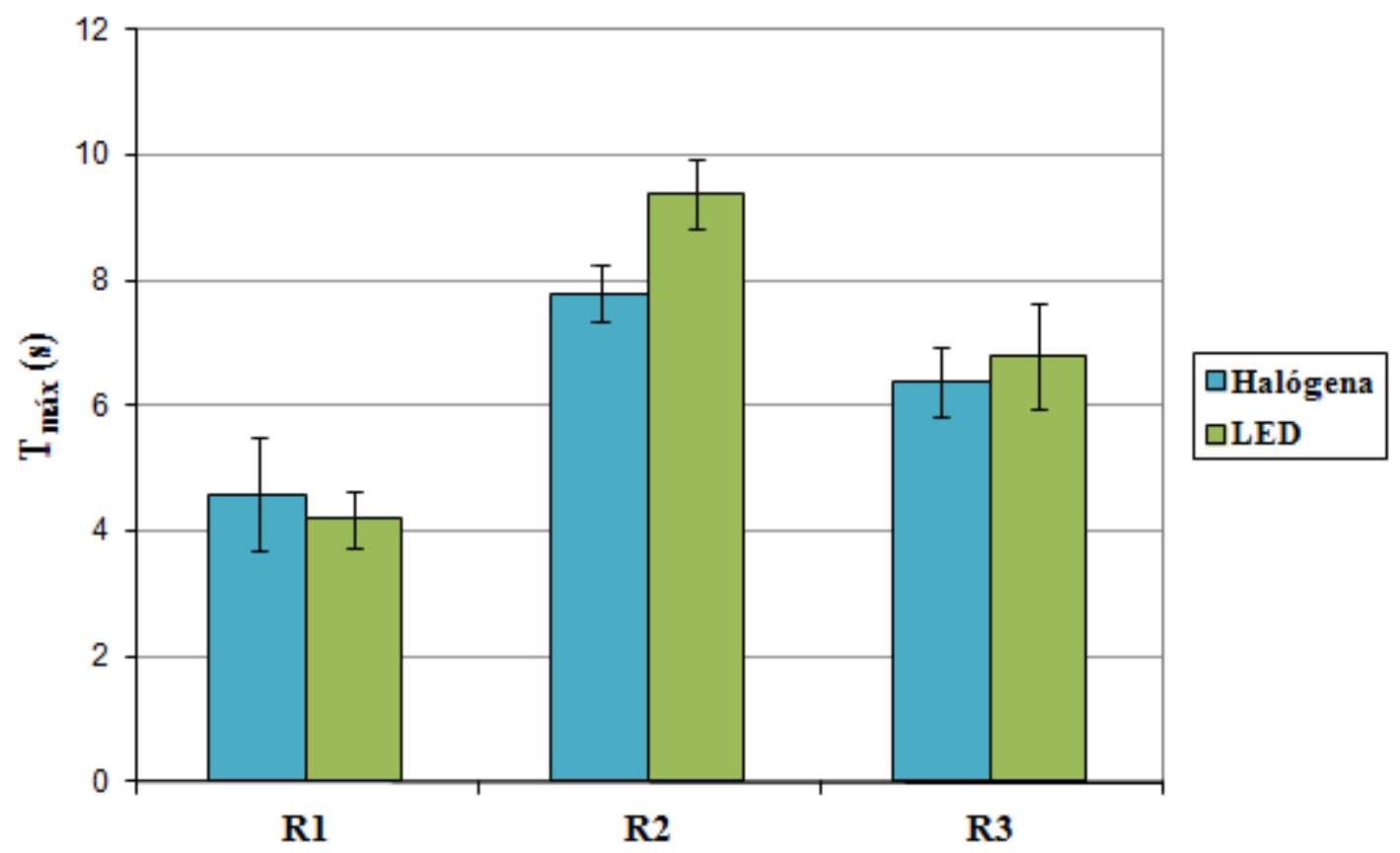




\subsubsection{Grau de conversão no $t_{m a ́ x}$}

Os valores de grau de conversão obtidos no tempo em que ocorreu a taxa máxima de conversão $\left(\mathrm{t}_{\text {máx }}\right)$ estão demonstrados na Tabela 9 para todas as condições testadas. Os valores variaram de $8,75 \%$ para a resina R2 fotoativada por LED à 17,04\% para a resina R1 fotoativada por lâmpada halógena.

Tabela 9 - Grau de conversão no $\mathrm{t}_{\text {máx }}$ para as diferentes resinas fotoativadas com as duas fontes de luz $(n=5)$

Grau de conversão no $t_{\text {máx }}(\%)$

\begin{tabular}{cccccc|ccccc}
\hline & \multicolumn{5}{c|}{ LED } & \multicolumn{5}{c}{ lâmpada halógena } \\
$\mathbf{R}$ & \multicolumn{5}{c}{} & & & \multicolumn{5}{c}{} \\
$\mathbf{R} 2$ & 14,55 & 15,46 & 11,08 & 13,04 & 10,18 & 12,27 & 11,80 & 14,56 & 17,04 & 15,98 \\
$\mathbf{R 3}$ & 10,68 & 10,48 & 8,75 & 15,43 & 14,18 & 11,97 & 13,59 & 12,53 & 12,90 & 14,05 \\
& 15,94 & 13,88 & 14,26 & 16,44 & 16,14 & 13,44 & 13,28 & 12,00 & 12,41 & 14,23 \\
\hline
\end{tabular}

Os valores do grau de conversão na $\mathrm{t}_{\text {máx }}$ foram analisados estatisticamente $\mathrm{e}$ encontram -se na Tabela 10.

Tabela 10 - Média, desvio padrão e resultado da Análise de Variância e Teste de Tukey para o grau de conversão no $t_{\text {máx }}$

\begin{tabular}{llllll}
\hline \multirow{2}{*}{ Resina } & LED & & & lâmpada halógena \\
\cline { 2 - 3 } \cline { 5 - 6 } média & $\mathrm{dp}$ & & média & $\mathrm{dp}$ \\
\hline R2 & $12,86^{\mathrm{a}}$ & $\pm 2,24$ & & $14,33^{\mathrm{a}}$ & $\pm 2,28$ \\
$\mathrm{R} 2$ & $11,90^{\mathrm{a}}$ & $\pm 2,79$ & & $13,01^{\mathrm{a}}$ & $\pm 0,83$ \\
$\mathrm{R} 3$ & $15,33^{\mathrm{a}}$ & $\pm 1,17$ & & $13,07^{\mathrm{a}}$ & $\pm 0,88$
\end{tabular}

Grupos com a mesma letra sobrescrita não possuem diferença estatisticamente significante entre si.

Foi observado que não houve diferenças estatisticamente significantes entre as resinas e nem entre as fontes de luz para o grau de conversão no $t_{\text {máx }}$ (Figura 29), possuindo todos os grupos valores de conversão similares no $t_{\text {máx }}$. 
Figura 29- Gráfico da média e desvio padrão do grau de conversão no $\mathrm{t}_{\text {máx }}$

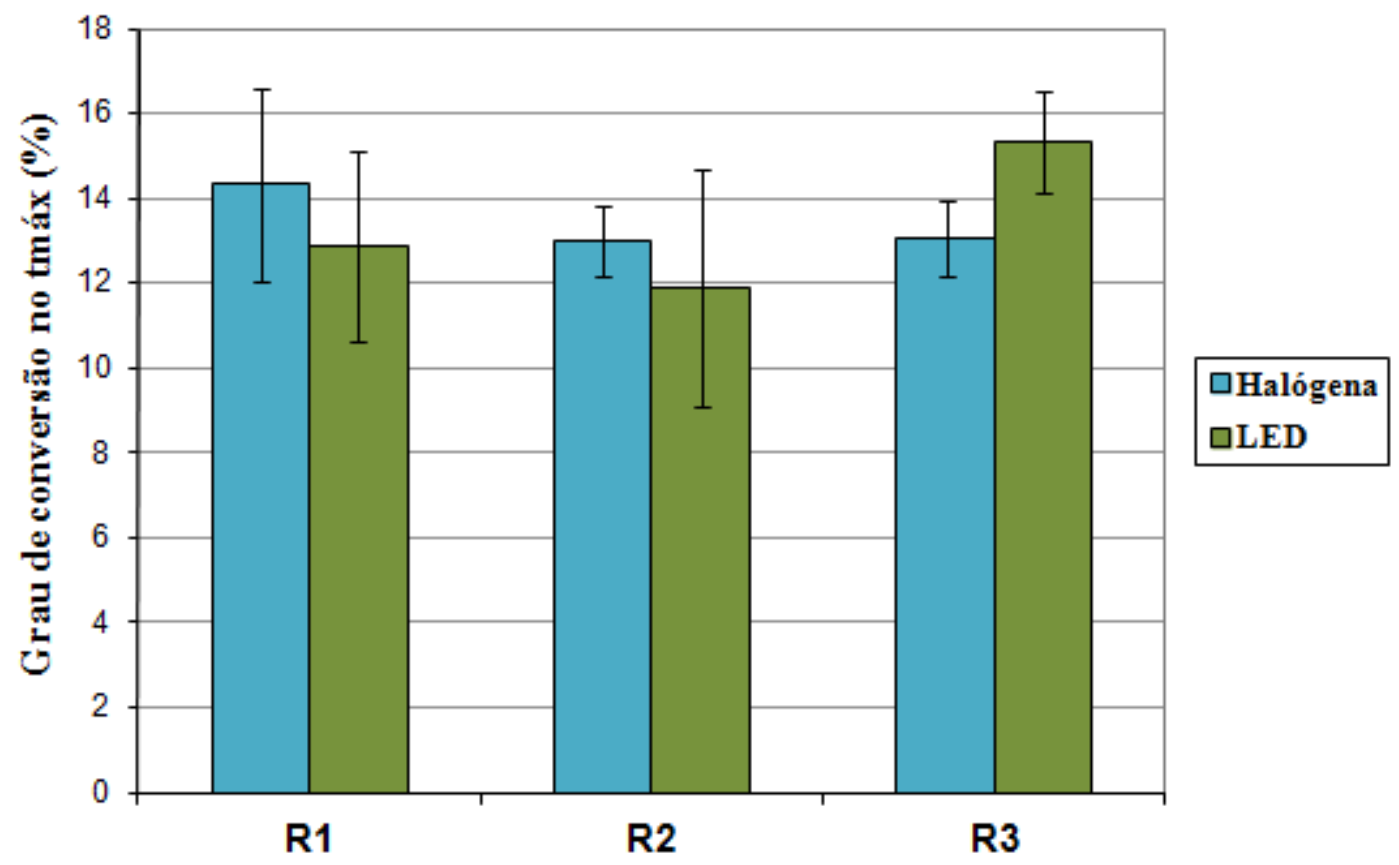

\subsection{Determinação dos monômeros residuais por HPLC}

\subsubsection{Otimização do método cromatográfico de análise dos monômeros residuais}

Durante o desenvolvimento do método, foi realizada uma otimização deste, testando as melhores condições para extração dos monômeros residuais TEGDMA e BisGMA. Os espécimes de resina, no caso, a R1 foram confeccionados em triplicata e fotoativados com LED. Os solventes foram testados para verificar a melhor condição de extração sendo eles: acetonitrila, metanol e etanol $75 \%$. Foi realizado o cálculo do coeficiente de variação (CV\%) que avaliou a proximidade entre várias medidas $(n=3)$ efetuada em uma mesma amostra obtidos em condições de repetibilidade.

E foi possível observar em relação a quantidade de monômeros residuais (M/M\%) que o solvente acetonitrila apresentou maior capacidade de extração (Tabela 11). 
Tabela 11 - Determinação de monômeros residuais em diferentes solventes

\section{M/M\% (dp) e CV\%}

\section{Monômeros}

Solvente

\begin{tabular}{c|cc|cc|cc} 
& \multicolumn{2}{c|}{ Acetonitrila } & \multicolumn{2}{c|}{ Metanol } & \multicolumn{2}{c}{ Etanol 75\% } \\
\hline TEGDMA & $1,031( \pm 0,11)$ & CV-10,9 & $0,621( \pm 0,05)$ & CV-8,6 & $0,493( \pm 0,01)$ & CV-2,5 \\
BISGMA & $0,915( \pm 0,01)$ & CV-1,3 & $0,761( \pm 0,07)$ & CV-9,3 & $0,267( \pm 0,02)$ & CV-10,5 \\
\hline
\end{tabular}

Realizamos também a comparação utilizando a agitação mecânica ou não dos espécimes no solvente, com uma barra magnética de PTFE $(10 \mathrm{~mm})$, durante o período de extração para verificar se a agitação mecânica poderia alterar os valores de extração dos monômeros.

E observamos uma maior extração dos monômeros residuais quando utilizamos agitação mecânica (Tabela 12).

Tabela 12 - Determinação de monômeros residuais utilizando ou não agitação mecânica

$$
\text { M/M\% (dp) e CV\% }
$$

\begin{tabular}{l|cc|cc}
\hline \multirow{2}{*}{ Monômeros } & \multicolumn{3}{c}{ Agitação } \\
& \multicolumn{2}{c}{ Com } & \multicolumn{2}{c}{ Sem } \\
TEGDMA & $1,660( \pm 0,09)$ & CV- 5,9 & $1,515( \pm 0,11)$ & CV $-7,6$ \\
BISGMA & $1,766( \pm 0,15)$ & CV- 9 & $1,409( \pm 0,16)$ & CV $-11,3$ \\
\hline
\end{tabular}

Foram também avaliados os tempos de extração dos monômeros residuais: 2 h, 6 h, 12 h, $24 \mathrm{~h}$ e $72 \mathrm{~h}$, e observamos um comportamento parecido entre os tempos de $24 \mathrm{~h}$ e $72 \mathrm{~h}$, demonstrando que o tempo de 24 h já é suficiente para a completa extração dos monômeros residuais (Tabela 13), melhor ilustrado na Figura 30.

Os CV\% para todos os testes de otimização mantiveram-se dentro dos parâmetros recomendados pela ANVISA, 2003, abaixo de $15 \%$. 
Tabela 13 - Determinação de monômeros residuais em função do tempo de extração

\section{M/M\% (dp) e CV\%}

\section{Tempo de agitação}

\begin{tabular}{|c|c|c|c|c|c|c|c|c|c|c|}
\hline Monômeros & \multicolumn{2}{|c|}{$2 \mathrm{~h}$} & \multicolumn{2}{|c|}{$6 h$} & \multicolumn{2}{|c|}{$12 \mathrm{~h}$} & \multicolumn{2}{|c|}{$24 h$} & \multicolumn{2}{|c|}{$72 \mathrm{~h}$} \\
\hline TEGDMA & $\begin{array}{c}0,923 \\
( \pm 0,12)\end{array}$ & $\begin{array}{l}\text { CV- } \\
13,6\end{array}$ & $\begin{array}{c}0,941 \\
( \pm 0,04)\end{array}$ & $\begin{array}{c}\mathrm{CV}- \\
4,4\end{array}$ & $\begin{array}{c}1,660 \\
( \pm 0,09)\end{array}$ & $\begin{array}{c}\mathrm{CV}- \\
5,9\end{array}$ & $\begin{array}{c}2,258 \\
( \pm 0,12)\end{array}$ & $\begin{array}{l}\mathrm{CV}- \\
5,4\end{array}$ & $\begin{array}{c}2,444 \\
( \pm 0,25)\end{array}$ & $\begin{array}{l}\mathrm{CV}- \\
10,5\end{array}$ \\
\hline BISGMA & $\begin{array}{c}0,829 \\
( \pm 0,03)\end{array}$ & $\begin{array}{c}\mathrm{CV}- \\
4,2\end{array}$ & $\begin{array}{c}0,915 \\
( \pm 0,01)\end{array}$ & $\begin{array}{c}\mathrm{CV}- \\
1,3\end{array}$ & $\begin{array}{c}1,766 \\
( \pm 0,15)\end{array}$ & $\begin{array}{l}\mathrm{CV}- \\
9,0\end{array}$ & $\begin{array}{c}2,531 \\
( \pm 0,19)\end{array}$ & $\begin{array}{c}\mathrm{CV}- \\
7,8\end{array}$ & $\begin{array}{c}2,505 \\
( \pm 0,27)\end{array}$ & $\begin{array}{l}\mathrm{CV}- \\
11,0\end{array}$ \\
\hline
\end{tabular}

Figura 30- Porcentagem de monômeros residuais em função do tempo de extração em acetonitrila

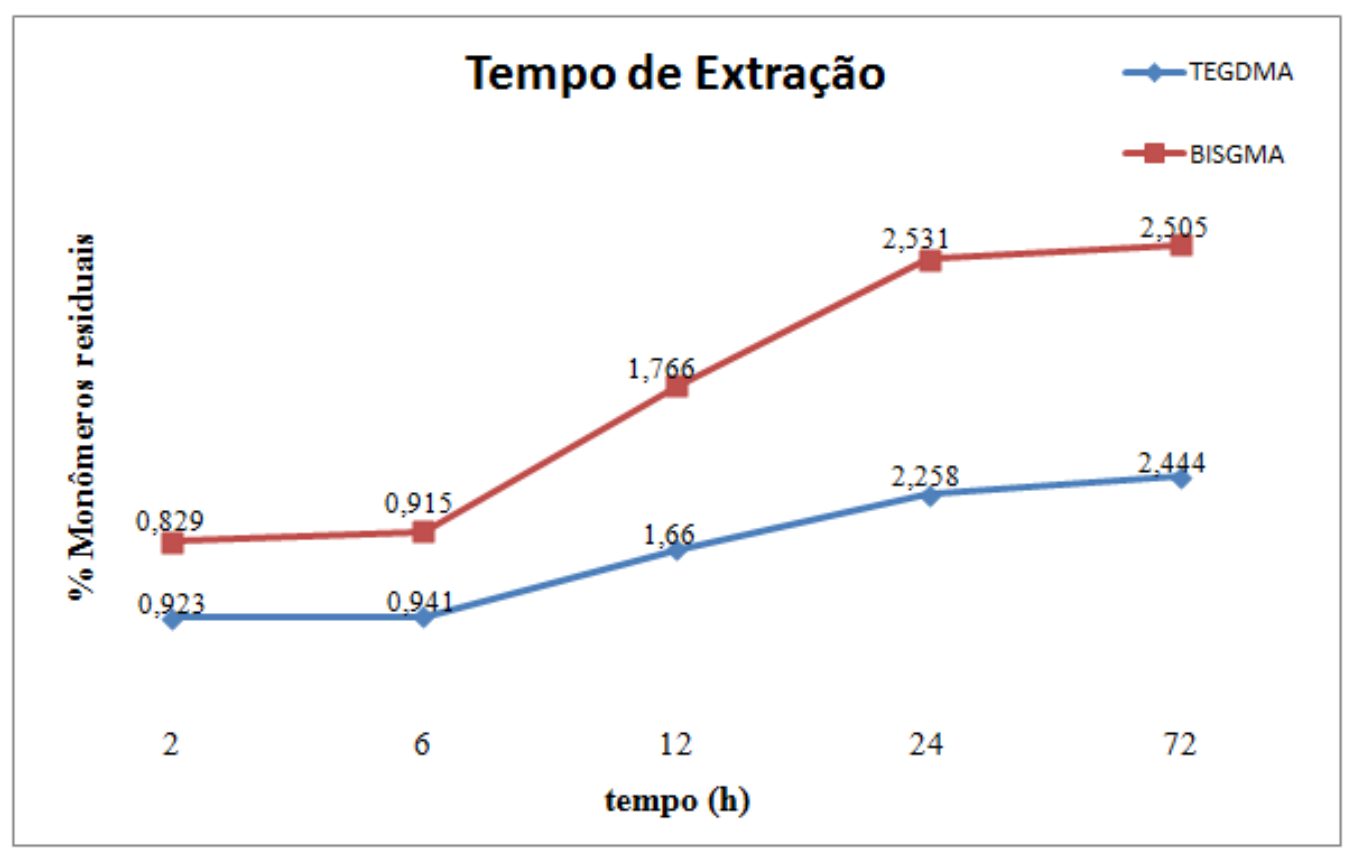

As melhores condições de extração dos monômeros residuais TEGDMA e BisGMA baseadas nos testes de otimização do método ocorreram quando os espécimes foram imersos em acetonitrila por $24 \mathrm{~h}$ com agitação mecânica, sendo essas condições padronizadas para a avaliação das amostras reais. 


\subsubsection{Validação do método cromatográfico de analise dos monômeros residuais}

Nos cromatogramas obtidos, foi observado a presença de valores quantificáveis dos monômeros TEGDMA e BisGMA que foram extraídos dos espécimes avaliados.

O tempo de retenção dos monômeros baseados nas soluções padrões foi 5,9 minutos para o TEGDMA e 8,7 minutos para o BisGMA, os picos se apresentaram bem separados um do outro (Figura 31).

Figura 31- Cromatograma dos monômeros liberados dos espécimes

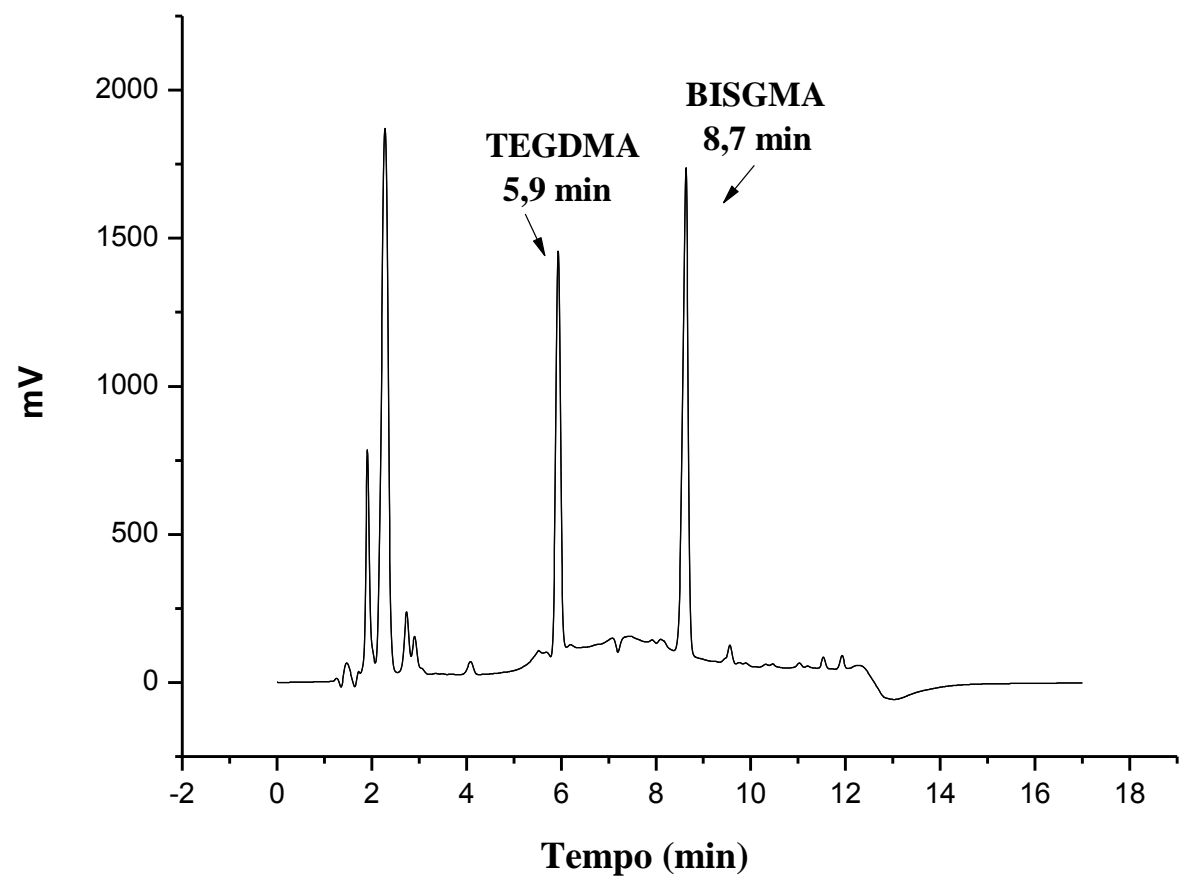

Antes de realizar os experimentos da validação e as análises das amostras, foi avaliada a capacidade do sistema de HPLC fornecer dados de qualidade confiável. Esta avaliação foi alcançada com experimentos de conformidade com o sistema "system suitability". Esses testes foram utilizados para verificar a performance do sistema para que este seja adequado para a análise a ser realizada (SHABIR, 2003). A conformidade do sistema é a verificação de um sistema para garantir a sua qualidade antes ou durante a análise de amostras desconhecidas. Parâmetros como fator de retenção $(\mathrm{k})$, repetibilidade (RSD da área de seis repetições), resolução $\left(R_{S}\right)$, fator de alargamento ou cauda e números de pratos teóricos foram 
medidos e comparados aos limites recomendados de acordo com a US-FDA, 2000 (Tabela $14)$.

Tabela 14 - Parâmetros avaliados de conformidade do sistema e recomendações

\begin{tabular}{|c|c|c|c|}
\hline \multirow[t]{2}{*}{ Parâmetros } & \multicolumn{2}{|c|}{ Parâmetros medidos } & Recomendações \\
\hline & TEGDMA & BisGMA & \\
\hline Fator de retenção (k) & 3,7208 & 5,8667 & $\begin{array}{c}\text { O pico deve estar bem } \\
\text { separado de outros e do } \\
\text { pico correspondente ao } \\
\text { tempo de retenção de um } \\
\text { composto não retido } t_{\mathrm{M}} \\
\mathrm{k}^{\prime}>2,0\end{array}$ \\
\hline Repetibilidade & 0,75558 & 0,7231 & $\mathrm{RSD} \leq 1 \%$ para $\mathrm{N} \geq 5$ \\
\hline Resolução $\left(\mathrm{R}_{\mathrm{s}}\right)$ & \multicolumn{2}{|c|}{9,19} & $\begin{array}{c}\mathrm{R}_{\mathrm{s}}>2 \text { entre o pico de } \\
\text { interesse e o interferente } \\
\text { potencial mais próximo } \\
\text { (outro produto de interesse, } \\
\text { impureza, produto de } \\
\text { degradação, padrão interno, } \\
\text { excipientes, etc) }\end{array}$ \\
\hline $\begin{array}{l}\text { Fator de alargamento ou } \\
\text { cauda (TF) }\end{array}$ & \multicolumn{2}{|c|}{1} & $\mathrm{TF} \leq 2$ \\
\hline $\begin{array}{l}\text { Número de pratos téoricos } \\
(\mathrm{N})\end{array}$ & 7380 & 12344 & $\begin{array}{c}\text { Em geral deve ser > } 2000 \\
\text { para HPLC }\end{array}$ \\
\hline
\end{tabular}

Baseado nos resultados obtidos, o sistema demonstrou-se de acordo para garantir a qualidade da análise cromatográfica.

Para verificar a confiabilidade dos dados analíticos gerados, foi realizada a validação da metodologia analítica de acordo com os "guidelines" do ICH (International Conference on Harmonisation for Registration of Pharmaceutical for Human) por meio da avaliação de vários parâmetros como: "system suitability", seletividade, linearidade, precisão, exatidão, limite de detecção e quantificação e robustez.

A seletividade foi avaliada pela comparação da injeção de amostras contendo os componentes da resina menos os monômeros de interesse (CQ, PPD e DMPT) e as amostras contendo somente as substâncias de interesse (os monômeros TEGDMA e BisGMA) e foi possível observar que não houve a presença de interferentes nos tempos de retenção dos monômeros avaliados (Figura 32). 
Figura 32- Cromatogramas sobrepostos do padrão $[-]$ e da seletividade $(-)$

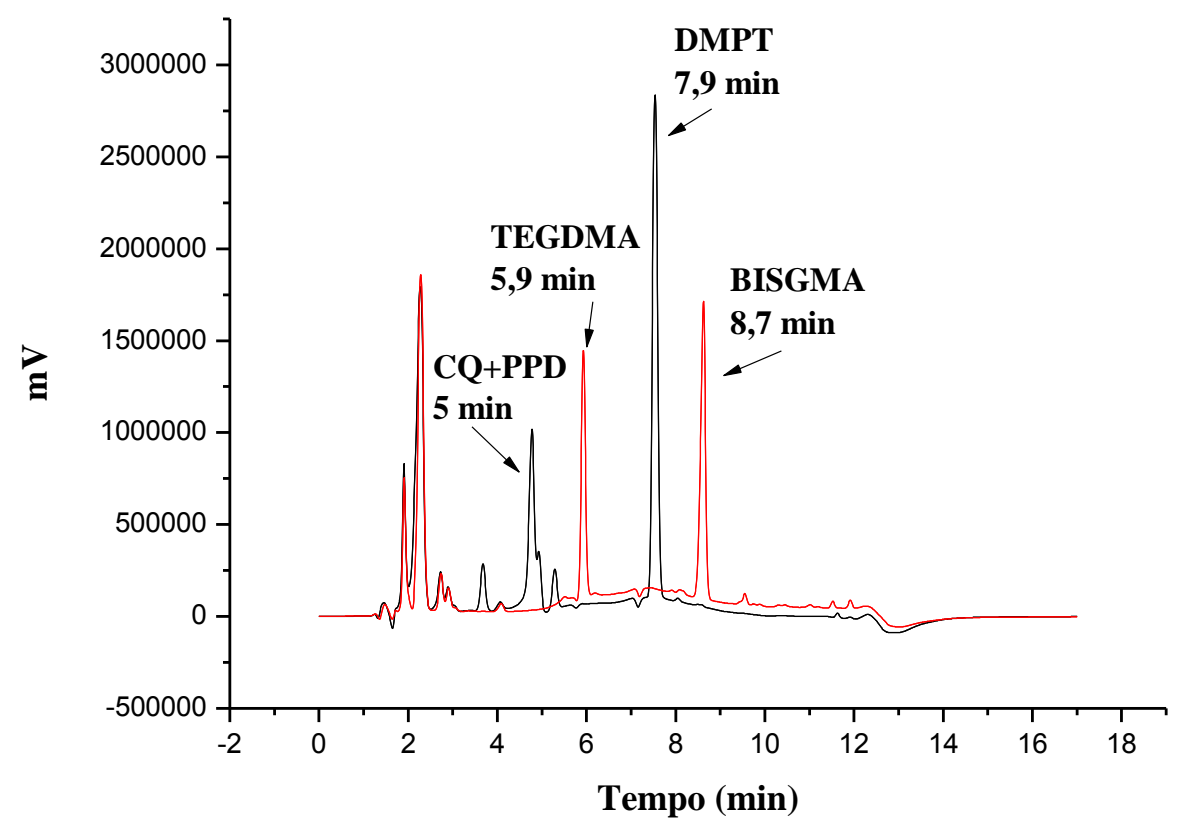

A linearidade é a capacidade do método em fornecer resultados diretamente proporcionais à concentração da substância em exame, dentro de uma determinada faixa de aplicação (CHASIN et al., 1998; RIBANI et al., 2004). O ICH "guidelines"(1995) especifica um mínimo de cinco concentrações a serem avaliadas.

As curvas analíticas de calibração foram construídas pela correlação entre o sinal medido (área do pico) e a concentração dos monômeros avaliados (TEGDMA e BisGMA).

O coeficiente de correlação obtido nesse estudo foi de $r=0,99$ estando de acordo com as recomendações do ICH (1995) e ANVISA (2003) que são de correlação igual a 0,99 e ao INMETRO (2003) 0,90 (Figura 33). 
Figura 33- Curvas de calibração dos monômeros TEGDMA (A) e BisGMA (B)
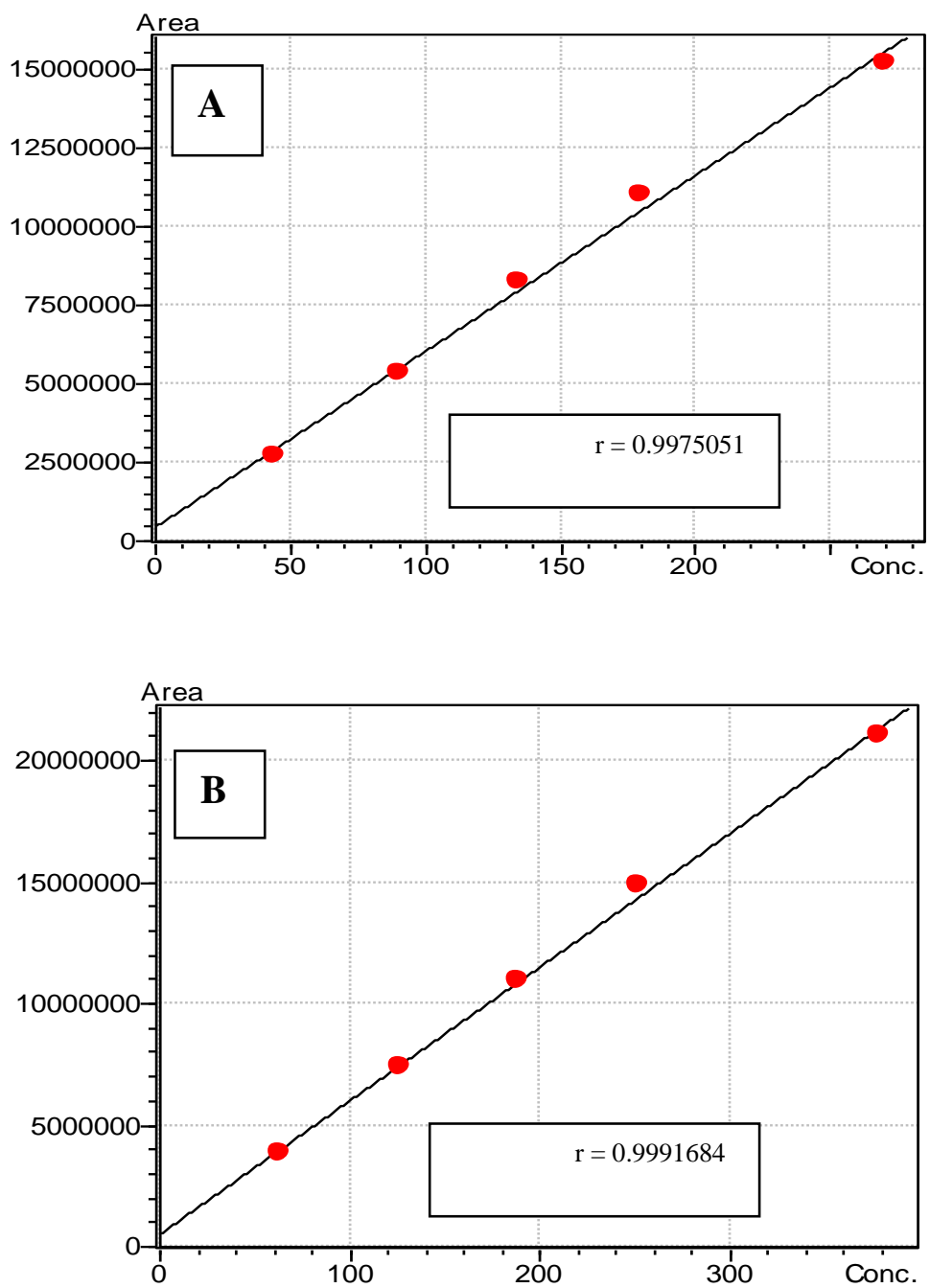

A exatidão representa o grau de concordância entre os resultados encontrados e um valor de referência aceito como verdadeiro (SHABIR, 2003). A exatidão foi avaliada através da análise de amostras com concentrações conhecida comparando-se com o valor medido (Tabela 15). 
Tabela 15 - Exatidão na determinação dos monômeros TEGDMA e BisGMA

\begin{tabular}{|c|c|c|c|}
\hline $\begin{array}{c}\text { Monômeros } \\
\left(\mu \mathrm{g} \mathrm{mL} \mathbf{~}^{-1}\right)\end{array}$ & $\begin{array}{l}\text { Concentração } \\
\left(\mu \mathrm{g} \mathrm{mL} \mathbf{L}^{-1}\right)\end{array}$ & $\begin{array}{c}\text { Exatidão } \\
(\%)\end{array}$ & $\begin{array}{c}\text { Média CV } \\
(\%)\end{array}$ \\
\hline $\begin{array}{c}\text { TEGDMA } \\
\left(\text { Con }_{\text {teoric }} 90\right)\end{array}$ & 87,44 & 97,16 & 3,79 \\
\hline $\begin{array}{c}\text { TEGDMA } \\
\left(\mathrm{Con}_{\text {teoric }} 136\right)\end{array}$ & 138,65 & 101,94 & 0,95 \\
\hline $\begin{array}{c}\text { TEGDMA } \\
\left(\text { Con }_{\text {teoric }} 279\right)\end{array}$ & 264,54 & 94,81 & 5,85 \\
\hline $\begin{array}{c}\text { BISGMA } \\
\left(\text { Con }_{\text {teoric }} 126\right)\end{array}$ & 111,12 & 88,19 & 4,18 \\
\hline $\begin{array}{c}\text { BISGMA } \\
\left(\text { Con }_{\text {teoric }} 190\right)\end{array}$ & 195,96 & 103,13 & 1,50 \\
\hline $\begin{array}{c}\text { BISGMA } \\
\left(\mathrm{Con}_{\text {teoric }} 378\right)\end{array}$ & 385,52 & 101,99 & 6,03 \\
\hline
\end{tabular}

O critério de aceitação para o coeficiente de variação deve ser menor que $15 \%$ e a exatidão deve estar entre 85 a $115 \%$. Os resultados desse estudo mantiveram-se dentro dos parâmetros recomendados pela ANVISA, 2003.

A precisão é o parâmetro que avalia a proximidade entre várias medidas efetuada em uma mesma amostra e pode ser expresso pelo cálculo do coeficiente de variação (CV\%), obtidos em condições de repetibilidade e/ ou reprodutibilidade.

De acordo com o ICH (1995) e ANVISA (2003) a repetibilidade deve ser verificada a partir de um mínimo de nove determinações cobrindo o limite especificado do procedimento (ex. três níveis, três repetições cada um), ou a partir de um mínimo de seis determinações a uma concentração similar ao valor esperado.

Nesse estudo a precisão foi calculada a partir de seis determinações de amostras realizadas em um curto intervalo de tempo nas mesmas condições (precisão intra-dia). A precisão inter-dias foi realizada nas mesmas condições após dois dias.

Os resultados para a precisão intra-e inter-dias estão na Tabela 16. Os valores dos monômeros residuais (M/M\%) variaram de 1,44 à 1,90 para o TEGDMA e de 2,95 à 3,93 para o BisGMA. 
Tabela 16 - Variabilidade intra- e inter-dias dos monômeros avaliados

\begin{tabular}{|c|c|c|c|c|c|c|c|}
\hline \multirow{2}{*}{\multicolumn{2}{|c|}{ Monômeros }} & \multicolumn{3}{|c|}{ Dia $1(n=6)$} & \multicolumn{3}{|c|}{ Dia $2(n=6)$} \\
\hline & & Média da & Média da & $C V(\%)$ & Média da & Média da & $C V(\%)$ \\
\hline \multirow{6}{*}{ 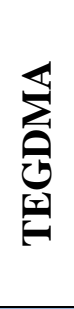 } & 1 & 93,37 & $1,66( \pm 0,03)$ & 2,19 & 112,92 & $1,89( \pm 0,03)$ & 1,87 \\
\hline & 2 & 94,66 & $1,75( \pm 0,01)$ & 0,91 & 92,94 & $1,72( \pm 0,05)$ & 3,09 \\
\hline & 3 & 74,29 & $1,68( \pm 0,10)$ & 6,46 & 98,60 & $1,76( \pm 0,08)$ & 4,67 \\
\hline & 4 & 82,74 & $1,88( \pm 0,04)$ & 2,31 & 98,57 & $1,90( \pm 0,11)$ & 5,97 \\
\hline & 5 & 102,51 & $1,76( \pm 0,03)$ & 1,84 & 64,88 & $1,62( \pm 0,08)$ & 5,43 \\
\hline & 6 & 86,51 & $1,44( \pm 0,01)$ & 1,30 & 98,59 & $1,76( \pm 0,04)$ & 2,24 \\
\hline \multicolumn{8}{|c|}{ Média entre o Dia 1 e o Dia $2=1,70( \pm 0,14)$ e $C V \%=8,5$} \\
\hline \multirow{6}{*}{$\sum_{\substack{n=0 \\
\infty}}^{\mathbb{S}}$} & $\mathbf{1}$ & 165,88 & $2,95( \pm 0,06)$ & 2,16 & 234,51 & $3,93( \pm 0,08)$ & 2,11 \\
\hline & 2 & 172,96 & $3,20( \pm 0,02)$ & 0,80 & 195,45 & $3,61( \pm 0,13)$ & 3,70 \\
\hline & 3 & 115,72 & $2,63( \pm 0,14)$ & 5,35 & 198,49 & $3,54( \pm 0,18)$ & 5,09 \\
\hline & 4 & 132,10 & $3,01( \pm 0,07)$ & 2,37 & 202,42 & $3,90( \pm 0,27)$ & 6,94 \\
\hline & 5 & 188,90 & $3,24( \pm 0,03)$ & 1,13 & 124,41 & $3,11( \pm 0,15)$ & 5,04 \\
\hline & 6 & 217,64 & $3,63( \pm 0,04)$ & 1,11 & 178,72 & $3,19( \pm 0,07)$ & 2,33 \\
\hline \multicolumn{8}{|c|}{ Média entre o Dia 1 e o Dia $2=3,11( \pm 0,30)$ e CV\% $=9,92$} \\
\hline
\end{tabular}

Os resultados de $\mathrm{M} / \mathrm{M} \%$ foram avaliados estatisticamente por ANOVA e teste de Tukey-Kramer $(\mathrm{p}<0.05)$. As medias das M/M\% e desvio padrões para o Dia 1 foram- 1,70 $\pm 0,14$ para o TEGDMA e 3,11 $\pm 0,3$ para o BisGMA e para o Dia 2 foram $-1,77 \pm 0,1$ para o TEGDMA e 3,55 $\pm 0,3$ para o BisGMA. Não foram observadas diferenças estatisticamente significantes quando comparados os resultados dos dias 1 e 2.

O coeficiente de variação (CV\%) entre os dias 1 e 2 foi de 8,65 para o TEGDMA e 9,92 para o BisGMA. Estes resultados estão de acordo com os critérios de recomendação do ICH (1995) e ANVISA (2003) que recomendam que o CV\% deve ser menor que $15 \%$.

O limite de detecção é definido com a menor concentração do analito presente na amostra que possa ser detectado, mas não quantificado. O limite de detecção do método observado foi de $4,5 \mu \mathrm{g} \mathrm{mL}^{-1}$ para o TEGDMA e $6 \mu \mathrm{g} \mathrm{mL}^{-1}$ para o BISGMA. Estes valores obtiveram a relação sinal-ruído de 5:1, baseados no ICH (1995).

O limite de quantificação é definido como a menor concentração do analito em uma amostra que pode ser determinado com precisão e exatidão aceitáveis nas condições operacionais do método. O limite de quantificação do método foi de $9 \mu \mathrm{g} \mathrm{mL}{ }^{-1}$ para o TEGDMA e $13 \mu \mathrm{g} \mathrm{mL}^{-1}$ para o BisGMA. Estes valores obtiveram a relação sinal-ruído de 10:1, baseados no ICH (1995). 
A robustez do método mostra a sensibilidade que este apresenta face a pequenas variações.

A robustez foi avaliada nesse estudo pela variação de parâmetros no método com o fluxo da fase móvel $\left(0,9,1,0\right.$ e $\left.1,1 \mathrm{~mL} \mathrm{~min}^{-1}\right)$ e temperatura da coluna $\left(53,55\right.$ e $\left.57^{\circ} \mathrm{C}\right)$ (Tabela 17). Os resultados foram avaliados pela ANOVA e teste de Tukey-Kramer $(\mathrm{p}<0.05)$

Tabela 17 - Robustez do método de determinação dos monômeros em função do fluxo e temperatura da coluna

\begin{tabular}{|c|c|c|}
\hline & $\begin{array}{c}\text { TEGDMA } \\
\text { (Média M/M\% - dp) }\end{array}$ & $\begin{array}{c}\text { BISGMA } \\
\text { (Média M/M\% - dp) }\end{array}$ \\
\hline \multicolumn{3}{|c|}{ Robustez Fluxo fase móvel } \\
\hline Fluxo $0.9 \mathrm{~mL} \min ^{-1}$ & $1,969( \pm 0,2)$ & $3,970( \pm 0,5)$ \\
\hline Fluxo $1.0 \mathrm{~mL} \mathrm{~min}^{-1}$ & $1,879( \pm 0,1)$ & $3,874( \pm 0,2)$ \\
\hline Fluxo $1.1 \mathrm{~mL} \mathrm{~min}^{-1}$ & $1,597( \pm 0,1)$ & $3,244( \pm 0,3)$ \\
\hline \multicolumn{3}{|l|}{$\begin{array}{c}\text { Robustez Temperatura } \\
\text { coluna }\end{array}$} \\
\hline $5^{\circ} \mathrm{C}$ & $1,901( \pm 0,2)$ & $3,938( \pm 0,4)$ \\
\hline $5^{\circ} \mathrm{C}$ & $1,879( \pm 0,1)$ & $3,874( \pm 0,2)$ \\
\hline $57^{\circ} \mathrm{C}$ & $1,817( \pm 0,1)$ & $3,707( \pm 0,3)$ \\
\hline
\end{tabular}

Baseado na análise estatística não foram observadas diferenças significantes entre os parâmetros avaliados, provando a habilidade do método em permanecer inalterado frente a pequenas variações de parâmetros no método desenvolvido.

Os resultados obtidos na validação demonstraram que o método desenvolvido foi suficientemente preciso e exato devido ao fato de os resultados manterem-se dentro dos parâmetros recomendados do ICH (1995) e ANVISA (2003).

\subsubsection{Determinação dos monômeros residuais nas amostras reais}

Foram determinados os valores de concentração média $\left(\mu \mathrm{g} \mathrm{mL}^{-1}\right)$, monômeros residuais (M/M\%) e o CV\% das resinas R1, R2 e R3 fotoativadas com LED e lâmpada halógena.

Os valores encontrados para a resina R1 fotoativada com LED e lâmpada halógena se encontram na Tabela 18. 
Tabela 18 - Monômeros residuais extraídos da resina R1 fotoativada com LED e lâmpada halógena $(n=6)$

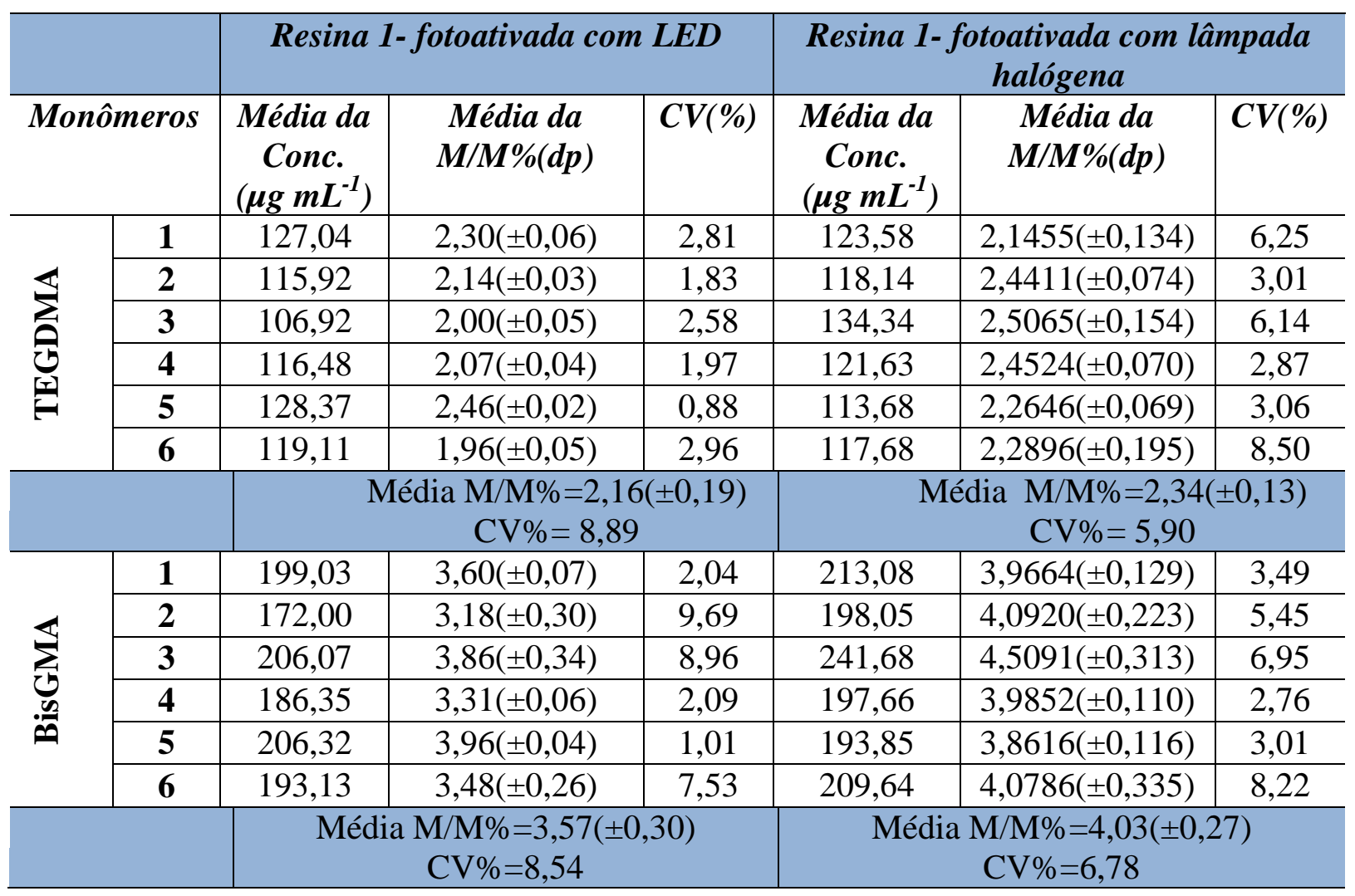

Para a resina $\mathrm{R} 1$, a quantidade de monômeros residuais (M/M\%) encontrados foi próxima quando se compara as duas fontes de fotoativação, tendo o aparelho de LED apresentado desempenho um pouco melhor.

Os valores médios para o monômero TEGDMA variaram de 2,16\% $\pm 0,19$ quando a resina $\mathrm{R} 1$ foi fotoativada por LED e 2,34\% $\pm 0,13$ quando fotoativada com lâmpada halógena. Para o monômero BisGMA os valores variaram de 3,57\% $\pm 0,30$ quando a $\mathrm{R} 1$ foi fotoativada com LED e 4,03\% $\pm 0,27$ quando fotoativada com lâmpada halógena.

Os valores encontrados de monômeros residuais TEGDMA e BisGMA para a resina R2 fotoativada com LED e lâmpada halógena se encontram na Tabela 19. 
Tabela 19 - Monômeros residuais extraídos da resina R2 fotoativada com LED e lâmpada halógena $(n=6)$

\begin{tabular}{|c|c|c|c|c|c|c|c|}
\hline & & \multicolumn{3}{|c|}{ Resina 2-fotoativada com LED } & \multicolumn{3}{|c|}{$\begin{array}{c}\text { Resina 2-fotoativada com lâmpada } \\
\text { halógena }\end{array}$} \\
\hline \multicolumn{2}{|c|}{ Monômeros } & $\begin{array}{c}\text { Média da } \\
\text { Conc. } \\
\left(\mu g \mathrm{~mL}^{-1}\right)\end{array}$ & $\begin{array}{l}\text { Média da } \\
M / M \%(d p)\end{array}$ & $C V(\%)$ & $\begin{array}{c}\text { Média da } \\
\text { Conc. } \\
\left(\mu g m L^{-1}\right)\end{array}$ & $\begin{array}{l}\text { Média da } \\
\text { M/M\%(dp) }\end{array}$ & $C V(\%)$ \\
\hline \multirow{6}{*}{ 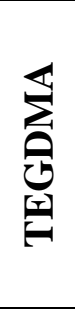 } & 1 & 188,79 & $3,52( \pm 0,30)$ & 8,59 & 148,28 & $1,97( \pm 0,03)$ & 1,66 \\
\hline & 2 & 183,21 & $3,45( \pm 0,02)$ & 0,69 & 120,29 & $2,15( \pm 0,04)$ & 2,17 \\
\hline & 3 & 182,25 & $3,50( \pm 0,07)$ & 2,18 & 108,55 & $1,84( \pm 0,02)$ & 1,12 \\
\hline & 4 & 185,89 & $3,41( \pm 0,10)$ & 2,95 & 118,10 & $2,07( \pm 0,05)$ & 2,56 \\
\hline & 5 & 179,54 & $3,45( \pm 0,04)$ & 1,27 & 104,86 & $1,73( \pm 0,02)$ & 1,38 \\
\hline & 6 & 195,09 & $3,61( \pm 0,13)$ & 3,65 & 128,20 & $2,06( \pm 0,08)$ & 3,92 \\
\hline & & \multicolumn{3}{|c|}{$\begin{array}{c}\text { Média M/M\%=3,49( } \pm 0,06) \\
\mathrm{CV} \%=1,98\end{array}$} & \multicolumn{3}{|c|}{$\begin{array}{c}\text { Média } \mathrm{M} / \mathrm{M} \%=1,97( \pm 0,15) \\
\mathrm{CV} \%=8,03\end{array}$} \\
\hline \multirow{6}{*}{$\sum_{\substack{\infty \\
\infty}}^{\mathbb{S}}$} & 1 & 395,14 & $7,37( \pm 0,50)$ & 6,89 & 270,03 & $4,77( \pm 0,16)$ & 3,45 \\
\hline & 2 & 415,64 & $7,84( \pm 0,06)$ & 0,78 & 317,48 & $5,68( \pm 0,10)$ & 1,89 \\
\hline & 3 & 391,31 & $7,52( \pm 0,10)$ & 1,44 & 289,72 & $4,92( \pm 0,22)$ & 4,56 \\
\hline & 4 & 383,22 & $7,04( \pm 0,14)$ & 2,04 & 298,65 & $5,25( \pm 0,13)$ & 2,54 \\
\hline & 5 & 388,04 & $7,46( \pm 0,06)$ & 0,87 & 272,48 & $4,51( \pm 0,05)$ & 1,17 \\
\hline & 6 & 442,47 & $8,19( \pm 0,22)$ & 2,74 & 321,45 & $5,18( \pm 0,18)$ & 3,51 \\
\hline & & \multicolumn{3}{|c|}{$\begin{array}{c}\text { Média M/M\%=7,57( } \pm 0,39) \\
\mathrm{CV} \%=5,26\end{array}$} & \multicolumn{3}{|c|}{$\begin{array}{c}\text { Média M/M\%= } 5,05( \pm 0,41) \\
\text { CV\% }=8,17\end{array}$} \\
\hline
\end{tabular}

Para a resina $\mathrm{R} 2$, a quantidade de monômeros residuais (M/M\%) encontrados foi maior quando se utilizou o aparelho de LED.

A maior quantidade de monômeros residuais extraídos dessa resina (R2) foi de 7,57 $\pm 0,39$, para o monômero BisGMA quando ela foi fotoativada com LED.

E a menor quantidade extraída da R2 foi para o monômero TEGDMA 1,97 $\pm 0,15$, quando essa resina foi fotoativada com lâmpada halógena.

Os valores dos monômeros residuais TEGDMA e BisGMA extraídos da resina R3 fotoativada com LED e lâmpada halógena se encontram na Tabela 20. 
Tabela 20 - Monômeros residuais extraídos da resina R3 fotoativada com LED e lâmpada halógena $(n=6)$

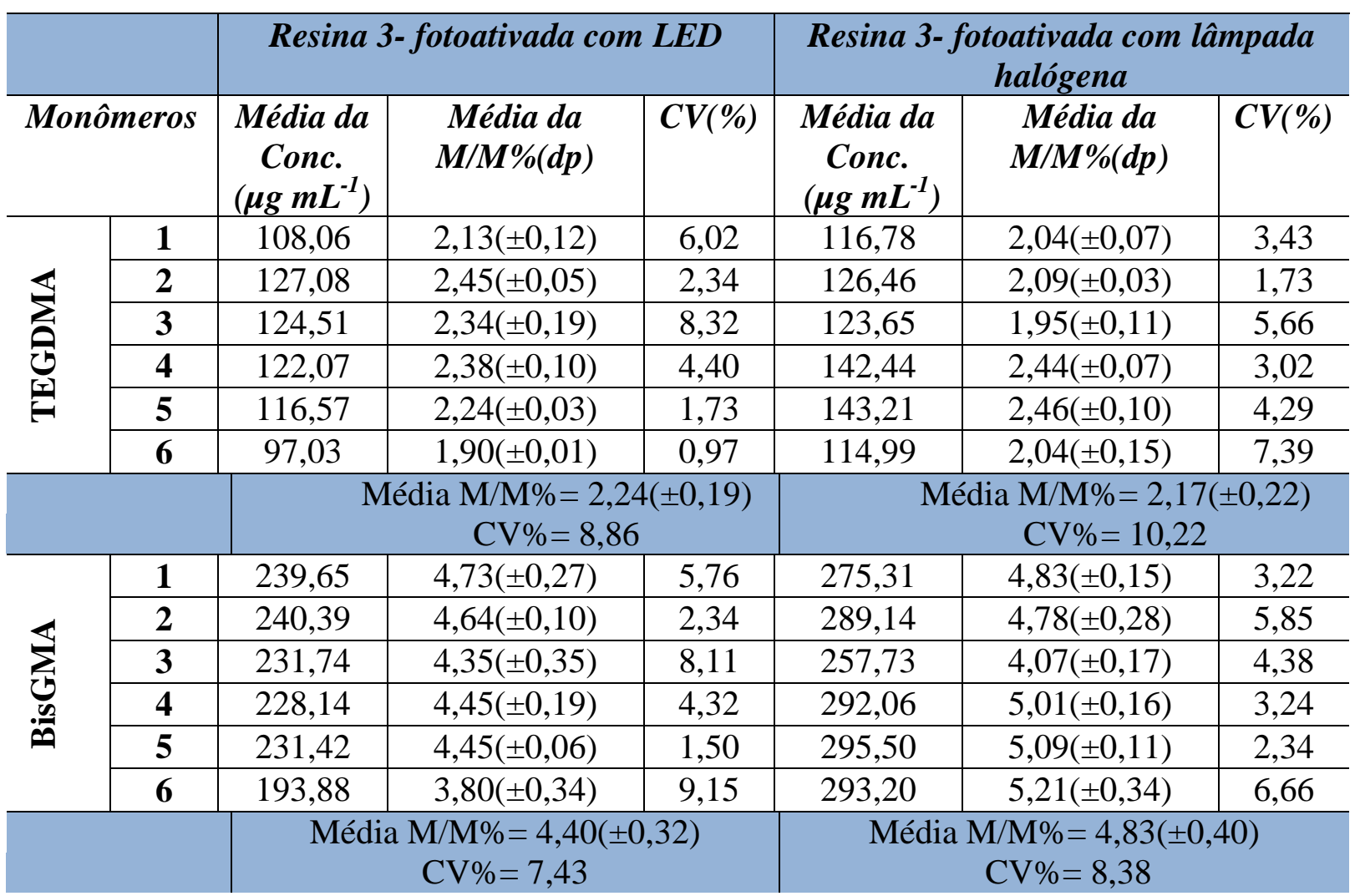

Para a resina $\mathrm{R} 3$, a quantidade de monômeros residuais (M/M\%) encontrados foi muito parecida quando se utilizou as duas diferentes fontes de fotoativação (lâmpada halógena e LED).

A quantidade de monômeros residuais extraídos da resina R3 para o monômero TEGDMA foi de 2,24 $\pm 0,19$ quando fotoativada com LED e 2,17 $\pm 0,22$ quando fotoativada com lâmpada halógena. E para o BisGMA foi de 4,40 $\pm 0,32$ quando fotoativada com LED e 4,83 $\pm 0,40$ quando fotoativada com lâmpada halógena.

A partir da observação de diferenças númericas entre os grupos, foi realizada a análise estatística para se verificar a possibilidade de significância entre os valores encontrados, tanto para o monômero TEGDMA, quanto para o monômero BisGMA para as três resinas (R1, R2 e R3) fotoativadas pelas duas fontes de luz (LED e lâmpada halógena). Utilizou-se análise de variância (ANOVA) e o teste post-hoc de Tukey com nível de significância de 5\% (p<0,05). Na Tabela 21 encontram-se os resultados para o monômero TEGDMA. 
Tabela 21 - Média, desvio padrão e resultado da Análise de Variância e Teste de Tukey para os monômeros residuais TEGDMA

\begin{tabular}{ccccccc}
\hline \multirow{2}{*}{ Resina } & \multicolumn{2}{c}{ LED } & & \multicolumn{2}{c}{ lâmpada halógena } \\
\cline { 2 - 3 } \cline { 5 - 6 } R1 & média & $\mathrm{dp}$ & & média & $\mathrm{dp}$ \\
\hline R2 & $3,16^{\mathrm{ab}}$ & $\pm 0,19$ & & $2,35^{\mathrm{b}}$ & $\pm 0,14$ \\
R3 & $3,49^{\mathrm{c}}$ & $\pm 0,07$ & & $1,98^{\mathrm{a}}$ & $\pm 0,16$ \\
& $2,24^{\mathrm{ab}}$ & $\pm 0,20$ & & $2,18^{\mathrm{ab}}$ & $\pm 0,22$
\end{tabular}

Grupos com a mesma letra sobrescrita não possuem diferença estatisticamente significante entre si.

Com a análise estatística foi possivel determinar que a quantidade de monômeros residuais TEGDMA, em relação a comparação entre fontes de luz, ocorreu diferença significante somente para a resina R2, sendo que esta apresentou maior quantidade de monômeros residuais $(3,49 \% \pm 0,07)$ quando esta resina foi fotoativada com LED.

Quando as resinas foram fotoativadas com a lâmpada halógena, a resina R1 não apresentou diferença significante da resina R3, mas apresentou em relação a resina R2. Quando estas foram fotoativadas pelo LED, a resina R2 apresentou diferença das demais resinas sendo estatísticamente significante.

Dessa maneira constatamos que as resinas R1 e R3 apresentaram comportamentos semelhantes em relação a quantidade de monômeros residuais TEGDMA determinados pelo método de HPLC, ilustrado na Figura 34. 
Figura 34- Gráfico da média e desvio padrão dos monômeros residuais TEGDMA

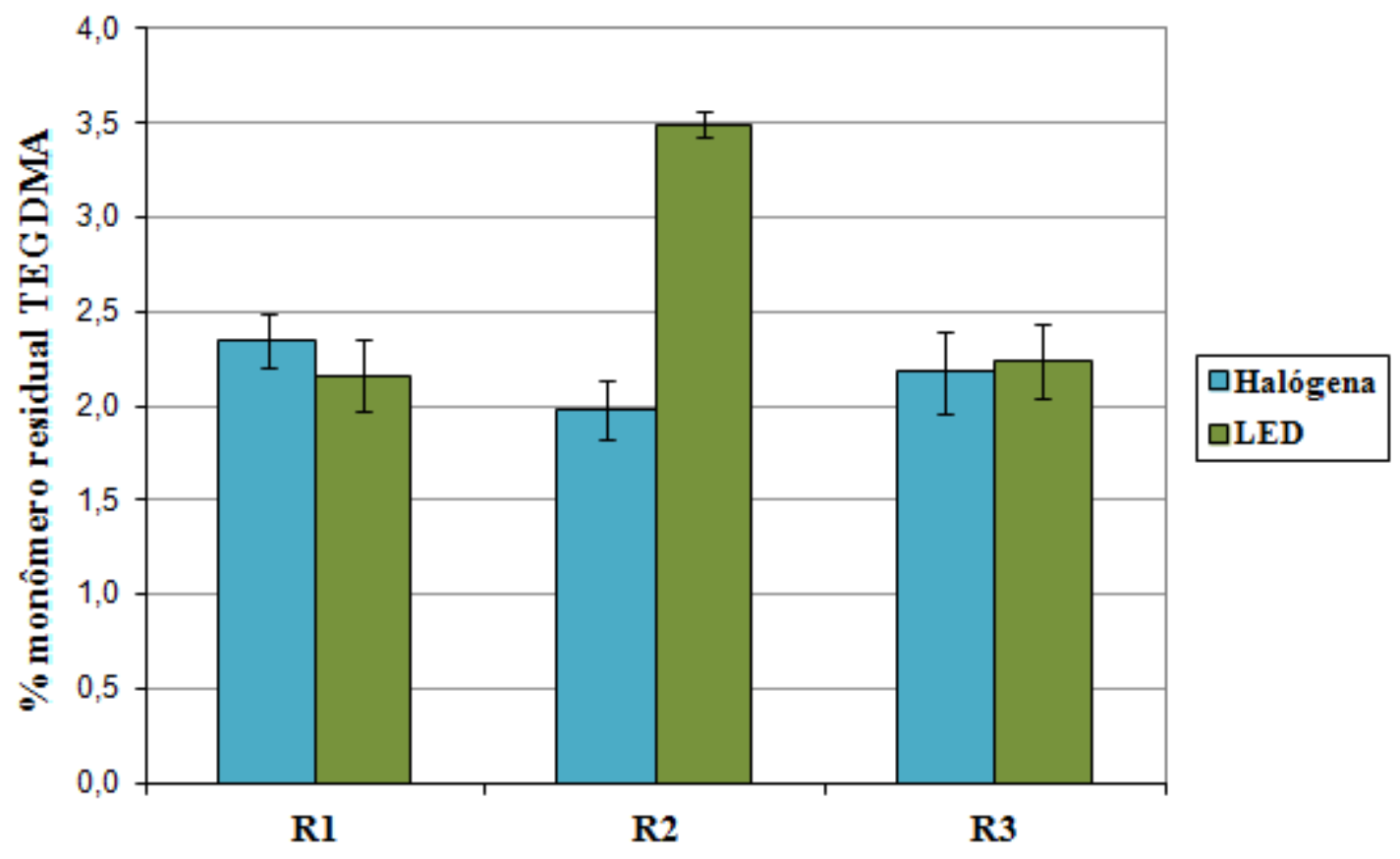

Os resultados da análise estatística para os monômeros residuais BisGMA encontramse na Tabela 22.

Tabela 22 - Média, desvio padrão e resultado da Análise de Variância e Teste de Tukey para os monômeros residuais BisGMA

\begin{tabular}{ccccccc}
\hline \multirow{2}{*}{ Resina } & \multicolumn{2}{c}{ LED } & & \multicolumn{2}{c}{ lâmpada halógena } \\
\cline { 2 - 3 } \cline { 5 - 6 } R1 & média & $\mathrm{dp}$ & & média & $\mathrm{dp}$ \\
\hline R2 & $3,57^{\mathrm{a}}$ & $\pm 0,30$ & & $4,08^{\mathrm{ab}}$ & $\pm 0,23$ \\
R3 & $7,57^{\mathrm{e}}$ & $\pm 0,40$ & & $5,06^{\mathrm{d}}$ & $\pm 0,41$ \\
& $4,41^{\mathrm{bc}}$ & $\pm 0,33$ & & $4,84^{\mathrm{cd}}$ & $\pm 0,41$
\end{tabular}

Grupos com a mesma letra sobrescrita não possuem diferença estatisticamente significante entre si.

Em relação aos resultados da análise estatística dos monômeros residuais BisGMA, foi possivel determinar que ocorreu diferença significante na quantidade de monômeros residuais em relação as fontes de luz somente para a resina $\mathrm{R} 2$, sendo que esta apresentou maior 
quantidade de monômeros residuais $(7,57 \% \pm 0,40)$ quando esta resina foi fotoativado com LED, como ocorreu com os monômeros residuais TEGDMA.

Quando as resinas foram fotoativadas com lâmpada halógena, a resina R2 não obteve diferença significante na quantidade de monômeros residuais em relação a resina R3, mas ambas tiveram significância em relação a resina R1 que apresentou menor quantidade de monômeros residuais BisGMA $(4,08 \% \pm 0,23)$.

Em relação a fotoativação com LED, todas as resinas apresentaram diferenças significantes entre $\mathrm{si}$, tendo a resina $\mathrm{R} 1(3,57 \% \pm 0,30)$ apresentado menor quantidade de monômeros residuais, seguida pela R3 $(4,41 \% \pm 0,33)$ e depois a R2 $(7,57 \% \pm 0,40)$ que apresentou maior quantidade de monômeros BisGMA residuais. Entretanto, quando as resinas R1 e R3 fotoativadas com LED foram comparadas com a resina R1 fotoativada com lâmpada halógena essas não obtiveram diferenças significantes entre elas. Isto significa, de certa forma, que a associação do PPD + CQ na resina (R3) quando fotoativada com o LED leva a uma menor liberação de monômeros BisGMA, semelhante aos resultados encontrados na resina contendo somente CQ $(\mathrm{R} 1)$ fotoativada pela lâmpada halógena.

Esses resultados estão melhor ilustrados na figura 35 .

Figura 35- Gráfico da média e desvio padrão dos monômeros residuais BisGMA

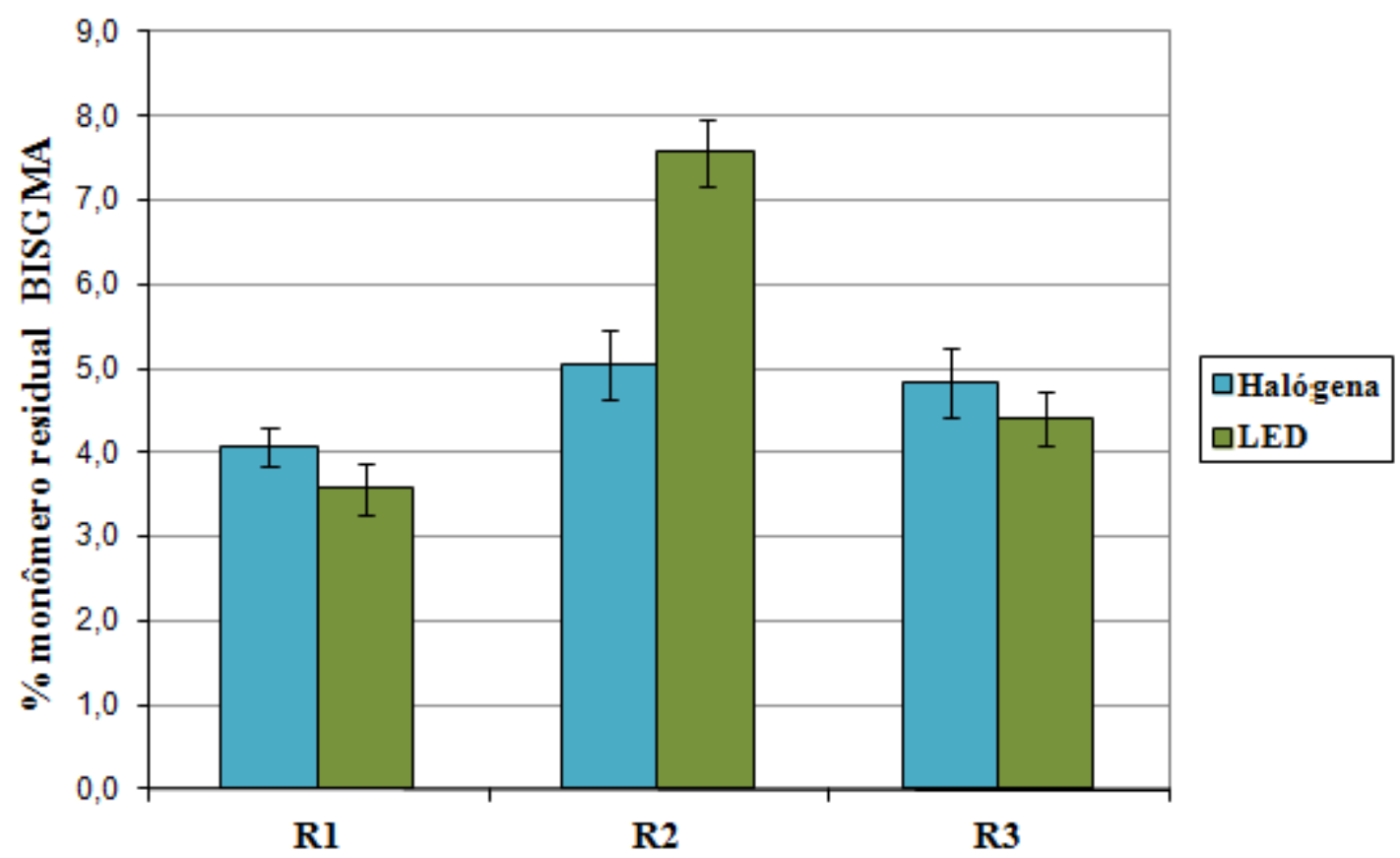


Com esses resultados foi possível observar que o monômero BisGMA foi liberado em maior quantidade que o monômero TEGDMA.

A resina R1, que possui como fotoiniciador somente a canforoquinona, obteve uma menor quantidade de monômeros residuais e a resina R2 que possui como fotoiniciador somente o PPD obteve uma maior quantidade de monômeros residuais.

A resina $\mathrm{R} 3$ com os dois fotoiniciadores ( $\mathrm{CQ}+\mathrm{PPD}$ ) apresentou um resultado próximo ao da resina $\mathrm{R} 1$, principalmente em relação a quantidade de monômeros TEGDMA residuais. 


\section{DISCUSSÃO}

Neste estudo foi demonstrado que a associação do fotoiniciador PPD à CQ levou a alterações na cinética da reação de polimerização da resina quando comparada com uma resina que possui somente o fotoiniciador CQ na sua composição.

O valor do grau de conversão de uma resina normalmente está em torno de 45 a 75\%, pois a reação de polimerização da resina nunca ocorre por completo, ficando dessa maneira monômeros não convertidos (FERRACANE; CONDOR, 1990; FERRACANE, 1994; PEUTZFELDT; ASMUSSEN, 2005). Entretanto, valores mínimos de grau de conversão para aplicação clínica da resina não são bem estabelecidos.

Essa reação incompleta de polimerização ocorre devido principalmente à característica do monômero BisGMA que apresenta em sua molécula grupos aromáticos no centro da cadeia que impedem o livre movimento dos dois grupos acrílicos existentes na extremidade da cadeia (ANDRZEJEWSKA, 2001). Devido essa rigidez o monômero torna-se muito viscoso requerendo um comonômero que geralmente é o trietilenoglicol dimetacrilato (TEGDMA) para ajustar a viscosidade. Como resultado, somente um grupo metacrilato é reativo, enquanto o outro fica menos ativo e apenas ocasionalmente consegue estabelecer uma polimerização cruzada (crosslink) com a molécula adjacente. Isto leva a um baixo grau de conversão. Geralmente a viscosidade da mistura BisGMA/ TEGDMA deve estar entre 1 e 2 Pa s, o que corresponde a proporções em peso entre 50\%/50\% e 70\%/30\% respectivamente (SIDERIDOU et al., 2002; PALACIO; ZAVAGLIA, 2003). Alguns trabalhos demonstraram que a incorporação de menores quantidades do monômero diluente TEGDMA, em relação ao BisGMA proporcionam um material com propriedades mecânicas superiores e menores valores de contração de polimerização (ELLIOT et al., 2001; SIDERIDOU et al., 2002), justificando dessa maneira a proporção BisGMA70\%/TEGDMA30\% utilizada nesse trabalho.

Em relação aos resultados de grau de conversão monomérica total após 300 segundos, a resina R3, que possui como fotoiniciadores a associação do PPD + CQ, apresentou valores intermediários em relação as demais resinas. Os maiores valores de conversão foram para a resina $\mathrm{R} 1$ tanto fotoativada com $\operatorname{LED}(65,90 \% \pm 1,81)$ quanto com a lampâda halógena $(64,40 \% \pm 0,83)$, e os menores valores encontrados ocorreram quando a resina R2 foi fotoativada pelo $\operatorname{LED}(33,64 \% \pm 1,73)$. A única resina que apresentou diferenças significantes em relação as fontes de luz foi a R2, conforme demonstrado na Tabela 4.

Essa diferença nos valores de grau de conversão monomérica em relação às fontes de luz, ocorreu principalmente na resina R2 devido a diferença no comprimento de onda desses 
equipamentos. Enquanto o aparelho de LED (Poly 600/Kavo) possui um comprimento de onda de 440-480 nm, o aparelho de lâmpada halógena (Demetron LC/SDS Kerr) possui um comprimento de onda de 400-525 nm. O aparelho de LED, obteve o pior desempenho geral quando fotoativou a resina R2 que possuía como fotoiniciador somente o PPD, mas em compensação quando fotoativou a resina $\mathrm{R} 1$ com somente $\mathrm{CQ}$, este aparelho obteve o melhor desempenho geral e valores comparáveis a lâmpada halógena quando fotoativou a resina R3 com CQ + PPD.

Segundo Neumann et al. (2005) o comprimento de onda do PPD é perfeitamente coberto pelos aparelhos de lâmpada halógena, mas não é totalmente atingido pela grande maioria dos aparelhos de LED, devido ao seu estreito espectro de emissão. Isso faz com que as resinas contendo esses diferentes fotoiniciadores, não sejam adequadamente polimerizadas por estes aparelhos, podendo apresentar baixo grau de conversão e baixas propriedades mecânicas (UHL et al., 2003; NEUMANN et al., 2005; OGUNYINKA et al., 2007). Alguns autores acreditam que essa menor eficiência não se deve somente a característica de absorção de luz desse fotoiniciador, mas também, a características fotoquímicas sendo este menos reativo (SCHROEDER et al., 2007, SCHNEIDER et al., 2009b).

Em compensação, a associação dos dois fotoiniciadores (CQ + PPD) produz um pico máximo de absorção de luz em torno de 452 nm (SCHNEIDER et al., 2008), possibilitando perfeitamente sua ativação por aparelhos dentro da faixa azul do espectro eletromagnético conforme observado neste trabalho.

Entretanto trabalhos recentes como de Brandt et al. (2011), observaram que a resina com fotoiniciador PPD obteve valores menores de grau de conversão quando fotoativada com aparelho de lâmpada halógena e valores de grau de conversão similares da resina com fotoiniciador CQ, quando fotoativada com aparelhos de LED e eles acreditam que essa efetividade ocorreu devido a altas doses de energia $\left(35,5 \mathrm{~J} \mathrm{~cm}^{-2}\right)$ que os equipamento de LED de terceira geração como o Ultralume LED5/Ultradent $\left(1.315 \mathrm{~mW} \mathrm{~cm}{ }^{-2}\right)$ apresentam, considerando não somente o espectro de distribuição da fonte de luz, que é mais amplo para esses equipamentos, mas também a habilidade de absorção de luz pelo fotoiniciador. Segundo Schneider et al. (2008), fica bem claro em seu trabalho a importância da densidade de potência absorvida na cinética da reação e propriedades finais do polímero formado quando considerada a comparação entre CQ e PPD.

Alguns trabalhos mostraram um melhor resultado de grau de conversão para resinas contendo somente o PPD quando comparadas à resinas contendo a CQ (PARK et al. 1999; SUN; CHAN 2000; PALACIO; ZAVAGLIA, 2003; ASMUSSEN; PEUTZFELDT, 2002. 
Segundo Park et al. (1999) e Sun e Chan (2000) pode existir a possibilidade de um efeito sinérgico na combinação da $\mathrm{CQ}+\mathrm{PPD}$, resultante de um segundo modo de geração de radicais livres, por meio da abstração de fótons e fotoclivagem. Além do que essa combinação poderia promover um maior espectro de absorção também aumentando a eficiência do sistema fotoiniciador. Entretando Neumann et al. (2006) não encontraram esse efeito sinérgico. Neste trabalho observamos um valor intermediário do grau de conversão monomérica para a resina com os dois fotoiniciadores CQ + PPD, resultados também observados por Schneider et al. (2009a) quando os fotoiniciadores foram utilizados em baixas concentrações e na proporção de 1:1 (fotoiniciador : amina) como neste trabalho. Mas Schneider et al. (2009a) e Brandt et al. (2011) não encontraram diferença significante entre a resina com CQ + PPD e a com somente CQ.

A relação entre fotoiniciador e co-iniciador também podem interferir no resultado final do grau de conversão. Alguns estudos realizados com PPD sugerem que a presença da amina terciaria não é fundamental para a reação de polimerização, por ser um fotoiniciador do tipo I que gera radicais livres por fragmentação de suas moléculas (fotoclivagem), sendo assim o PPD menos dependente do co-iniciador para gerar radicais livres, (PARK et al. 1999; SUN; CHAN 2000; NEUMANN et al. 2006). Entretanto, outros estudos mais recentes demonstraram uma melhor efetividade do PPD com a utilização de um co-iniciador, por isso existem ainda algumas dúvidas a respeito do mecanismo de formação de radicais livres desse fotoiniciador (EMAMI; SÖDERHOLM, 2005; SCHROEDER et al., 2007; SCHNEIDER et al., 2009b).

A taxa da amina (co-iniciador) também é um fator estudado. Diferentes quantidades de amina em relação ao fotoiniciador promovem diferentes resultados. Valores variando de $0,1 \%$ à 3,5\% em peso foram estudados (PARK et al., 1999; STANSBURRY, 2000; PALACIO; ZAVAGLIA, 2003; SCHNEIDER et al., 2008; SCHNEIDER et al., 2009a; BRANDT et al., 2011). Todavia, concentrações altas de fotoiniciador podem comprometer a estética final da resina principalmente aquelas de cores mais claras. Além disso, o aumento também de amina no sistema de fotoiniciação é limitada devido sua característica citotóxica, carcinogênica e mutagênica (NIE; BOWMAM, 2002). A amina em excesso pode retardar o processo reacional, podendo também contribuir para o amarelamento inicial do polímero e para o escurecimento posterior da resina, devido a rápida oxidação sofrida por estes compostos (STUDER \& KONIGER, 2001).

Park et al. (1999), estudaram diferentes quantidades de fotoiniciadores, que variaram de 0 à $3,2 \%$ em peso, além da mistura dos dois agentes até o limite de 3,4\% em peso, e 
observaram que o maior grau de conversão ocorreu na combinação de PPD e CQ nas proporções de 1:1 à 1:4. Maiores concentrações de PPD aumentaram o grau de conversão, o que não ocorreu com a CQ que não mostrou melhorias em altas concentrações. Schneider et al (2009a) também estudaram diferentes taxas de fotoiniciador e amina para a CQ e o PPD. As taxas estudadas foram: $2: 1,1: 1,1: 15$ e $1: 2$, sendo a quantidade de fotoiniciador de $0,3 \% \mathrm{em}$ peso e a amina variou de 0,15\% à 0,6\% em peso. Observaram que as de taxas de 1:15 e 1:2 obtiveram melhor resultado independente do tipo de fotoiniciador. Segundo Peutzfeldt \& Asmussen (1989) as concentrações de canforoquinona e amina na ordem de 0,1 a 0,2\% são as mais aceitáveis, e não apenas a quantidade, mas também o tipo de amina, é muito importante para as propriedades físicas do material.

Segundo alguns trabalhos (PARK et al. 1999; SUN; CHAE, 2000; STANSBURRY, 2000; NEWMANN et al., 2006) o fotoiniciador PPD pode apresentar como vantagem em relação a CQ a diminuição no grau de amarelamento da resina, pois o PPD apresenta uma coloração mais clara que a CQ facilitando sua incorporação à resina em maiores quantidades. Entretanto Schneider et al. (2008), provaram que esta diminuição no grau de amarelamento da resina ocorre somente quando o PPD é utilizado em concentrações baixas $(0,33 \%)$.

Além disso, alguns autores acreditam que a reação de polimerização com o fotoiniciador PPD ocorre mais lentamente (EMAMI; SODERHOLM, 2005; SCHNEIDER et al., 2009; BRANDT et al., 2011), levando dessa maneira a uma diminuição na taxa máxima de conversão $\left(\operatorname{Rp}^{\text {máx }}\right)$, sem alteração nos valores de grau de conversão quando comparados a uma resina com fotoiniciador CQ (EMAMI; SODERHOLM, 2005; ASMUSSEN; PEUTZFELDT, 2002; SCHNEIDER et al., 2008; BRANDT et al., 2011).

Neste trabalho foi demonstrado que os valores da $\mathrm{Rp}^{\text {máx }}$ diminuíram nas resinas que apresentavam o fotoiniciador PPD concordando com os demais autores (Tabela 6). O valor mais alto encontrado da $\mathrm{Rp}^{\text {máx }}$ foi para a resina $\mathrm{R} 1(3,13 \% / \mathrm{s} \pm 0,31)$ fotoativada por lâmpada halógena e o valor mais baixo foi para resina $\mathrm{R} 2(1,26 \% / \mathrm{s} \pm 0,30)$ fotoativada por LED. Entretanto, diferentes valores de grau de conversão monomérica foram encontrados para as 3 resinas estudas R1, R2 e R3 sendo esses valores significantes entre si (Tabela 4).

O efeito sinérgico entre CQ + PPD conforme Park et al. (1999) encontraram em seu trabalho, obtendo valores de conversão maiores para essa associação, não foi demonstrado neste trabalho. Essa diferença pode ter ocorrido devido a altas concentrações utilizadas do fotoiniciador por esses autores $(1,8 \%$ em peso na proporção de $1: 1)$. Neste trabalho utilizamos uma concentração bem menor de $0,1 \%$ em peso de CQ + 0,1\% em peso de PPD sendo uma proporção de 1:1 com o co-iniciador. Outros autores também não observaram esse efeito 
sinérgico com essa associação dos fotoiniciadores e sim uma similaridade nos valores do grau de conversão quando comparado com a CQ (SCHNEIDER et al., 2008; SCHROEDER et al, 2007; SCHNEIDER et al., 2009; BRANDT et al., 2011). Entretanto, Corrêa et al. (2003) observou valores mais baixos de conversão quando associou PPD com $\mathrm{CQ}$, menores do que as resinas com somente PPD ou CQ/ amina. Ele acredita que uma possível explicação seria a reação do PPD com a matriz resinosa usada por ele, alterando os valores de absorção desta resina, devido a alteração na conformação dos grupos carbonila.

Portanto, a primeira hipótese do trabalho não está correta, pois a resina com dois fotoiniciadores (CQ + PPD) obteve menores valores de grau de conversão monomérica quando comparada com a resina com somente CQ. Entretanto, a segunda hipótese do trabalho está correta, pois esta resina apresentou melhor desempenho em relação a taxa máxima de polimerização $\left(\mathrm{Rp}^{\mathrm{máx}}\right)$, isto é obteve um menor valor de $\mathrm{Rp}^{\text {máx }}$.

Segundo Schneider et al. (2009b) essa reação mais lenta, devido a menor taxa máxima de polimerização $\left(\mathrm{Rp}^{\text {máx }}\right)$ promovida pelo fotoiniciador PPD leva a uma redução na taxa máxima de tensão, diminuindo consequentemente a formação de fendas, que podem levar a microinfiltração da restauração e sensibilidade pós-operatória.

O tempo de ocorrência da taxa máxima de conversão $\left(t_{\text {máx }}\right)$ aconteceu mais rapidamente para a resina com CQ. A adição do PPD nas resinas permitiu que o $t_{\text {máx }}$ ocorresse mais tardiamente. A ocorrência da taxa máxima de conversão variou desde um tempo de $4,20 \mathrm{~s} \pm 0,45$ segundos até $9,40 \mathrm{~s} \pm 0,55$ segundos (Tabela 8 ), sendo assim, resinas que apresentavam o PPD em sua composição apresentaram uma reação mais lenta. Resultados similares também foram encontrados por outros autores (SCHNEIDER et al., 2008). Além disso uma pequena diferença do $t_{\text {máx }}$ no próprio grupo foi encontrada (Tabela 7), o que pode ter ocorrido devido ao fato que o acionamento do gatilho do fotoativador é controlado manualmente e uma pequena diferença no instante de acionamento pode produzir diferentes $t_{m a ́ x}$, detectados pela espectroscopia infravermelha em tempo real.

Schneider et al. (2009a) acreditam que uma explicação para as resinas com PPD apresentarem um $\mathrm{t}_{\text {máx }}$ mais tardiamente, é o fato que sistemas com PPD podem ser menos reativos como resultado de uma menor interação com o co-iniciador. Além disso, essas resinas com PPD tendem a alcançar valores de polimerização mais lentamente que as com $\mathrm{CQ}$, pois a taxa e a velocidade de polimerização são dependentes da densidade de energia absorvida pela resina (SCHNEIDER et al., 2008). 
Baseados nos valores de $t_{\text {máx }}$, é importante observar que protocolos de fotoativação de resina onde são recomendados tempos de exposição iniciais reduzidos, podem prejudicar o grau de conversão total da resina, consequentemente as propriedades desta.

Denis et al. (2012b) demonstraram que é possível conseguir também uma diminuição no tempo em que ocorre a taxa máxima de conversão da resina ( $t_{\text {máx }}$ ) utilizando uma modulação da fotoativação, isto é, a intensidade de luz do aparelho de fotoativação inicia-se mais baixa e aumenta após alguns segundos. Acredita-se que essa diminuição na intensidade de luz inicialmente proporciona uma melhor acomodação das moléculas, diminuindo as tensões de contração da resina devido a uma reação de conversão mais lenta (SAKAGUCHI; BERGE, 1998). Entretanto, alguns autores acreditam que a lenta polimerização inicial fornece poucos centros de formação do polímeros, resultando em uma estrutura mais linear com baixo grau de reticulação, podendo assim, ocasionar o aumento do desgaste e degradação da resina no meio bucal, sendo esse fato ainda muito controverso (ASMUSSEN; PEUTZFELDT, 2001a; SOH; YAP, 2004).

Todas as resinas preparadas neste trabalho apresentaram valores de grau de conversão similares no $t_{m a ́ x}$, isto é, no tempo em que ocorreu a taxa máxima de conversão. Os valores variaram de $11,90 \% \pm 2,79$ à $15,33 \% \pm 1,17$ (Tabela 10). Isto significa que o tipo do fotoiniciador utilizado não influenciou no valor do grau de conversão quando ocorreu a $\mathrm{Rp}^{\text {máx }}$ concordando com o trabalho de Schneider et al. (2009b).

Após ocorrer $0 \mathrm{t}_{\text {máx, }}$ a mobilidade das cadeias polimérica torna-se progressivamente mais restrita em consequência do aumento na viscosidade e redução do volume livre, ficando a reação de propagação limitada. Dessa maneira, as reações tornaram-se controladas por difusão. Esse comportamento é conhecido como efeito Trommsdorff ou simplismente efeito gel (ANDRZEJEWSKA, 2001).

A formação da estrutura polimérica na reação de polimerização da resina ocorre na fase de propagação e inclui uma mistura de cadeias lineares, ligações cruzadas e um emaranhado de segmentos de cadeias interpenetradas (ANDRZEJEWSKA, 2001). A redução na efetividade da densidade das ligações cruzadas pode reduzir a resistência mecânica e resistência à ação de solventes (SIDERIDOU et al., 2011). Por isso uma polimerização insuficiente da resina composta interfere também não só nas propriedades mecânicas do material, mas também nas propriedades biológicas, favorecendo a liberação de seus componentes não ligados a rede polimérica, podendo estes monômeros residuais alcançarem à polpa dentária via túbulos dentinários, além de poderem causar reações alérgicas, efeitos citotóxicos e genotóxicos (WATAHA et al., 1999; SCHWENGBERG et al., 2005; 
CAMPANHA et al., 2006; GOLDBERG, 2008). Dessa maneira, uma melhor polimerização do material melhora também a sua biocompatibilidade, uma vez que ela está associada, principalmente à natureza e quantidade dos componentes liberados (PALACIO; ZAVAGLIA, 2003).

Menos de $10 \%$ do percentual de monômeros residuais dos grupos metacrilatos são capazes de serem extraídos da resina e o restante encontra-se ligado a rede polimérica como grupamento pendente na cadeia (FERRACANE, 1994), esses monômeros que são parcialmente reagidos, podem produzir um efeito plastificante no polímero mas não são passíveis de solubilização (VAKIPARTA et al., 2006). Somente os monômeros, que não participam da formação da rede polimérica, podem ser extraídos da massa polimérica por meios aquosos ou solventes orgânicos (FERRACANE, 1994; MULLER et al., 1997). O tipo de solvente usado na extração pode ter efeito significante na quantidade de monômeros residuais extraídos (FERRACANE, 1994; MOHARAMZADEH et al., 2007).

O tempo de extração também pode influenciar na quantidade de monômeros residuais extraídos (WATAHA et al., 1999; FERRACANE, 1994). Entretanto, Ferracane e Condor (1990) demonstraram que $75 \%$ dos monômeros residuais foram extraídos nas primeiras três horas em solvente orgânico (etanol/água) e 50\% em água e que o tempo de 24 horas é suficiente para extração total de monômeros residuais (FERRACANE; CONDOR 1990; PELKA et al., 1999). Mas outros estudos em meio aquoso, mostraram que a liberação total pode levar semanas. Segundo Wataha et al. (1999), monômeros residuais continuam sendo liberados até 14 dias em saliva artificial em quantidades suficientes para causar efeitos citotóxicos in vitro.

Na otimização do método cromatográfico para análise dos monômeros residuais foi observada uma maior extração nas primeiras 24 horas, concordando com o trabalho de Ferracane e Condor (1990). O solvente orgânico que obteve melhor desempenho para extração dos monômeros foi a acetonitrila também utilizado por Pelka et al. (1999).

Segundo Muller et al. (1997) moléculas monoméricas que possuem estrutura menor e mais flexível tem pouca polaridade, sendo assim mais fácil a difusão através da rede polimérica quando comparado com uma molécula maior e mais complexa. Baseado nisso o monômero TEGDMA é o mais favorável estruturalmente para se difundir facilmente através da rede polimérica podendo este ser liberado em maiores quantidades que o BisGMA.

Entretanto, quando avaliamos a quantidade de monômeros residuais obtidos pela técnica de cromatografia (HPLC), foi possível observar que o monômero BisGMA foi liberado em maior quantidade que o monômero TEGDMA, resultado esse também encontrado 
em outros trabalhos (KOMURCUOGLU et al., 2005; POLYDOROU et al., 2007). A explicação para esse fato é que dependendo da interação solvente-monômero, o solvente pode facilitar a difusão desse monômero. Sendo assim o monômero TEGDMA que tem baixa hidrofobicidade pode ser encontrado em grandes quantidades em meio aquoso, entretanto o monômero BisGMA que apresenta uma natureza hidrofóbica faz com que essas moléculas sejam menos liberadas em soluções aquosas, mas com o uso de solventes orgânicos é possível a esse extração deste.

Segundo Muller et al. (1997), o uso de solventes orgânicos é a melhor escolha se o objetivo do trabalho for verificar a quantidade total de monômeros residuais presentes na resina. Entretanto, a quantidade de monômeros extraídos não necessariamente é a quantidade de monômeros liberados em água ou saliva, sendo assim a extração com solventes uma condição limítrofe.

A quantidade de monômeros extraídos neste trabalho variou de $1,98 \% \pm 0,16 \%$ à $3,34 \% \pm 0,07 \%$ para os monômeros TEGDMA e de 3,57\% $\pm 0,30 \%$ à 7,57\% $\pm 0,40 \%$ para os monômeros BisGMA (Tabelas 21 e 22). Esses valores correspondem a resultados encontrados também por outros autores (FERRACANE; CONDOR 1990; MUNKSGAARD et al., 2000; BAGIS; RUEGGEBERG, 2000). Entretanto, maiores e menores quantidade de monômeros residuais também foram observadas em outros trabalhos (SPAHL et al., 1998; VAKIPARTA et al., 2006; MILETIC et al., 2009).

Segundo Ferracane e Condor (1990), quando os monômeros foram extraídos em água os valores variaram de 0,5 à $2 \%$ em peso, já em etanol $75 \%$ foi de 2 à $6 \%$ e para Rathbun et al. (1991) os valores variaram com diferentes solventes orgânicos como etanol (4,6\%), clorofórmio $(7,5 \%)$ e tolueno $(11 \%)$ em extração realizada por 7 dias. Essas diferenças ocorrem porque o solvente orgânico é mais eficiente para extrair componentes da resina do que o meio aquoso, devido a habilidade de penetrar na matriz polimérica e expandir os espaços entre as cadeias, facilitando assim a liberação desses monômeros não reagidos.

É difícil uma comparação entre trabalhos em relação a quantidade de monômeros residuais extraídos, pois muitos fatores podem influenciar no resultado como: o tipo de solvente utilizado para a extração, o volume de extração do meio, o tempo de extração, o tamanho da amostra utilizada. Além disso, não existe uma padronização na unidade a ser utilizada para quantificar esses monômeros. Uma grande variedade de unidades já foram utilizadas como: $\mu \mathrm{g} \mathrm{mL}^{-1}$, $\mathrm{ppm}, \mathrm{mmol} \mathrm{mL} \mathrm{m}^{-1}, \mathrm{mg} \mathrm{g}^{-1}, \mathrm{M} / \mathrm{M} \%, \mu \mathrm{g} \mathrm{cm}^{-2}, \mathrm{~mol} \mathrm{~m}^{-2}, \mathrm{~mol} \mathrm{~m}^{-3}$, por isso Van Landuyt et al. (2011) fizeram uma revisão de literatura a respeito da quantidade de monômeros residuais liberados em resinas e recomendaram a padronização de unidades. 
Apesar de alguns autores acreditarem que uma reação mais lenta de polimerização, como ocorreu com a resina com CQ + PPD (R3), pode levar a uma menor reticulação (crosslink) das cadeias monoméricas e consequentemente ocasionar uma maior degradação e liberação de monômeros em solventes (ASMUSSEN; PEUTZFELDT, 2001ab; SOH; YAP, 2004; EMAMI; SODERHOLM, 2005), não foi isso que foi observado neste trabalho, que mostrou uma diferença significante em relação ao grau de conversão avaliado pelo FT-IR entre as resinas com CQ (R1) e com CQ + PPD (R3). No entanto, quando esses monômeros residuais TEGDMA e BisGMA foram extraídos da resina pela técnica cromatográfica (HPLC) essa diferença significante não foi encontrada, principalmente em relação aos monômeros TEGDMA, concordando com o trabalho de Brandt (2010) que acredita que mais importante que a velocidade da reação é a composição do material, visto que, o PPD pode atuar como agente de ligações cruzadas, apesar dele produzir uma reação mais lenta, produzindo assim um monômero com maior densidade de ligações cruzadas.

Isto leva a acreditar que apesar de haver essa diferença em relação ao grau de conversão quando comparamos essas duas resinas (R1 e R3), a quantidade de monômeros residuais principalmente do TEGDMA possíveis de serem liberados no meio bucal é similar para as duas resinas, demonstrando que o grau de reticulação obtido com essa associação dos dois fotoiniciadores é comparável com o da resina com somente a $\mathrm{CQ}$, concordando com Lovell et al. (2001) que acredita que a estrutura do polímero, isto é o grau de reticulação não é afetado pela alteração na taxa de polimerização. Segundo Muller et al. (1997), o grau de reticulação (crosslink) pode aumentar ou diminuir o efeito do solvente na expansão entre as moléculas possibilitando uma maior ou menor difusão na cadeia polimérica, sendo assim quanto maior o grau de reticulação menor é a liberação dos monômeros residuais.

É esperado que um maior grau de conversão proporcione uma maior quantidade de ligações cruzadas. Entretanto, alguns estudos mostraram que o grau de conversão é um fator muito importante, mas não é suficiente para caracterizar a estrutura tridimensional das resinas e que diferentes concentrações de $\mathrm{C}=\mathrm{C}$, presença de grupos pendentes e monômeros residuais, coexistem no mesmo polímero (ASMUSSEN; PEUTZFELDT, 2001ab; SOH; YAP, 2004).

Alguns trabalhos investigam a possibilidade de correlação entre grau de conversão e solubilidade. Tanaka et al. (1991), mostraram que um aumento no tempo de fotoativação de 30s para 50s diminuiu significantemente a quantidade de monômeros residuais liberados em água. Sideridou et al. (2011) acreditam que quanto mais alto grau de conversão menores são os valores de solubilidade. Entretanto Ferracane (1994), encontrou pouca correlação entre grau de conversão e solubilidade. Asmussen e Peutzfeldt (2001b) acreditam que resinas com 
diferentes graus de reticulação (crosslink) podem ter valores similares de conversão monoméricas e as características da rede polimérica tem maior relação com as propriedades mecânicas do que com a conversão monomérica (ASMUSSEN; PEUTZFELDT, 2001ab). Brandt et al. (2011), encontraram em seu trabalho valores um pouco maiores de microdureza Knoop para as resinas com a associação dos fotoiniciadores CQ + PPD quando comparada com as resinas com somente CQ ou PPD, o que pode ser um indicio de um maior grau de reticulação.

Portanto, a terceira hipótese do trabalho não está correta, pois a resina experimental que possui dois fotoiniciadores (CQ + PPD) apesar de ter sido observado alterações nos

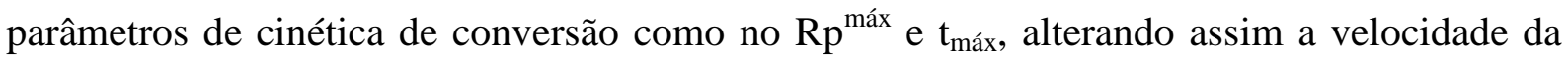
reação de polimerização nesta resina. Isso não levou a um aumento significante na quantidade de monômeros residuais extraídos, principalmente em relação ao monômero TEGDMA.

Acreditamos que essa reação mais lenta não teve interferência negativa na reticulação da cadeia polimérica, pelo contrário, pois apesar de menor grau de conversão desta resina (R3) em relação a resina com somente CQ (R1), a quantidade de monômeros residuais extraídos principalmente do TEGDMA foi similar para as duas resinas.

A quantidade de monômeros residuais em relação a comparação entre fontes de luz mostrou uma diferença significante somente para a resina R2 (PPD), sendo que esta apresentou a maior quantidade de monômeros residuais tanto para o TEGDMA $(3,49 \% \pm 0,07)$ quanto para o BisGMA $(7,57 \% \pm 0,40)$ quando foi fotoativado com LED (Tabelas 21 e 22). Essa diferença significante para a resina R2 também ocorreu em relação aos valores de grau de conversão conforme observado anteriormente.

As fontes de luz não tiveram muita interferência na quantidade de monômeros residuais TEGDMA quando as resinas R1 e R3 foram comparadas entre si. Já em relação ao monômero BisGMA, a associação do PPD a CQ na resina (R3) quando fotoativada com o LED levou a uma liberação de monômeros BisGMA semelhante aos resultados encontrados na resina contendo somente CQ (R1) fotoativada pela lâmpada halógena (Tabela 22).

Dessa maneira, a quarta hipótese do trabalho está correta, pois o aparelho de LED obteve um desempenho similar ao aparelho de lâmpada halógena nas resinas experimentais R3 com os dois fotoiniciadores (CQ + PPD), devido ao aumento no valor do pico máximo de absorção quando são associados os dois fotoiniciadores, possibilitando sua fotoativação por aparelhos dentro da faixa azul do espectro eletromagnético.

Observamos neste trabalho que a resina experimental R2, que possui somente o fotoiniciador PPD, não é uma opção viável devido ao pior comportamento em relação aos 
paramêtros estudados, principalmente quando fotoativada com LED. Entretanto, a resina R3 que possui a associação dos dois fotoativadores CQ + PPD, pode ser uma boa opção, pois quando comparada com a resina R1 obteve vantagens como: redução na taxa máxima de conversão $\left(\mathrm{Rp}^{\text {máx }}\right)$, bem como o momento em que esta ocorreu $\left(\mathrm{t}_{\text {máx }}\right)$, podendo dessa forma reduzir tensões de contração geradas dente/resina. Apesar do fato dela ter produzido valores de grau de conversão um pouco menores que a resina $\mathrm{R} 1$, esses monômeros residuais não foram liberados, levando a crer que esta associação da CQ + PPD pode levar a altos valores de densidade de ligações cruzadas (crosslink), além do fato dessa resina ser adequadamente fotoativada com aparelhos de LED. 


\section{Conclusão}




\section{CONCLUSÃO}

- A primeira hipótese do trabalho não está correta, pois a resina com os dois fotoiniciadores (CQ + PPD) obteve menores valores de grau de conversão monomérica quando comparada com a resina com somente CQ.

- A segunda hipótese do trabalho está correta, pois a utilização dos fotoiniciadores $(\mathrm{CQ}+\mathrm{PPD})$ em uma mesma resina possibilitou um melhor desempenho em relação a taxa máxima de polimerização $\left(\mathrm{Rp}^{\text {máx }}\right)$, isto é obteve um menor valor de $\mathrm{Rp}{ }^{\text {máx }}$ em relação a resina com somente CQ.

- A terceira hipótese do trabalho não está correta, pois as alterações nos parâmetros de cinética de conversão como no $\mathrm{Rp}^{\text {máx }}$ e $\mathrm{t}_{\text {máx }}$ na resina com os dois fotoiniciadores $\mathrm{CQ}+\mathrm{PPD}$ não levaram a um aumento significante na quantidade de monômeros residuais extraídos, principalmente em relação ao monômero TEGDMA.

- A quarta hipótese do trabalho está correta, pois o aparelho de LED demonstrou um desempenho similar ao aparelho de lâmpada halógena nas resinas com os dois fotoiniciadores (CQ + PPD) comprovando sua efetividade quando se utiliza essa associação. 
Referências Bibliográficas 


\section{REFERÊNCIAS BIBLIOGRÁFICAS}

ALLEN, N.S. Photoinitiators for UV and visible curing of coatings: mechanism and properties. Journal of Photochemistry and Photobiology A: Chemistry, v. 100, p. 101-107, 1996.

ASMUSSEN, E.; PEUTZFELDT, A. Influence of composition on rate of polymerization contraction of light-curing resin composites. Acta Odontologica Scandinavica, v. 60, p. 146$150,2002$.

ASMUSSEN, E.; PEUTZFELDT, A. Influence of pulse-delay curing on softening of polymer structures. Journal of Dental Research, v. 80, p. 1570-1573, 2001 a.

ASMUSSEN, E.; PEUTZFELDT, A. Influence of selected components on crosslink density in polymer structures. European Journal Oral Sciences, v. 108, p. 282-285, 2001 b.

ANDRZEJEWSKA, E. Photopolymerization kinetics of multifunctional monomers. Progress in Polymer Science, v. 26, p. 60-65, 2001.

ATAI, M.; WATTS, D.C. A new kinetic model for the photopolymerization shrinkage-strain of dental composites and resin- monomers. Dental Materials, v. 22, p. 785-791, 2006.

BAGIS, Y.H.; RUEGGEBERG, F.A. The effect of post-cure heating on residual, unreacted monomer in a commercial resin composite. Dental Materials, v. 16, p. 244-247, 2000.

BALA, O.; OLMEZ, A.; KALAYCI, S. Effect of LED and halogen light curing on polymerization of resin-based composites. Journal of Oral Rehabilitation, v. 32, p. 134$140,2005$.

BRAGA, R.R.; FERRACANE, J.L. Contraction stress related to degree of conversion and reaction kinetics. Journal of Dental Research, v. 81, p. 114-118, 2002.

BRANDT, W.C. Efeito do fotoiniciador sobre propriedades físicas, mecânicas e térmicas de compósitos experimentais fotoativados por luz de lâmpada halógena e LEDs. 2010. 83f. Tese (Doutorado em Materiais Dentários) - Faculdade de Odontologia de Piracicaba, Universidade Estadual de Campinas, Piracicaba, 2010. 
BRANDT, W.C.; TOMASELLI, L.O.; CORRER-SOBRINHO, L.; SINHORETI, A.A.C. Can phenyl-propanedione influence Knoop hardeness, rate of polymerization and Bond strength of resin composite restorations? Journal of Dentistry, v. 39, p. 438-447, 2011.

BRASIL. Ministério da Saúde. Agência Nacional de Vigilância Sanitária. Resolução no 899 de 29 de maio de 2003. Guia para validação de métodos analíticos e bioanalíticos. Brasília, 2003.

BOWEN R. L. Properties of a silica-reinforced polymer for dental restorations. The Journal of American Dental Association, v. 66, p. 57-64, 1963.

CALIXTO, L.R.; LIMA, D.M.; QUEIROZ, R.S.; RASTELLI, A.N.S.; BAGNATO, V.S.; ANDRADE, M.F. Curing depth of composite resin light cured by LED and halogen lightcuring units. Laser Physics, v. 18, p. 1365-1369, 2008.

CAMPANHA, N.H.; PAVARINA, A.C.; GIAMPAOLO, E.T.; MACHADO, A.L.; CARLOS, I.Z.; VERGANI, C.E. Cytotoxicity of hard chairside reline resins: effect of microwave irradiation and water bath postpolymerization treatments. International Journal of Prosthodontics, v. 19, p. 195-201, 2006.

CHASIN, A.A.M.; NASCIMENTO, E.S.; RIBEIRO-NETO, L.M.; SIQUEIRA, M.E.P.B.; ANDRAUS, M.H.; SALVADORI, M.C.; FERNÍCOLA, N.A.G.; GORNI, R.; SALCEDO, S. Validação de métodos em análises toxicológicas: uma abordagem geral. Revista Brasileira de Toxicologia, v. 11, p. 1-6, 1998.

COBB, D.S.; VARGAS, M.A.; RUNDLE, T. Physical properties of composites cured with conventional light or argon laser. American Journal of Dentistry, v. 9, p. 199-202, 1996.

COLLINS, C.H.; BRAGA, G.L.; BONATO, P.S. Introdução a métodos cromatográficos. Campinas. Editora da Unicamp, 1997. 279p.

CORRÊA, I. C. Análise do grau de conversão de uma resina experimental fotopolímerizavel: Um estudo espectrométrico em função de diferentes fotoiniciadores e fonte de luz. 2003. 213f. Tese (Doutorado em Materiais Dentários) - Faculdade de Odontologia, Universidade de São Paulo, São Paulo, 2003.

D’ALPINO, P.H.; SVIZERO, N.R.; PEREIRA, J.C.; RUEGGEBERG, F.A.; CARVALHO, R.M.; PASHLEY, D.H. Influence of light-curing sources on polymerization reaction kinetics of a restoration system. American Journal of Dentistry, v. 20, p. 46-52, 2007. 
DARONCH, M.; RUEGGEBERG, F.A.; DE GOES, M.F.; GIUDICI, R. Polymerization kinetics of pré-heated composite. Journal of Dental Research, v. 85, p. 38-43, 2006.

DECKER, C.; ZAHOUILY, K.; DECKER, D.; NGUYEN, T.; VIET, T. Performance analysis of acylphosphine oxides in photoinitiated polymerization. Polymer, v. 24, p. 7551-7560, 2001.

DENIS, A.B. Fotoativação de resina composta por diferentes fontes de luz e avaliação da profundidade de polimerização por diversos métodos. 2007. 117f. Dissertação (Mestrado em Bioengenharia) - Programa de Pós graduação em Bioengenharia, Universidade de São Paulo, São Carlos, 2007.

DENIS, A.B.; PLEPIS, A.M.G.; MARTINS, V.C.A.; PEREIRA, J.C.; PRAKKI, A. Properties of experimental resins based on synthesized propoxylated bis-GMA with different propionaldehyde ratios. Materials Research, v. 15, p. 397-402, 2012a.

DENIS, A.B. VIANA, R.B.; PLEPIS, AM.G. Kinetic parameters and monomeric conversion of different dental composites using standard and soft-start photoactivation mode. Laser Physics, v. 23, p. 1099-1104, 2012b.

DENIS, A.B.; VIANA, R.B.; PLEPIS, A.M.G. The effect of different photoactivation sources on a nanocomposite resin. Acta Scientiarum Technology, 2012c. In press

ELLIOTT, J.E.; LOVELL, L.G. BOWNMAN, C.N. Primary cyclization in the polymerization of bis-GMA and TEGDMA: a modeling approach to understanding the cure of dental resins. Dental Materials, v. 17, p. 253-259, 2001.

EMAMI, N.; SODERHOLM, K.J. Influence of light-curing procedures and photo-initiator composition on the degree of conversion of light curing units resins. Journal of Materials Science: Materials in Medicine, v. 16, p. 47-52, 2005.

FRANCO, E. B.; LOPES, L. G. Conceitos atuais na polimerização de sistemas restauradores resinosos, Biodonto, v. 1, n. 2, p. 1-61, 2003.

FERRACANE, J. L. Correlation between hardness and degree of conversion during the setting reaction of unfilled dental restorative resins. Dental Materials, v. 1, p. 11-14, 1985.

FERRACANE, J.L. Elution of leachable components from composites. Journal of Oral Rehabilitation, v. 21, p. 441-452, 1994. 
FERRACANE, J. L. Resin composite- State of the art. Dental Materials, v. 27, p. 29-38, 2011.

FERACANE, J.L.; CONDON, J.R. Rate of elution of leachable components from composites from composites. Dental Materials, v. 6, p. 282-287, 1990.

GOLDBERY, M. In vitro and in vivo studies on the toxicity of dental resin components: a review. Clinical Oral Investigations, v. 12, p. 1-8, 2008.

HANSEL C.; LEYHAUSEN G.; MAI, U.E.; GEURTSEN, W. Effects of various resin composite (co)monomers and extracts on two caries-associated micro-organisms in vitro. Journal of Dental Research, v. 77, p. 60-67, 1998.

HOFMANN, N.; DENNER, W.; HUGO, B.; KLAIBER, B. The influence of plasma arc vs. halogen standard or soft-start irradiation on polymerization shrinkage kinetics of polymer matrix composites. Journal of Dentistry, v. 31, p. 383-393, 2003.

IMAZATO, S.; McCABE, J.F.; TARUMI, H.; EHARA, A.; EBISU, S. Degree of conversion of composites meansured by DTA and FTIR Dental Materials, v. 17, p. 178-183, 2001.

INSTITUTO NACIONAL DE METROLOGIA, NORMALIZAÇÃO e QUALIDADE INDUSTRIAL (IN METRO). Orientações sobre validação de métodos de ensaios químicos. Brasília, 2003. DOQ-CGCRE-008.

INTERNATIONAL CONFERENCE ON HARMONISATION (ICH). Validation of analytical procedures: Methodology. Geneva, 1995. Q2B (CPMP/ICH/281/95).

JANDT, K. D.; MILLS, R. W. BLACKWELL, G. B. ; ASHWORTH, S. H. Depth of cure and compressive strength of dental composites cured with blue light emitting diodes (LED).

Dental Materials, v. 16, p. 41-47, 2000.

KALACHANDRA, S.; SANKARAPANDIAN, M.; SHOBA, H. K.; TAYLOR, D. F. MCGRATH, J. E. Influence of hydrogen bonding on properties of Bis-GMA analogs. Journal of Materials Science Materials Medicine, v. 8, p. 283-286, 1997.

KOMURCUOCLU, E.; OLMEZ, S.; VURAL, N. Evaluation of residual monomer elimination methods in three different fissure sealants in vitro. Journal of Oral Rehabilitation, v. 32, p. 116-121, 2005. 
KURACHI, C.; TUBOY, A. M.; MAGALHAES, D. V.; BAGNATO, V.S. Hardness evaluation of a dental composite polymerized with experimental LED-based devices. Dental Materials, v. 17, p. 309-315, 2001.

LANÇAS, F.M. The role of the separation sciences in the $21^{\text {th }}$ century. Journal of Brazilian Chemical Society, v. 14, p. 183-187, 2003.

LOVELL, L. G.; BERCHTOLD, K. A.; ELLIOTT, J.E.; LU, H.; BOWMAN, C.N. Understanding the kinetics and network formation of dimethacrylate dental resins. Polymers for Advanced Technologies, v. 12, p. 335-45, 2001.

MICALI, B.; BASTING, R.T. Effectiveness of composite resin polymerization using lightemitting diodes (LEDs) or halogen-based light-curing units. Brazilian Oral Research, v. 18, p. 266-270, 2004.

MICHELSEN, V.B.; MOE, G.; SKALEVIK, R.; JENSEN, E.; LYGRE, H. Quantification of organic eluates from polymerized resin-based dental restorative materials by use of GC/MS. Journal of Chromatography B, v. 850, p. 83-91, 2007.

MILETIC, V.; SANTINI, A.; TRKULJA, I. Quantification of monomer elution and carboncarbon double bonds in dental adhesive systems using HPLC and micro-Raman spectroscopy. Journal of Dentistry, v. 37, p. 177-184, 2009.

MILLS, R. W.; UHL, A.; JANDT, K. D. Optical power outputs, spectra and dental composite depth of cure, obtained with blue light emitting diodes (LED) and halogen light curing units (LCUs). British Dental Journal, v. 193, p. 459-463, 2002.

MOHARAMZADEH, K.; VAN NOORT,R.; BROOK, I.M.; SCUTT, A.M. HPLC analysis of components released from dental composites with different resin compositing using different extraction media. Journal of Materials Science: Materials in Medicine, v. 18, p. 133-37, 2007.

MOSNACEK, J.; LUKAC, I. Irradiation of camphorquinone in glassy polymer matrices in the absence and presence of molecular oxygen. Journal Photochemistry and Photobiology A: Chemistry, v. 151, p. 95-104, 2002.

MULLER, H.; OLSSON, S.; SODERHOLM, K.J. The effect of comonomer composition, silane heating, and filler type on aqueous TEGDMA leachability in model resin composites. European Journal Oral Sciences, v. 105, p. 362-368, 1997. 
MUNKSGAARD, E.C.; PEUTZFELDT, A.; ASMUSSEN, E. Elution of TEGDMA and BISGMA from a resin and a resin composite cured with halogen or plasma light. European Journal Oral Science, v. 108, p. 341-345, 2000.

NEUMANN, M.G.; SCHIMITT, C.C.; FERREIRA G.C.; CORRÊA, I.C. The initiating radical yields and the efficiency of polymerization for various dental photoinitiators excited by different light curing units. Dental Materials, v. 22, p. 576-584, 2006.

NEUMANN, M.G.; MIRANDA, W.G.; SCHMITT, C.C.; RUEGGEBERG, F.A.; CORRÊA, I.C. Molar extinction coefficients and the photon absorption efficiency of dental photoinitiators and light curing units. Journal of Dentistry, v. 33, p. 525-532, 2005.

NIE, J.; BOWMAN, C.N. Synthesis and photopolymerization of N,N'- dimethyl - N,N'-di (methacryloxy ethyl)- 1,6- hexanediamine as a polymerizable amine coinitiator for dental restorations. Biomaterials, v. 23, p. 1221-1226, 2002.

OGUNYINKA, A.; PALIN W.M.; SHORTALL, A.C.; MARQUIS, P.M. Photoinitiation chemistry affects light transmission and degree of conversion of curing experimental dental resin composites. Dental Materials, v. 23, p. 807-813, 2007.

PALACIO, R.E.L.; ZAVAGLIA, C.A.C. The monomeric formulation optimization of dental composite: mechanical and kinetic studies. Artificial Organs, v. 27, p. 419-423, 2003.

PARK, Y. J.; CHAE, K. H.; RAWLS, H. R. Development of a new photoinitiation system for dental light-cure composite resin. Dental Materials, v. 15, n. 2, p. 120-127, 1999.

PELKA, M.; DISTLER, W.; PETSCHELT, A. Elution parameters and HPLC-detection of single components from resin composite. Clinical Oral Investigations, v. 3, p. 194-200, 1999.

PEUTZFELDT, A.; ASMUSSEN, E. Hardness of restorative resins: effect of camphoroquinone, amine, and inhibitor. Acta Odontologica Scandinavica, v. 47, p. 229-231, 1989.

PEUTZFELDT, A.; ASMUSSEN, E. Resin composite properties and energy density of light cure. Journal of Dental Research, v. 84, p. 659-662, 2005.

PEUTZFELDT, A. Resin composites in dentistry; the monomer systems. European Journal of Oral Sciences, v. 105, p. 97-116, 1997. 
PRAKKI, A.; TALLURI, P.; MONDELLI, R.L.; KALACHANDRA, S. Influence of additives on the properties of Bis-GMA/ Bis-GMA analog comonomers and corresponding copolymers. Dental Materials, v. 23, p. 1199-1204, 2007.

PRAKKI, A.; CILLI, R.; MONDELLI, R.L.; KALACHANDRA, S. In vitro wear, surface roughness and hardness of propanol-containing and diacetyl-containing novel composites and copolymers based on bisGMA analogs. Dental Materials, v. 25, p. 410-417, 2008.

PRAKKI, A.; PEREIRA, P. N. R.; KALACHANDRA, S. Effect of propionaldehyde and 2,3butanedione additives on the mechanical properties of BIS-GMA analog-based composites.

Dental Materials, v. 25, p. 26-32, 2009.

PRICE, R.B.; FELIX, C.A.; ANDREOU, P. Knoop hardness of ten resin composites irradiated with high-power LED and quartz-tungsten-halogen lights. Biomaterials, v. 26, p. 2631-2641, 2005.

POLYDOROU, O.; TRITTLER, R. HELLWIG, E. KUMMERER, K. Elution of monomers from two conventional dental composite materials. Dental Materials, v. 23, p. 1535-1541, 2007.

RASTELLI, A.N.S.; JACOMASSI, D.P.; BAGNATO, V.S. Degree of conversion and temperature increase of a composite resin light cured with an argon laser and blue LED. Laser Physics, v. 18, p. 1570-1575, 2008.

RATHBUN, M.A.; CRAIG, R.G.; HANKS, C.T.; FILISKO, F. E. Cytotoxicity of Bis-GMA dental composite before and after leaching in organic solventy. Journal of Biomedical Materials Research, v. 25, p. 443-457, 1991.

RAZALI, N.M.; WAH, Y.B. Power comparations of Shapiro-Wilk, Kolmogorov-Smirnov, Lilliefors and Anderson-Darling tests. Journal of Statistical Modeling and Analytics, v. 2, p. 21-33, 2011.

REICHL, F.X.; DURNER, J.; HICKEL, R.; SPAHL, W.; KEHE, K.; WALTHER, U.; GEMPEL, K.; LIEBL, B.; KUNZELMANN, K.H.; HUME, W. Uptake clearance and metabolism of tegdma in guinea pigs. Dental Materials, v. 18, p. 581-589, 2002.

RIBANI, M.; BOTTOLI, C.B.G.; COLLINS, C.H.; JARDIM, I.C.S.F.; MELO, L.F.C.M. Validação em métodos cromatográficos e eletroforéticos. Química Nova, v. 27, p. 771-780, 2004. 
RUEGGEBERG, F. A. Contemporary issues in photocuring. Compendium, v. 20, p. 4-15, 1999. Suplement.

RUEGGEBERG, F.A.; BLALOCK, J.; CALLAN, R.S. LED curing lights-what's new? Compendium, v. 26, p. 586-591, 2005.

SAKAGUCHI, R.L.; BERGE, H.X. Reduced light energy density decreases post-gel contraction while maintaining degree of conversion in composites. Journal of Dentistry, v. 26, p. 695-700, 1998.

SCHNEIDER, L.F.J; CAVALCANTE, L.M.; CONSANI, S.; FERRACANE, J.L. Effect of co-initiator ratio on the polymer properties of experimental resin composites formulated with camphorquinone and phenyl-propanedione. Dental Materials, v. 25, p. 369-375, 2009a.

SCHNEIDER, L.F.J; CONSANI, S.; SAKAGUCHI, R.L.; FERRACANE, J.L. Alternative photoinitiator system reduces de rate of the stress development without compromising the final properties of the dental composite. Dental Materials, v. 25, p. 566-572, 2009b.

SCHNEIDER, L.F.J.; PFEIFER, C.S.C.; CONSANI, S.; PRAHL, S.A.; FERRACANE, J.L. Influence of photoinitiator type on the rate of polymerization, degree of conversion, hardness and yellowing of dental resins composites. Dental Materials, v. 24, p. 1169-77, 2008.

SCHROEDER, W.; ARENAS, G.; VALLO, C. Monomer conversion in a light-cured dental resin containing 1-phenil-1,2-propanodione photosensitizer. Polymer International, v. 56, p. 1099-1105, 2007.

SCHROEDER, W.F.; COOK, W.D.; VALLO, C.I. Photopolymerization of N,N dimethylaminobenzyl alcohol as amine co-initiator for light-cured dental resins. Dental Materials, v. 24, p. 686-693, 2008.

SCHWENGBERG, S.; BOHLEN, H.; KLEINSASSEN, N.; KEHE, K.; SEISS, M.; WALTHER, U.I. In vitro embryotoxicity assessment with dental restorative materials. Journal of Dentistry, v. 33, p. 49-55, 2005.

SHABIR, G.A. Validation of high-performance liquid chromatography methods for pharmaceutical analysis understanding the differences and similarities between validation requirements of the US Food and Drug Administration, the US Pharmacopeia and the International Conference on Harmonization. Journal of Chromatography A, v. 987, p. 5766, 2003. 
SIDERIDOU, I.D.; KARABELA, M.M. Sorption of water, ethanol or ethanol/water solutions by light-cured dental dimethacrylate resins. Dental Materials, v. 27, p. 1003-1010, 2011.

SIDERIDOU, I.; TSERKI, V.; PAPANASTASIOU, G. Effect of chemical structure on degree of conversion in light-cured dimethacrylate-based dental resins. Biomaterials, v. 23, p. 1819$29,2002$.

SILVA, P.C.G.; PORTO-NETO, S.T.; LIZARELLI, R.F.Z.; BAGNATO, V.S. Orthodontic brackets removal under shear and tensile bond strength resistance tests- a comparative test between light sources. Laser Physics Letters, v. 5, p. 220-226, 2008.

SILVERSTEIN, R. M.; WEBSTER, F. X. Identificação espectrométrica de compostos orgânicos. 6. ed. Rio de Janeiro: Livros Técnicos e Científicos Editora, 2000. p. 67-135.

SOARES, L.V. Cromatografia líquida de alta eficiência. In: SOARES, L.V. Curso básico de instrumentação para analistas de alimentos e fármacos. São Paulo: Ed. Manole, 2006. p. 169-223.

SOH, M. S.; YAP, A. U. J. Influence of curing modes on crosslink density in polymer structures. Journal of Dentistry, v. 32, p. 321-326, 2004.

SPAHL, W.; BUDZIKIEWICZ, H.; GEURTSEN, W. Determination of leachable components from four commercial dental composites gas and liquid chromatography/mass spectrometry. Journal of Dentistry, v. 26, p. 137-145, 1998.

STANSBURY, J.W. Curing dental resins and composites by photopolymerization. Journal Esthetic Dentistry, v. 12, p. 300-308, 2000.

STUDER, K.; KONIGER, R. Initial photoyellowing of photocrosslinked coatings. European Coatings Journal, v. 1, p. 26-37, 2001.

SUN, G.J.; CHAE, K. H. Properties of 2,3-butanedione and 1-phenyl-1,2- propanedione as new photosensitizers for visible light cured dental resin composites. Polymer, v. 41, p. 6205$6212,2000$.

TANAKA, K.; TAIRA, M.; SHINTANI, H.; WAKASA, K. Residual monomers (TEGDMA and BISGMA) of a set visible-light-cured dental composite resin when immersed in water. Journal of Oral Rehabilitation, v. 8, p. 353-362, 1991. 
TESHIMA, W.; NOMURA, Y.; NOBUYUKI, T.; URABE, H.; OKAZAKI, M.; NAHARA, Y. ESR study of camphoroquinone/amine photoinitiator systems using blue light-emitting diodes. Biomaterials, v. 24, p. 2097-2103, 2003.

TRUJILLO, M.; NEWMAN, S.M.; STANSBURY, J.W. Use of near-IR to monitor the influence of external heating on dental composite photopolymerization. Dental Materials, v. 20, p. 766-77, 2004.

UNITED STATES FOOD AND DRUG ADMINISTRATION (US-FDA). Guidance for industry, analytical procedures and method validation. Rockville, 2000. p. 1-33.

UNITED STATES PHARMACOPEIA CONVENTION. US Pharmacopeia 30, validation of compendial procedures. Rockville, 2007. p. 1225.

UHL, A.; MILLS, R.W.; JANDT, K.D. Photoinitiator dependent composite depth of cure and Knoop hardness with halogen and LED light curing units. Biomaterials, v. 24, p. 1787-1795, 2003.

VAKIPARTA, M.; PUSKA, M.; VALLITTU, P.K. Residual monomers and degree of conversion of partially bioresorbable fiber-reinforced composite. Acta Biomaterialia, v. 2, p. 29-37, 2006.

VAN ITERSON, R.A. A guide to validation in HPLC. Disponível em: <www.standardbase.hu/tech/HPLC\%20validation\%20PE.pdf $>$. Acesso em: 07 jun. 2011.

VAN LANDUTY, K.L.; NAWROT, T.; GEEBELEN, B.; DE MUNCH, J.; SNAUWAERT, J.; YOSHIHARA, K.; SCHEERS, H.; GODDERIS, L.; HOET, P.; VAN MEERBEEK, B. How much do resin-based dental materials release? A meta-analytical approach. Dental Materials, v. 27, p. 723-747, 2011.

VARGAS, M. A.; COBB, D. S.; SCHMIT, J. L. Polymerization of composite resins: argon laser vs conventional light. Operative Dentistry, v. 23, p. 87-93, 1998.

WATAHA, J.C.; RUEGGEBERG, F.A.; LAPP, C.A.; LEWIS, J.B.; LOCKWOOD, P.E.; ERGLE, J.W.; METENBURG, D.J. In vitro cytotoxicity of resin-containing restorative materials after aging in artificial salive. Clinical Oral Investigations, v. 3, p. 144-149, 1999. 
Anexo 


\section{ANEXO \\ PRODUÇÃO CIENTÍFICA NO PERÍODO DO DOUTORADO}

\section{- ARTIGOS}

DENIS, A.B.; PLEPIS, A.M.G.; MARTINS, V.C.A.; PEREIRA, J.C.; PRAKKI, A. Properties of experimental resins based on synthesized propoxylated bis-GMA with different propionaldehyde ratios. Materials Research, v. 15, p. 397-402, 2012.

DENIS, A.B.; VIANA, R.B.; PLEPIS, A.M.G. Kinetics parameters and monomeric conversion of different dental composites using standard and soft-start photoactivation modes. Laser Physics, v. 22, p. 1099-1104, 2012.

DENIS, A.B.; VIANA, R.B.; PLEPIS, A.M.G. The effect of different photoactivation sources on a nanocomposite resin. Acta Scientiarum Technology, 2012. In press

DENIS, A.B.; DIAGONE, C.; PLEPIS, A.M.G. Residual monomer determination of dental resins with different photoinitiators. Journal of Adhesion Science and Technology.

(Submetido em maio/2012)

DENIS, A.B.; PLEPIS, A.M.G. Evaluation of degree of monomer conversion and polymerization kinetic parameters in experimental resins with different photoinitiators. (Em fase de redação).

\section{- PRÊMIO}

Diploma of distinction for a student presentation.

Recebido no congresso Polychar 20 - World Forum on Advanced Materials, de 26 a 30 de 2012 em Dubrovnik, Croácia pelo trabalho: "Residual monomer determination of dental resins with different photoinitiators" 


\section{- CONGRESSOS}

DENIS, A. B.; RASTELLI, A. N. S; PLEPIS, A. M. G. Resina composta odontológica fotoativada por diferentes fontes de luz. In: $5^{\circ}$ Congresso Latino Americano de Órgãos Artificiais e Biomateriais, 2008, Ouro Preto. Anais do 5 COLAOB, 2008.

DENIS, A. B.; VIANA, R. B.; PLEPIS, A. M. G. Kinetic parameters and monomeric conversion of different dental composites. In: 86th General Session \& Exhibition of the International Association for Dental Research, 2008, Toronto, Canada. Journal of Dental Research (special issue B) - CD- Rom of Abstract, 2008. v. 87

$>$ PLEPIS, A. M. G.; DENIS, A. B.; AMARAL, M. B. Depth of cure of composite using halogen, LED and laser.. In: 86th General Session \& Exhibition of the International Association for Dental Research, 2008, Toronto, Canada. Journal of Dental Research (special issue B), 2008. v. 87. p. 2355.

DENIS, A. B.; VIANA, R. B.; CILLI, R.; PLEPIS, A. M. G.; PRAKKI, A. Avaliação de diferentes quantidades de propionaldeido em comonômeros a base de Bis-GMA propoxilado. In: 25 Reunião Anual da Sociedade Brasileira de Pesquisa Odontológica, 2008, Águas de Lindóia. Brazilian Oral Research, 2008. v. 22. p. 193

DENIS, A. B. ; DIAGONE, C. ; LANÇAS, F. M. ; PLEPIS, A. M. G. Desenvolvimento de metodologia por HPLC para determinação de monômeros residuais e fotoiniciadores em resinas odontológicas. In: XII Congresso Latino Americano de Cromatografia e Técnicas Relacionadas, 2008, Florianópolis - SC. Livro de Resumos do XII Congresso Latino Americano de Cromatografia e Técnicas Relacionadas, 2008.

$>$ DENIS, A. B.; PLEPIS, A. M. G.; PRAKKI, A. Effect of different propionaldehyde ratios on copolymers based on CH3-BISGma. In: 87th General Session \& Exhibition of International Association for Dental Research IADR/ AADR/ CADR, 2009, Miami, USA Journal of Dental Research (special issue B), 2009. v. 88.

DENIS, A. B.; PLEPIS, A. M. G.; PRAKKI, A. . Avaliação da Adição de Propionaldeido em Resinas Compostas Odontológicas. In: IV Encontro regional dos usuários de técnicas termoanalíticas, 2009, São Carlos. Livro do IV Encontro regional dos usuários de técnicas termoanalíticas, 2009.

DENIS, A. B. ; PLEPIS, A. M. G. ; MARTINS, V. C. A. ; AMARAL, M. B. ; PRAKKI, A. Microhardness and rheological properties of copolymers based on CH3-BisGMA. In: 88th General Session \& Exhibition of the International Association for Dental Research (IADR)/ 5th General Session of the Pan European Region of the IADR, 2010, Barcelona, Espanha. Journal of Dental Research (special issue-meeting abstracts), 2010. v. 89. p. abstract 2303. 
DENIS, A. B.; DIAGONE, C.; LANÇAS, F. M.; PLEPIS, A. M. G. Desenvolvimento e validação de método para determinação de monômeros residuais de resinas odontológicas. In: X Workshop de pós-graduação: A nova pós-graduação do IQSC, 2010, São Carlos. Anais do Workshop de pós-graduação: A nova pós-graduação do IQSC, 2010.

DENIS, A. B. ; DIAGONE, C. ; LANÇAS, F. M. ; PLEPIS, A. M. G. Development and Validation Method for Determination of Residual Monomers. In: 89th General Session \& Exhibition of the International Association for Dental Research, 2011, San Diego, USA. Journal of Dental Research (special issue-meeting), 2011. p. abstract 1971.

DENIS, A. B. ; DIAGONE, C. ; PLEPIS, A. M. G. Residual monomer determination of dental resins with different photoinitiators. In: Polychar 20 - World Forum on Advanced Materials, 2012, Dubrovnik, Croácia. Polychar 20 - World Forum on Advanced MaterialsBook of Abstracts, 2012. p. 206 


\title{
Properties of Experimental Resins Based on Synthesized Propoxylated bis-GMA with Different Propionaldehyde Ratios
}

\author{
Aline Bassi Denis ${ }^{\mathrm{a}}$, Ana Maria Guzzi Plepis ${ }^{\mathrm{a}}$, Virginia da Conceição Amaro Martins ${ }^{\mathrm{a}}$, \\ Jose Carlos Pereira ${ }^{\mathrm{b}}$, Renato Cilli, Anuradha Prakkid* \\ ${ }^{a}$ São Carlos Chemistry Institute, University of São Paulo - USP, CEP 13566-590, São Carlos, SP, Brazil \\ ${ }^{\mathrm{b}}$ Department of Operative Dentistry, Endodontics and Dental Materials, Bauru Dental School, \\ University of São Paulo - USP, CEP 17012-901, Bauru, SP, Brazil \\ ${ }^{\mathrm{C}}$ Department of Dental Materials and Operative Dentistry, Faculty of Dentistry, \\ University of Fortaleza - UNIFOR, Fortaleza, Ceara, Brazil \\ ${ }^{\mathrm{d}}$ Restorative Department, Faculty of Dentistry, University of Toronto, M5G 1G6, Toronto, ON, Canada
}

Received: March 18, 2011; Revised: February 8, 2012

The effect of different propionaldehyde ratios on the properties of bis-GMA-based comonomers and copolymers diluted with propoxylated bis-GMA $\left(\mathrm{CH}_{3}\right.$ bis-GMA) was evaluated. Five experimental comonomers were prepared combining bis-GMA with $\mathrm{CH}_{3}$ bis-GMA and propionaldehyde at $0,2,8$, $16,24 \mathrm{~mol} \%$. Light polymerization was effected with the use of $0.2 \mathrm{wt}$. (\%) each of camphorquinone and $N, N$-dimethyl-p-toluidine. Resin degrees of conversion $(\% \mathrm{DC})$ were evaluated by FT-IR spectrophotometry and $T_{g}$ by Differential Scanning Calorimeter. Complex viscosity $\left(\eta^{*}\right)$, the effect of temperature on $\eta^{*}$, and Microhardness $(H)$ for dry and wet samples were also determined. Data were analyzed by Student's t-test, one-way ANOVA and Tukey-Kramer test $(\alpha=0.05)$. The group with $24 \mathrm{~mol} \%$ additive had a significant increase in \%DC and $H$, and the lowest comonomer $\mathrm{T}_{g}$ and $\eta *$. No remarkable variation was noted in copolymers $\mathrm{T}_{g} \mathrm{~s}$. All resins presented Newtonian behavior of viscosity, which linearly decreased with increased temperature. The $\eta^{*}$ decreased sigmoidally as the additive ratio increased.

Keywords: aldehyde, bis-GMA analog, microhardness, rheology

\section{Introduction}

It has been reported that the incorporation of propionaldehyde as an additive to bis-GMA/TEGDMA (bisphenol glycidyl dimethacrylate/triethyleneglycol dimethacrylate) and UDMA/HEMA (urethane dimethacrylate/hydroxyethyl methacrylate) resins significantly improved their degree of conversion ${ }^{1,2}$, mechanical properties ${ }^{3}$ and in vitro wear resistance ${ }^{4}$. The extent of conversion continuously increased as the propanal content increased from 0 to $40 \mathrm{~mol} \%{ }^{1}$. Properties such as flexural strength, diametral tensile strength, modulus of elasticity, and wear resistance improved up to an additive content of 24 to $32 \mathrm{~mol} \%$, above which the properties did not present significant changes ${ }^{3,4}$. The possibility should, however, be considered that in excess this rather volatile and relatively toxic component may leach and evaporate from the resin affecting its biocompatibility.

In Dentistry, dilution of bis-GMA with the more hydrophilic TEGDMA is known to cause clinical adverse effects, mainly because of the increase in water sorption and polymerization shrinkage ${ }^{5,6}$. To overcome these unwanted effects studies have been directed toward developing low viscosity, hydroxyl free, more hydrophobic bis-GMA analogs such as the propoxylated bis-GMA (2,2-bis(4-(2methacryloxyprop-1-oxy)phenyl)propane), as a replacement for TEGDMA in bis-GMA mixtures ${ }^{7,8}$. The properties of

*e-mail: anuradha.prakki@dentistry.utoronto.ca
bis-GMA copolymers and composites containing $\mathrm{CH}_{3}$ bisGMA (Figure 1) have been evaluated. Due to TEGDMA being a more flexible monomer, with a higher degree of conversion, the Young's modulus and flexural strength values of bis-GMA/TEGDMA systems were higher ${ }^{9}$.

To improve its mechanical properties, propionaldehyde has been incorporated into the bis-GMA/ $\mathrm{CH}_{3}$ bis-GMA system. The ratios of $24 \mathrm{~mol}$ and $32 \mathrm{~mol} \%$ were used because they were shown to promote the highest increases in the properties of methacrylates ${ }^{3,4}$. In this latter system, a significant increase was also noted in the degree of conversion ${ }^{10}$ and properties such as wear, strength, modulus of elasticity and hardness ${ }^{11,12}$. Considering the lack of studies with regard to incorporation of lower ratios of aldehyde into the mentioned developmental resin, the objective of this study was to evaluate the physical, rheological, and mechanical properties of bis-GMA diluted with $\mathrm{CH}_{3}$ bisGMA containing 0,2,8, 16 and $24 \mathrm{~mol} \%$ propionaldehyde.

\section{Materials and Methods}

\subsection{Materials}

Bis-GMA, the photosensitizer camphorquinone (CQ, Kerr Corp., CA 92867-5422, USA), reducing agent $N, N$ dimethyl-p-toluidine (DMPT, Alfa Aesar, NH 03087 - 


\title{
Kinetic Parameters and Monomeric Conversion of Different Dental Composites Using Standard and Soft-Start Photoactivation Modes ${ }^{1}$
}

\author{
A. B. Denis", R. B. Viana ${ }^{* *}$, and A. M. G. Plepis \\ Instituto de Química de São Carlos, Universidade de São Paulo, 13560-970, São Carlos - SP, Brasil \\ *e-mail: alinebdenis@yahoo.com.br \\ **e-mail: rommelbv@yahoo.com.br \\ Received February 8, 2012; published online May 11, 2012
}

\begin{abstract}
This paper evaluates the photopolymerization kinetics and degree of conversion of different commercial dental composites when photoactivated by a LED curing unit using two different modes (standard and soft-start mode). The investigation was performed on with RelyX ARC (dual-cured), Filtek Z-350 (Nanocomposite), Filtek Z-250 (Hybrid), and Filtek Z-350flow (Flowable) resin composites. The analysis used was attenuated total reflection with a Fourier transform infrared (ATR-FTIR). The RelyX ARC resin demonstrated the highest degree of conversion with both LED photoactivation modes. For this resin a $28 \%$ decrease in maximum rate was observed and the time to reach its highest rate was almost 2.3 times higher than when the soft-start photoactivation light curing was used. Z-350flow resin recorder a higher maximum rate using the soft-start mode rather than the standard mode. In contrast, the $\mathrm{Z}-250$ showed a higher value using the standard mode. Although Z-250 and Z-350 showed a higher total degree of conversion effectiveness using the soft-start mode, RelyX and Z-350flow achieved a higher value using the standard mode.
\end{abstract}

DOI: $10.1134 / \mathrm{S} 1054660 \mathrm{X} 12060011$

\section{INTRODUCTION}

The degree of conversion (DC) is one of the most important factors that affects the clinical performance of composite resins. The mechanical, physical and biological properties of the composite have been correlated to the DC value [1]. In general, higher DC values can be obtained by applying higher power density of photoactivation [2].

Some studies have shown that superior mechanical properties can be obtained by using high curing intensity; however, these properties are also accompanied by increased shrinkage and greater stress development [3-5]. Considering these aspects, some studies found that the shrinkage stress can be reduced by using a softstart photoactivation mode [6-9]. The soft-start mode employs an initial light activation at low intensity followed by a second activation at a higher intensity that is usually comparable to the continuous (standard) mode. In this mode, fewer radicals are produced and a lower conversion of double bonds is observed if the molecules are activated at lower intensities [10]. Yoshikawa et al. [8] suggested that the soft-start photoactivation mode can also improve the adaptation of the resin composite to the cavity walls and reduce the shrinkage stress. On the other hand, when the polymerization reaction starts more slowly, more time is available to minimize the polymerization contraction; therefore the gel-point can be achieved later [9-11].

${ }^{1}$ The article is published in the original.
In photo-polymerization processes, the light intensity has been shown to be an essential factor influencing the polymerization rate [8-10]. In other studies, researchers have also demonstrated that the polymerization rate can influence the resin contraction stress [9-11]. Nevertheless, in clinical conditions, the use of the soft-start light curing unit (LCU) mode has been the focus of several discussions speculating that the initial lower intensity of light could be a positive aspect that might lead to a small stress of contraction in the final polymerization of the resin. Therefore, the characterization of the kinetic properties of the polymerization is an important step in understanding the effects of the individual parameters with each photoactivation mode.

The purpose of this study was to evaluate the effect of the composite photoactivation mode on different composite formulations. In this study, a dual-cured resin cement (RelyX ARC), a nanocomposite (Z-350), a flowable (Z-350flow) and a hybrid resin (Z-250) were employed using standard and soft-start LED photoactivation modes. This study determined the total conversion degree, maximum conversion rate and the exposure time when the maximum rate was reached for each system.

\section{MATERIAL AND METHODS}

Four commercial composites resins were used in this study: Filtek ${ }^{\mathrm{tm}} \mathrm{Z}-250$, Filtek ${ }^{\mathrm{tm}} \mathrm{Z}-350$, Filtek ${ }^{\mathrm{tm}}$ $\mathrm{Z}$-350flow and a dual-cured resin cement, RelyX ${ }^{\mathrm{tm}}$ 


\title{
The effect of different photoactivation sources on a nanocomposite
}

\section{resin}

Aline B. Denis*, Rommel B. Viana*, Ana M. G. Plepis

Instituto de Química de São Carlos, Departamento de Química e Física Molecular, Universidade de São Paulo, São Carlos - SP, Brasil.

\section{*Corresponding authors:}

Ana Bassi Denis

E-mail: alinebdenis@yahoo.com.br

Rommel Bezerra Viana

E-mail: rommelbv@yahoo.com.br

\begin{abstract}
This paper evaluates the effects of different light sources on the polymerization degree of conversion (DC\%) and Vickers microhardness number (VHN) of a nanocomposite resin. Three different depths were measured in this study $(1,2$ and $3 \mathrm{~mm})$, while a halogen lamp, a LED and an argon ion laser photoactivation methods were used. In contrast to other studies, the conditions to each photoactivation source such as same the exposure time and the same power density were considered. It was also shown that increasing the depth lowers the VHN, while at each of the depths was observed that the three light sources behaved similarly. The correlation between the VHN and DC\% is shown, however only a weak correlation is observed between, which implies that a higher DC\% value does not necessarily indicate a higher VHN one.
\end{abstract}

Keywords: photopolymerization; mechanical properties; light-curing; infrared spectroscopy; composite resin 


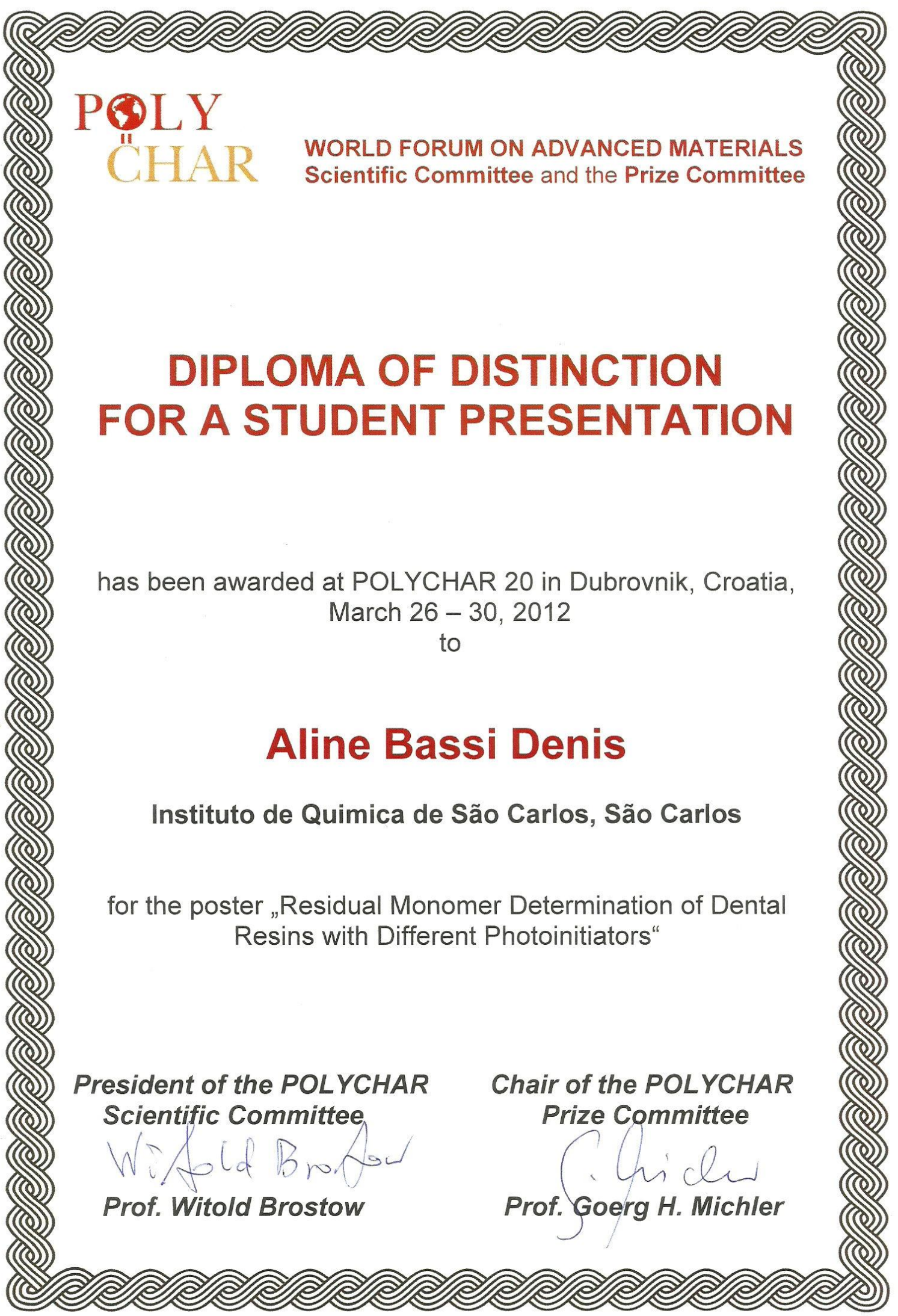

